LBL -7303

$\mathrm{UC}-37 \circ \mathrm{\alpha}$

\author{
CORRECT LONS FOR \\ CONPONENT IMPERFECTIONS AND AZIMUTH ERRORS \\ IN AM AUTOHATIC SELF-COMPEKSATING ELLIPSOMETER
}

Craig 6. Smith, Janet S. Remer, and

Rolf H. Muller

RECFIVED

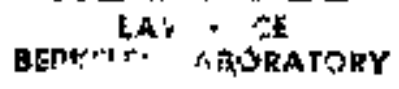

August 1978

OCT $\angle B$ B $19 / 8$

DOCUMERI I SLLTION

Prepared for the $V$. S. Department of Energy under Contract $W-7405-E N G-48$

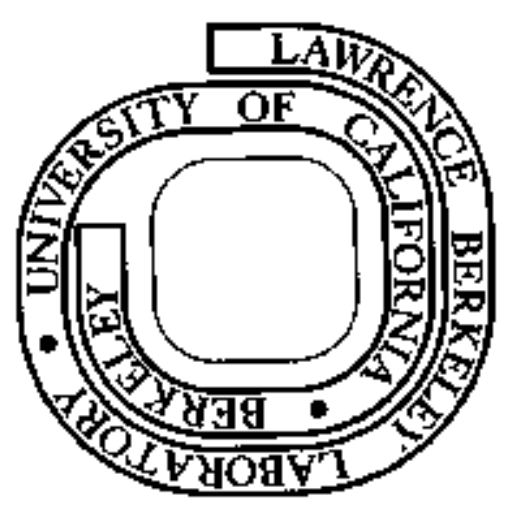

TWO-WEEK LOAN COPY

This is a Library Circulating Copy which may be borrowed for two weeks. For a personal retention copy, call Tech. Info. Division, Ext. 6782 


\section{LEGAL NOTICE}

This report was prepared as an account of work sponsored by the United States Government. Nelther the Untted States nor the Department of Energy, nor any of their employees, nor any of their contractors, subcontractors, or their employees, makes any warranty, express or Implied, or assumes any legal liability or responsibility for the accuracy, completeness or usefulness of any information, apparatus, product or process disclosed, or represents that its use would not infringe privately owned rights. 


\title{
GORRECTIONS FOR
}

COMPONENT IMPERFECTIONS AND AZIMUTH ERRORS

IN AN AUTOMATIC SELF-COMPENSATIMG ELLIPSOMETER

Craig G. Snith, Janet S. Rerler, and Rolf H. Muller

Materials and Molecular Research Division

Lawrence Berkeley Laboratory

University of California

Berkeley, California 94720

\begin{abstract}
An analysis of the first-order effects of component imperfections and azimuth errors in an automatic, self-compensating ellipsometer is presented. Twenty-three parameters in a linearized theory are used to compute the ellipsoneter parameters $\Delta$ and $\psi$ from polarizer, quarter wave compensator, and analyzer azimuths. These parameters are evaluated using $\mathbf{5 6}$ experimental measurements. The effectiveness of the corrections is recognized by a substantial decrease of the dffferences between 4-zone measurements. The theoretical dependence of the magnitude of errors on the orfentation of the polarizer, analyzer, and quarter wave plate was experimentally verified.
\end{abstract}


TABLE OF CONTENTS

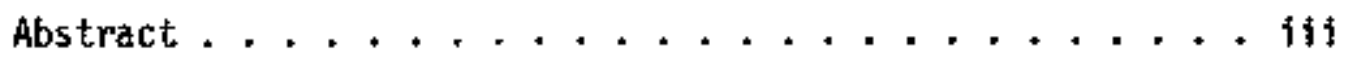

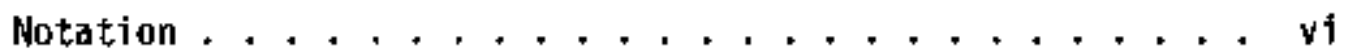

I. BACKGROUND AND THEORY $\ldots \ldots \ldots \ldots$

A. Components of the Ellipsometer ......... 2

B. Rotated and Standard Coordinate Systems for the

Measurement of the Hulling Angles ......... 2

c. Zones and Groups ............. 7

D. One-Zone and Four-Zone Measurements ........ 8

E. Theory ..................... 10

F. The Jones calculus ..............12

G. Component Imperfections Treated as First Order

Series Expansions ............... 17

H. Birefringence in the Polarizer Faraday Cell .... 19

II. EVALUATIOH OF THE PARAMETERS . . . . . . . . . 35

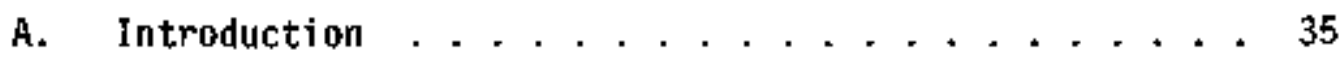

B. Experimental Procedure ............ 35

C. Expressfons for the Parameters ......... 37

D. Index of Parameter Expressions .......... 46

III. RESULTS AND DISCUSSION . . . . . . . . . . 48

A. Parameter Values .............. 48

B. The Variation of Imperfection Effects with $\psi$ and $\Delta \ldots 48$

c. Verification of the Theory . ......... 51

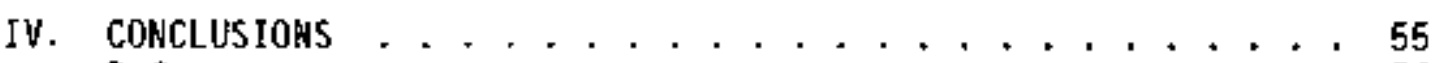

References ................. 56

APPENDIX A: Tables ............ 57

APPENDIX B: An Approximate Determination of $\psi$ and $B \ldots .73$

APPENDIX C: Program COMPER ............ . 78

APPENDIX D: The Group Dependence of the 5igns of the Parameter Values . . . . . . . . . . . 92

APPENDIX E: Measurements Used to Determine the

Parameter Values ........... 94 
MOTATION

A,a Analyzer azimuth (degree). As a subscript, refers to the component.

C,c Quarter wave plate azimuth (degree). As a subscript, refers to the component.

$C^{\star} \quad$ FCI-C

$E_{x} \quad$ Electrical field vector perpendicular to plane of specimen surface.

Ey Electric field vector parallel to plane of specimen surface.

FC Refers to measurements made with Faraday cells.

FCI Glass core in the polarizer Faraday cell azimuth. Refers to component as a subscript.

FCR Glass core in the analyzer Faraday cell azimuth. Refers to component as a subscript.

NFC Refers to measurements made without the Faraday cells.

NW Refers to measurements made without windows.

P,p Polarizer azimuth (degree). As a subscript, refers to component.

$P^{*} \quad P-F C I$

R(w) Rotator matrix describing orientation of principle frame of reference for a component.

$r_{s} \quad$ Reflection coefficient in direction perpendicular to specimen surface.

$r_{p} \quad$ Reflection coefficient in direction parallel to specimen surface. 
$\mathbf{T}_{\mathbf{j}} \quad$ Transmission matrix for component $\mathrm{f}$.

$T_{j}^{*} \quad R(j) T_{j} R(-j)$

${ }^{t}{ }_{i j}$ Describes non-jdeal effect of component $j$ on the electric field intensity (degree).

$T_{2 j}$ Describes non-idea 3 effect of component $j$ on phase of the electric field.

WI, WR Entrance and exit window azimuths. As a subscript, refers to components.

$Z_{j} \quad$ Refers to azimuths of component $\mathrm{j}$.

$\triangle \quad$ Relative phase shift due to reflection from specimen surface (degree).

\$B Specimen mispositioning error (degree).

os Deviation in $\Delta$ due to component imperfections.

$\delta \rho_{j} \quad$ Deviation in $\rho_{j}$ due to imperfections in component $j$.

84 Deviation in $\psi$ due to component imperfections.

$\delta Z_{j} \quad$ Error in az1muth of component $j$.

$E_{x} \quad$ Phase of electric field vector in $x$-direction.

$E_{y} \quad$ Phase of electric field vector in $y$-direction.

$Y_{Z_{j}} \quad$ Coupling constant for $Z_{j}$ error $\delta Z_{j}$.

$\gamma_{\rho_{j}} \quad$ Coupling constant for $\rho_{j}$ error $\delta \rho_{j}$.

$\lambda$ Wavelength of light, angstroms.

$\phi \quad$ Angle of incidence (degree). 
$\rho_{j} \quad$ Relative transmittance for component $j$.

$\rho_{s} \quad$ Specimen reflectance ratio, $=r_{p} / r_{s}$

$\Psi \quad$ Relative intensfty parameter due to reflection from specimen surface (degree).

$v \quad$ Frequency of light. 


\section{BACKGROUND AND THEORY}

Ellipsometry is used to study the surface properties of materials immersed in an optically transparent medium. The two quantities of interest in ellipsometry studies are the changes, due to reflection from the surface, in the relative anplitude $\psi$ and the relative phase $\Delta$ of two orthogonal components of the electric field vector which describe the state of polarization of the probing 1 ight beam.

When the components of the ellipsometer contain imperfections, their effects on the phase and amplitude of the 1 ight must be included in the interpretation of ellipsometer measurements. Imperfections in the ellipsometer are assumed to be either calfbration errors in the graduated azimuth circles of the polarizer, anatyzer, and quarter wave plate, deviation from quarter wave retardation, or flaws in the optjcal components due to strain-generated birefringence and polarizationdependent absorption.

The purpose of this analysis is to obtain a set of equations for $\psi$ and $\Delta$ which compensate for the component imperfections. This analysis extends the word of Azzan and Bashara ${ }^{1}$ on error corrections for a manual compensating ellpsometer to the use of an automatic self-compensating ellipsometer. The self-compensating ellipsometer uses Faraday cells to rotate the plane of polarization, thus enabling the elljpsometer to follow rapid changes in the state of the surface. The Faraday cells add two more imperfect components to the analysis, which results in more error terms in the equations for $\psi$ and $A$. The Faraday cells are assumed to be both bivefringent and dicroic, thus producing both relative phase and relative attenuation effects. 
A. Components of the Ellipsometer

The components of the ellipsometer are arranged in the following sequence (Figure 1): polarizer P, polarizer Faraday cell FCI, quarter wave plate $C$, entrance cell window $\mathrm{WI}$, specimen $S$, exit cell window WR, analyzer Faraday cell FCR, and analyzer A. The abbreviations used to represent each component ( $P, \mathrm{FCl}$, etc.) will also be used in other contexts: as subscripts to designate to which component a parameter refers; and to represent angles of rotation. These latter usages will be introduced in the following sections.

B. Rotated and Standard Coordinate Systems for the Measurement of the Nulling Angles

There are two possible coordinate systems for the measurement of the nulling azimuth angles of the analyzer and polarizer. In one system, the nulling angles are called standard azinuth angles and are denoted by $a$ and $p$ (for analyzer and polarizer). In the other, they are called rotated azimuth angles and are denoted by $A$ and $P$.

The two coordinate systems are defined by the experimental set-up, specifically by the positioning of the specimen, which in turn depends on the nature of the experiment. Figures 2 and 3117 ustrate the two different experimental set-ups. If the spectmen plane is horizontal (Figure 2), then the coordinate system is standard; if the specimen plane is vertical, the coordinate system is rotated (Figure 3).

The orientation of the orthogonal components, $E_{x}$ and $E_{y}$, of the electric field vector is defined relative to the plane of the specimen. The $E_{y}$-axis is parallel to the plane of the specimen, and the positive $E_{x}$-axis is in the direction of a vector in the plane defined by the 


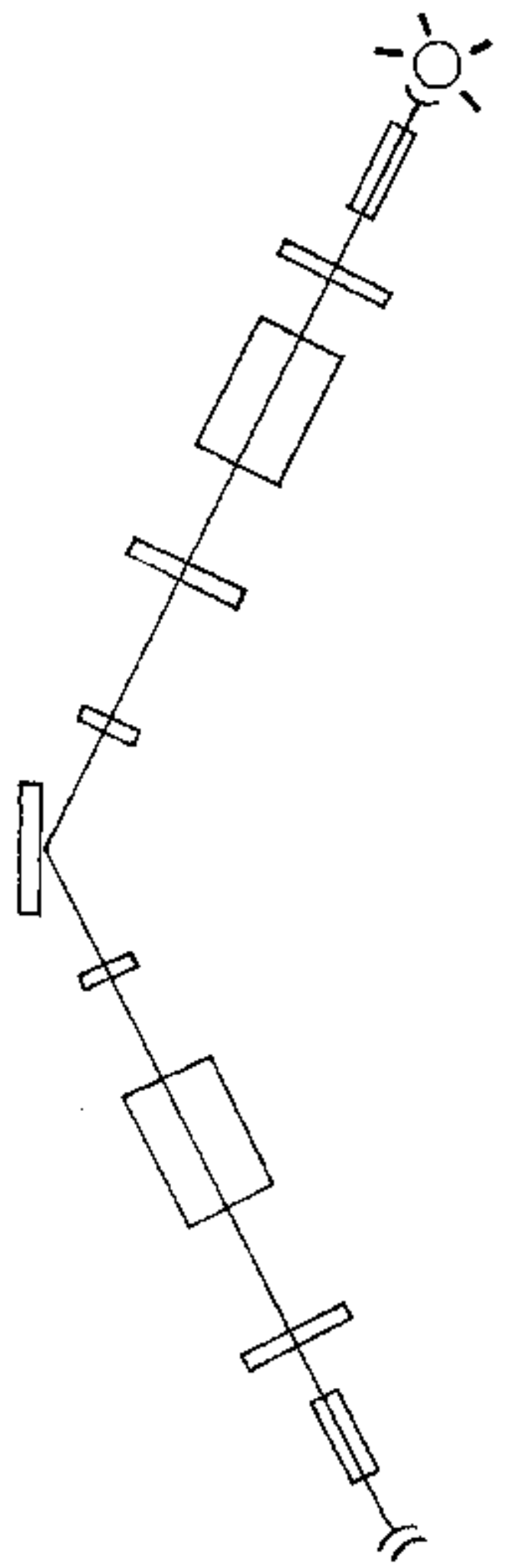

LIGHT SOURCE

COLLIIMATOR

POLARIZER (P)

POLARIZER

FARADAY CELL (FCI)

QUARTER WAVE

COMPEHSATOR (C)

ENTRANCE

CELL WINDOW (WI)

SPECIMEN (S)

EXIT

CELL HINDOW (WR)

ANALYZER

FARADAY CELL (FCR)

ANALYZER (A)

TELESCOPE

PHOTOMULETIPLIER

XBL 774-8330

Fig. i. Components of the automatic self-compensating ellipsometer. 


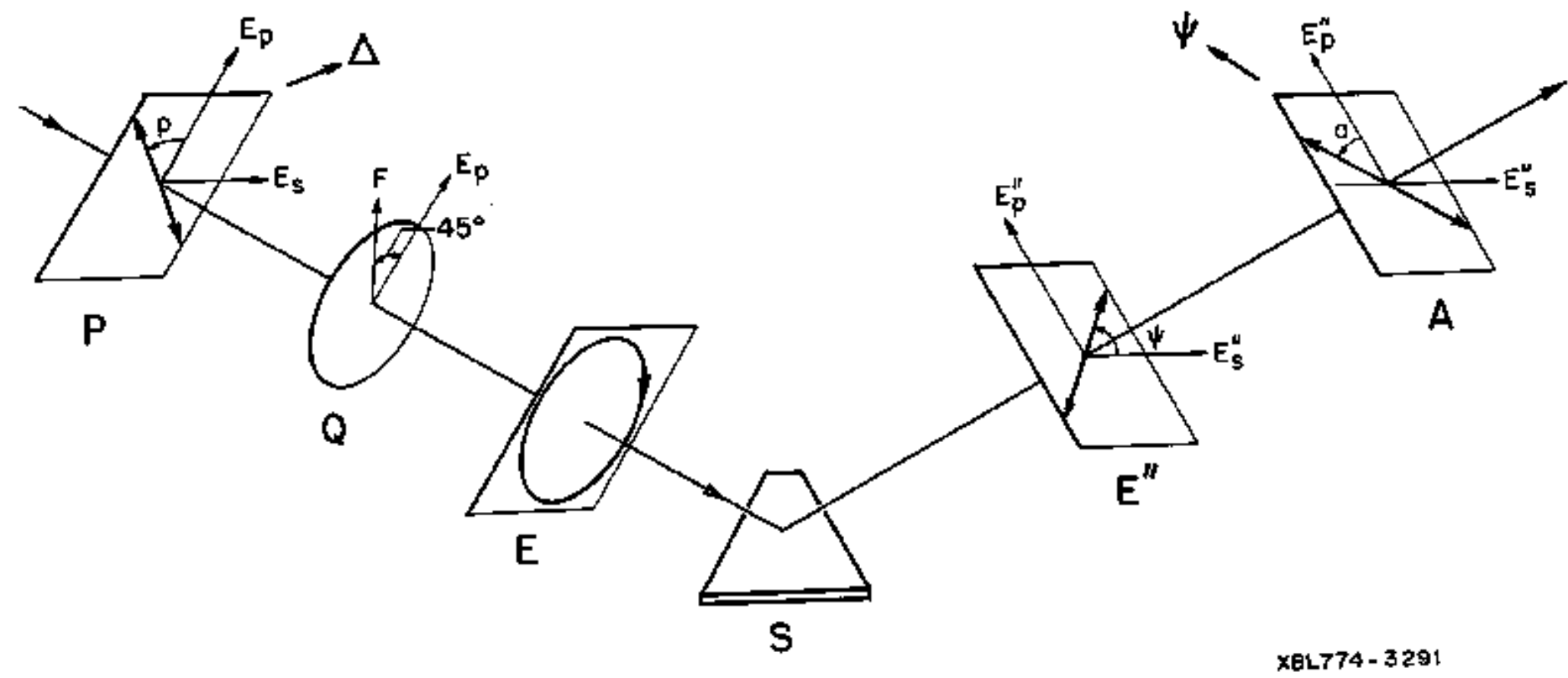

Fig. 2. Horizontal specimen orientation definfing standard coordinate system. 
-5-

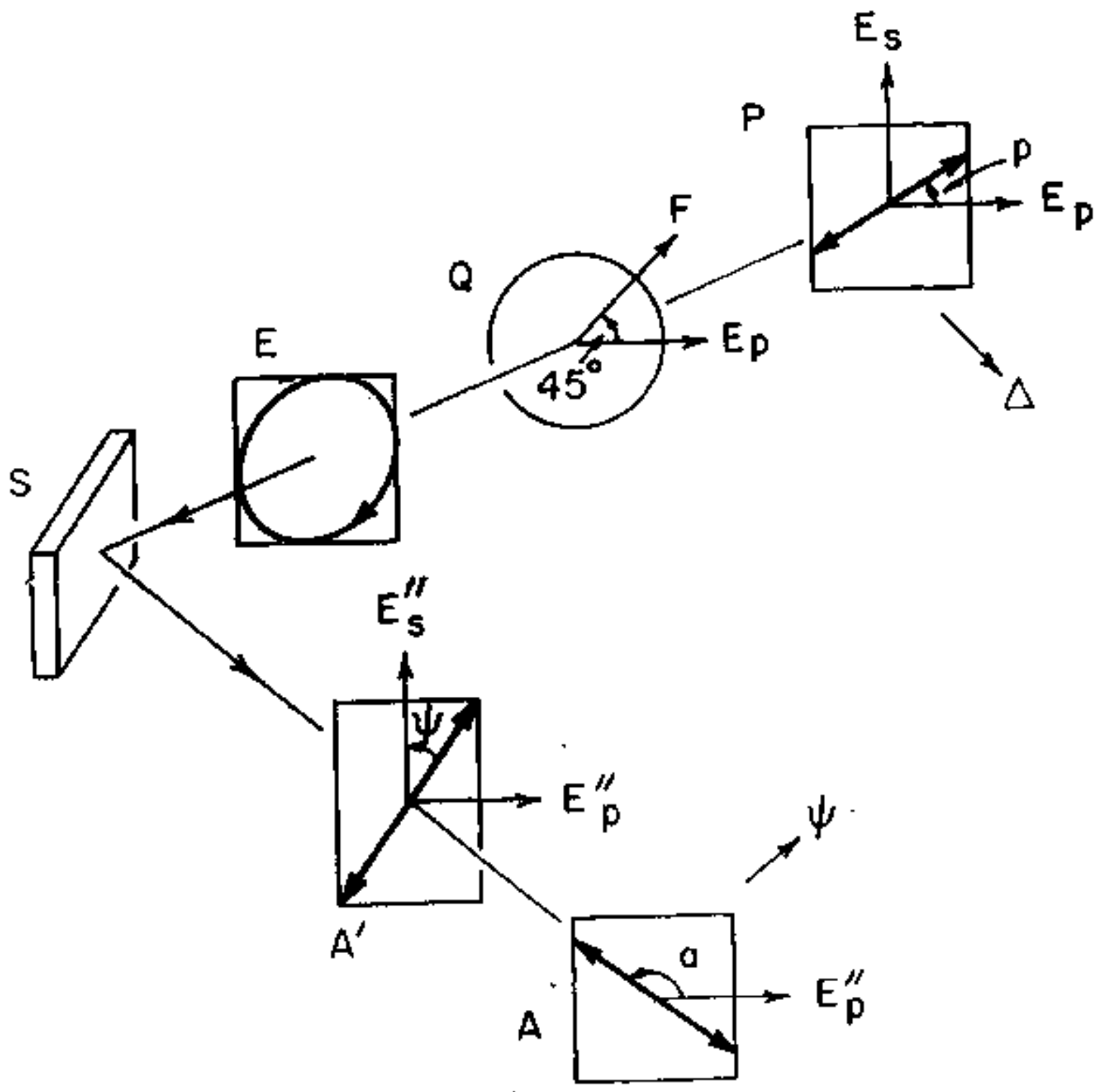

XmL $719-4419$

Fig. 3. Vertical specimen orientation defining rotated coordinate system. Azimuths $\mathrm{p}, \mathrm{a}$, and $\mathrm{q}$ referred to as (capital) $P, A$, and $Q$ in text. 
incident and reflected beams. Rotating the specimen plane counterclockwise from a vertical position (rotated system) to a horizontal position (standard system) therefore rotates the $E_{x}-E_{y}$ coordinate system by $90^{\circ}$ (In the counterclockwise direction).

Though the azimuth circle of the polarizer can be moved, the transmission axis of the polarizer remains fixed with respect to the azimuth circle. The same is true in regard to the transmission axis of the analyzer. The azimuth angle of the polarizer is measured counterclockwise from the positive $\mathrm{E}_{x}$ axis to the transmission axis of the polarizer (Indlcated in the figures by a heavy double pointed arrow), and the azfmuth angle of the analyzer is measured counterclockwise from the positive $E_{x}{ }^{\prime \prime}$ axis to the analyzer transmission axis (see Figures 2 and 3 ).

Because the two coordinate systems are related by a $90^{\circ}$ rotation, the polarizer and analyzer azinuths in each system are related by:

$$
\begin{aligned}
& P=P \pm 90^{\circ}, \\
& A=a \pm 90^{\circ} .
\end{aligned}
$$

In keeping with the rotation for the anaiyzer and polarizer azimuth angles, the setting of the quarter wave plate is denoted by $c$ if the nulling angles have been measured in the standard systes or by $\mathrm{C}$ if the nulling angles have been measured in the rotated system, and

$$
c=c \pm 90^{\circ} \text {. }
$$


Some derivations and results given in this paper do not depend on the coordinate system used to measure the nulling angles. For that reason, infess otherwise noted, $\mathrm{A}, \mathrm{P}$ and $\mathrm{C}$ will be used throughout this paper to refer in general to the andlyzer and polarizer azimuth angles and the setting of the quarter wave plate in either coordinate system. If the resuits depend on the coordinate system used, both sets of results will be given.

\section{c. Zones and Groups}

The values of $\psi$, the relative amp 1 itude, and $\Delta$, the relative phase, are not measured directly, but are calculated from the nulling azimuth angles of the analyzer and polarizer respectively. The ranges of $\psi$ and $\Delta$ and the nulling aztmuth angles are :

$$
\begin{array}{ll}
\text { v: } 0^{\circ}-90^{\circ} & \text { a, } A: 0^{\circ}-180^{\circ} \\
\Delta: 0^{\circ}-360^{\circ} & p, P: 0^{\circ}-180^{\circ}
\end{array}
$$

Though the value of $\Delta$ depends explicitly only on $P$, the equation defining the ideal value of $\Delta$ in terms of $P$ is not the same for all values of $\Delta$. In fact, the defining equation for $\Delta$ depends also on the range of $A$ and on $C$, though neither $A$ nor $C$ appear in the equation. For this reason, it is conventent to distinguish 76 categories called somes to which a measurement, consisting of a value of $P, C$ and $A$ can belong. The 16 zones are defined as follows: The range of $A$ is divided into two subranges, $0^{\circ}-90^{\circ}$ and $90^{\circ}-180^{\circ}$; the range of $\mathrm{P}$ is divided into four subranges, $0^{\circ}-45^{\circ}, 45^{\circ}-90^{\circ}, 90^{\circ}-135^{\circ}$ and $135^{\circ}-180^{\circ}$, 
and the value of $C$ is 1 imited to two possibilities, $45^{\circ}$ and $-45^{\circ}\left(135^{\circ}\right)$. Taking all possible combinations of the subranges of $A$ and $P$ and the value of $C$ yields 16 zones. Mreover, the zones are grouped into four larger categories called groups, which depend on the range of $A$. It is a convention that the groups which correspond to a certain range of $\Delta$ are lettered and that the four zones, which comprise one of the lettered groups, are numbered according to the range of the polarizer azimuth. 2 However, the numbering of zones is not the same for rotated polarizer azimuths as for standard polarizer aximuths. Table El gives the definition of groups and Table E2 the definition of zones.

The ideal (uncorrected) value of $\psi$ and 4 for each zone, as well as the corresponding ranges of the polarizer and analyzer azimuths for both the standard and rotated azimuth system, are given in Appendix A.

\section{One-Zone and Four-Zone Measurements}

$A$ one-zone measirement consists of a value of $A, P$ and $C$. The vajue of $C^{\prime}$ may be efther $45^{\circ}$ or $135^{\circ}$ and is set before the nulling angles $A$ and $P$ are found. $A$ one-zone measurement may be taken on either a bare, unchanging surface or on a surface that is rapidly changing. After the nulling angles have been measured, the zone to which the triplet (C, A, P) belongs can be found from Table I which contajns the zone and group divisions. The triplet will belong to one and only one of these zones, hence the name one-zone measurement. Once the correct zone is determined, the tdeal values of $\psi$ and $s$ may be calculated using the appropriate formulas. 
TABLE El. Definition of group lettering

\begin{tabular}{cc}
\hline \hline Graup & Range of $A$ \\
\hline$A$ & $0^{\circ}-90^{\circ}$ \\
$B$ & $90^{\circ}-180^{\circ}$ \\
$C$ & $180^{\circ}-270^{\circ}$ \\
$D$ & $270^{\circ}-360^{\circ}$
\end{tabular}

TABLE E2. Definition of zone numbering

\begin{tabular}{crr}
\hline \hline Zone & $\begin{array}{c}\text { Range of } \\
\text { standard } \\
\text { azimuth } p\end{array}$ & $\begin{array}{r}\text { Range of } \\
\text { rotated } \\
\text { azimuth P }\end{array}$ \\
\hline 1 & $0^{\circ}-45^{\circ}$ & $90^{\circ}-135^{\circ}$ \\
2 & $45^{\circ}-90^{\circ}$ & $135^{\circ}-180^{\circ}$ \\
3 & $90^{\circ}-135^{\circ}$ & $0^{\circ}-45^{\circ}$ \\
4 & $135^{\circ}-180^{\circ}$ & $45^{\circ}-90^{\circ}$ \\
\hline
\end{tabular}


A four-sone mearement is actually four one-zone measurements that al1 belong to the same group, but $f a 71$ into the four different zones within that group. Since each set $(C, A, P)$ defines a value of $\psi$ and a value of $\Delta$, a four-zone measurement is only meaningful if taken on an unchanging surface so that the four one-zone measurements all define the same values of $\psi$ and $\Delta$. Ideally the values of $\psi$ and $\Delta$ calculated from the four one-zone measurements should be the same. This is rarely the case, however, and the conclusion drawn is that the components of the ellipsometer contain imperfections which affect the measurements. The assumption that disagreement in the four-zone measurements is a result of imperfect components is centrat to this analysis, because the aim of using the corrected equations (to be derived in following sections) is to improve the agreement of the four one-zone measurements.

Given below is a four-zone measurement and values of $\psi$ and $\Delta$ calculated from the ideal equations in Table I. For comparison, the corrected values of $\psi$ and $\Delta$ are given.

\section{E. Theory}

The analysis of Azzant and Bashara uses the Jones Calculus to describe the optical effect of each component on the state of polarization of the light as it passes through the ellapsometer. The Jones Calculus, invented in 1940 and 1941 by R. Clark Jones, ${ }^{3}$ uses a matrix to represent an optical device such as a polarizer or retarder and a vector to describe the state of polarization of a beam of light. The passage of the light through a component corresponds to multiplication of the 
Four-zone measurement made on bare zinc

\begin{tabular}{c|rrr}
\hline Zone & c & a & \multicolumn{1}{c}{ P } \\
\hline B1 & $135^{\circ}$ & $37.68^{\circ}$ & $5.23^{\circ}$ \\
B2 & $45^{\circ}$ & $40.06^{\circ}$ & $84.03^{\circ}$ \\
B3 & $135^{\circ}$ & $142.70^{\circ}$ & $95.35^{\circ}$ \\
B4 & $45^{\circ}$ & $145.09^{\circ}$ & $174.42^{\circ}$ \\
\hline
\end{tabular}

Idear values of $\psi$ and $A$ calculated from four-zone measurement

\begin{tabular}{c|cc}
\hline Zone & $\psi^{\circ}$ & $A^{\circ}$ \\
\hline B1 & 37.68 & 100.46 \\
B2 & 40.06 & 101.94 \\
B3 & 37.30 & 100.70 \\
B4 & 34.91 & 101.16 \\
\hline
\end{tabular}

Corrected values of $\Psi$ and $\Delta$

\begin{tabular}{c|cc}
\hline \hline Zone & $\psi$ & $\Delta$ \\
\hline B1 & 37.473 & 100.422 \\
B2 & 37.509 & 100.632 \\
B3 & 37.472 & 100.392 \\
B4 & 37.452 & 300.742 \\
\hline
\end{tabular}


vector representing the light by the component's matrix. The effect of imperfections in a companent is treated as a first-order Taylor series expansion about the ideal component value.

F. The Jones Calculus

To define the spatial arrangement of the ellipsometer, we use a rightahanded rectangular coordinate system with $x, y$ and $z$ axes. The components of the ellipsometer $l$ ie along the $z$ axis which is perpendicular to the planes cantaining the components. When the axes of a component are parallel to the $x$ and $y$ axes, the component is said to be in its principal frame of reference. In this case, the Jones transmission matrix of either a partial polarizer or a retardation plate is given by $e^{i \phi_{N}}$, where $N$ equals

$$
N=\left(\begin{array}{ll}
N_{x} & 0 \\
0 & N_{y}
\end{array}\right)
$$

where

$$
\begin{aligned}
& N_{x}=\exp \left[-i(2 \pi d / \lambda)\left(n_{x}-i k_{x}\right)\right] \\
& N_{y}=\exp \left[-i(2 \pi d / \lambda)\left(n_{y}-i k_{y}\right)\right]
\end{aligned}
$$


and $d$ is the thickness of the plate; $\lambda$ is the wavelength of the light in a vacuum; $n_{x}$ and $n_{y}$ are the principal indices of refraction in the $x$ and $y$ directions; and $k_{x}$ and $k_{y}$ are the principal extinction coefficients in the $x$ and $y$ directions.

For a partial polarizer the principal indices of refraction are equal, $n_{x}=n_{y}=n$, and the Jones matrix has the form $e^{i \phi_{N_{p}}}$ where

$$
N_{p}=\left(\begin{array}{cc}
P_{x} & 0 \\
0 & P_{y}
\end{array}\right) \text {, }
$$

$e^{i \phi}$ is the absolute phase factor and $P_{x}$ and $P_{y}$ are the principal transmittances in the $x$ and $y$ directions, respectively. If the absolute phase of the two components of light is of no interest, then $N_{p}$ may be used alone as the matrix representation of the partial polarizer. This form of the Jones matrix is called the standard matrix.

For a retardation plate, the principal extinction coefficients, $k_{x}$ and $k_{y}$, are both zero and the Jones matrix has the form $e^{i \phi} N_{R}$,

$$
N_{R}=\left(\begin{array}{cc}
e^{i \gamma} & 0 \\
0 & e^{-i \gamma}
\end{array}\right) \text { and } \gamma=\delta / 2
$$

where $\delta$ is the retardance. As in the previous case, the absolute phase factor $e^{i \phi}$ may be omitted so that the standard matrix of a retardation plate is $\mathrm{N}_{\mathrm{R}^{*}}$. Appendix 2 of Reference (4) 11sts the standard Jones matrices for commonly used optical devices. 
For this analysis the standard Jones matrix is further simplified by dividing each entry in the matrix by the entry in the upper left-hand corner of the matrix, and then dropping the divisor. The representation of the partial polarizer is then

$$
T_{p}=\left(\begin{array}{ll}
1 & 0 \\
0 & \rho_{p}
\end{array}\right),
$$

where $\rho_{p}$ is the relative transmittance for the polarizer, $P_{y} / P_{x}$. For the retardation plate,

$$
T_{R}=\left(\begin{array}{ll}
1 & 0 \\
0 & \rho_{R}
\end{array}\right) \text {. }
$$

where $\rho_{R}{ }^{2} e^{-i \delta}$ is also called the relative transmittance.

Using this simplification, each component of the ellipsometer has the same diagonal form when in its principal frame of reference. Thus, for the $j$ th component,

$$
\mathbf{T}_{\mathbf{j}}=\left(\begin{array}{ll}
1 & 0 \\
0 & p_{j}
\end{array}\right)
$$

where $\rho_{j}$ is the relative transmittance. However, if the component is not in its principal frame of reference, then its Jones matrix $T_{j}^{*}$ is related to the Jones matrix $\mathrm{T}_{\mathfrak{j}}$ by 


$$
T_{j}^{*}=R(w) T_{j} R(-w)
$$

where $R(\omega)$ and $R(-\omega)$ are the rotator matrices

$$
R(\omega)=\left(\begin{array}{cc}
\cos \omega & \sin \omega \\
-\sin \omega & \cos \omega
\end{array}\right) \text { and } R(-\omega)=\left(\begin{array}{cc}
\cos \omega & -\sin \omega \\
\sin \omega & \cos \omega
\end{array}\right) \text {. }
$$

The angle w measures the amount by which the coordinate system associated with the componemt has been ratated with respect to the fixed $x-y$ coordinate system.

The form of the Jones vector that will be used in this analysis is just

$$
\vec{E}=\left(\begin{array}{c}
E_{x} \\
E_{y}
\end{array}\right)
$$

where $E_{x}$ and $E_{y}$ are the scalar components of the electric field vector along the $x$ and $y$ axes. $E_{x}$ and $E_{y}$ are further defined by

$$
\begin{aligned}
& E_{x}=A_{x} \exp \left[1\left(\varepsilon_{x}+2 \pi \nu t\right)\right] \\
& E_{y}=A_{y} \exp \left[1\left(\varepsilon_{y}+2 \pi \nu t\right)\right]
\end{aligned}
$$


where $A_{x}$ and $A_{y}$ are the maximum values of $E_{x}$ and $E_{y}$, and $\varepsilon_{x}$ and $E_{y}$ are the phase components of $E_{x}$ and $E_{y}$ at time $t=0$. In problems not concerned with time, the time factor $e^{i 2 \pi v t}$ can be dropped so that

$$
\begin{aligned}
& E_{x}=A_{x} \exp \left(i \varepsilon_{x}\right) \\
& E_{y}=A_{y} \exp \left(i \varepsilon_{y}\right)
\end{aligned}
$$

Subscripts on $\vec{E}, E_{x}$ and $E_{y}$ will be used to designate through which component the light has just passed.

With the major elements of the Janes calculus defined, we can now express the optical effect of the sequence of ellipsometer components as a chain of matrix multiplication:

$$
\left(\begin{array}{c}
E_{x} \\
E_{y}
\end{array}\right)_{\text {final }}=T_{A}^{*} T_{F C R}^{*} T_{W R}^{*} T_{S} T_{W I}^{*} T_{C}^{*} T_{F C I}^{*} R(-P)\left(\begin{array}{c}
E_{x} \\
E_{y}
\end{array}\right)_{\text {initial }}
$$

Two points should be noted in connection with the matrix multiplication given above. First, because the Jones vector representation of light is limfted to polarized light, the first use of the Jones vector is to describe the state of polarization of the light after it has passed through the polarizer. Therefore, the Jones matrix for the polarizer 
$\mathrm{T}_{\mathrm{P}}^{*}$ does not appear in the matrix chain through the counter rotator matrix $\mathrm{R}(-\mathrm{P})$ does. Secondly, the Jones matrix for the specimen is

$$
T_{S}=\left(\begin{array}{ll}
\rho_{S} & 0 \\
0 & 1
\end{array}\right)
$$

where $\rho_{s}$ is the specimen reflectance ratio.

G. Component Imperfections Treated as First-Order Series Expansians

For the purpose of this analysis, the relative transmittance of an optlcal component contains the measure of the imperfection within that component. For a small imperfection in the $j$ th component, the relative transmittance $\rho_{j}$ is given by

$$
\rho_{j}=\rho_{j}^{o}+\delta \rho_{j}
$$

where $\rho_{j}^{0}$ is the ideal relatfve transmittance and $\delta_{p_{j}}$ is a measure of the imperfection. Since the imperfection may affect both the intensity and the relative phase of the light,

$$
\delta \rho_{j}=t_{1 j}+i t_{2 j}
$$

where $t_{1 j}$ measures of the effect of the imperfection on the intensity and $t_{2 j}$ measures the effect on the relative phase. 
Due to calibration errors the true azimuth angle $Z_{j}$ (this refers to $C, A$ or $P$ ) may vary from the measured azimuth $Z_{j}^{0}$ by a smatl deviation $\delta Z_{j}:$

$$
z_{j}=z_{j}^{0}+\delta z_{j}
$$

When the light flux transmitted by the analyzer is a minimum, the value of $\rho_{s}$, the ratio of the complex reflection coeffictents $\left(r_{p} / r_{s}\right)$ for the specimen, is given by equation (4):

$$
\rho_{s}=f\left(z_{j}, \rho_{j}\right)
$$

The first order Taylor series expansion of (4) about $p_{j}$ and $z_{j}$ is

$$
\rho_{s}=f\left(z_{j}, \rho_{j}\right)+\sum_{j} \gamma_{j} \delta z_{j}+\sum_{j} \gamma_{\rho_{j}} \delta_{\rho_{j}}
$$

The coupling constants $\gamma_{z j}$ and $\gamma_{\rho j}$ determine the way in which the azimuth error $\delta Z_{j}$ and a component imperfection $\delta \rho_{j}$ couple onto an error in $\rho_{s}$.

The zeroth-order approximation to $\rho_{s}$, given by

$$
\rho_{s}^{0}=f\left(z_{j}^{0}, \rho_{j}^{0}\right)
$$


is the value of $\rho_{s}$ when the measured azimuths are substituted into the error-free ellipsometry equations in Table $I$. The corresponding corrections to $\psi$ and $\Delta, \delta \psi$ and $\delta \Delta$, are found by taking the logarfthmic differential of $\rho_{5}=\tan \psi e^{i \Delta}$,

$$
\delta \rho_{s} / \rho_{s}=2 \delta \psi / \sin 2 \psi+i \delta \Delta
$$

The expressions for $\delta \psi$ and $\delta \Delta$ are therefore.

$$
\begin{aligned}
& \delta \psi=\operatorname{ts} \sin 2 \psi \operatorname{Re}\left(\delta \rho_{s} / \rho_{s}\right) \\
& \delta \Delta=\operatorname{Irn}\left(\delta \rho_{s} / \rho_{s}\right)
\end{aligned}
$$

H. Birefringence in the Polarizer Faraday Cell

The coupling constants for the polarizer, analyzer, quarter wave plate, and entrance and exit cell windows, as well as the corresponding corrections to $\psi$ and $\Delta$ are derived in Reference 1 . It can be shown that $\gamma_{\rho_{F C R}}$ has the same form as $\gamma_{\rho_{W R}}$ The derivation of the constant $\gamma_{\rho_{F C I}}$ i.s presented here; the procedure will first be outlined and the algebraic steps and simplifications will follow.

For the purpose of determining $\gamma_{\rho_{\mathrm{FCI}}}$, the other components are assumed to be ideal; therefore

$$
\rho_{s}=\rho_{s}^{\circ}+\gamma_{\rho F C I} \delta_{F C I}
$$


The imperfection in the glass core of the Faraday cell is assumed to affect both the intensity and the relative phase of the light beam so that

$$
\delta \rho_{\mathrm{FCI}}=\mathrm{t}_{1 \mathrm{FCI}}+\hbar \mathrm{t}_{2 \mathrm{FCI}}
$$

The measure of the imperfection $\delta \rho_{\mathrm{FCI}}$ is embedded in the Jones matrix for the Faraday cell:

$$
T_{F C I}^{*}(F C I)=R(F C I)\left(\begin{array}{cc}
1 & 0 \\
0 & \rho_{F C I}
\end{array}\right) R(-F C I)
$$

where

$$
\rho_{\mathrm{FCI}}=\rho_{\mathrm{FCI}}^{\circ}+\delta \rho_{\mathrm{FCI}} .
$$

The result of the chain of matrix multiplications (from right to left), $T_{S}^{*} T_{C}^{*} T_{F C I}^{*} T_{\rho}^{*}$, acting on the incident beam, is the vector $\left\langle E_{x, s}, E_{y, s}\right)$. The ratio of the components of this vector defines the specimen reflectance ratio:

$$
\rho_{5}=\frac{E_{x, s}}{E_{y, s}}
$$


This ratio contains the term $\delta \rho_{\mathrm{FCl}}$ which häs been carried through the matrix mult1plication like a constant. Using algebraic simplifications and triganometric identities, the single-term expression for $a_{s}$ given in equation (D), can be separated into two terms, one of which is multiplied by $\delta \rho_{F C I}$. Comparison of this to equation (A) yields expressions for $\rho_{S}^{o}$ and $\gamma_{\mathrm{FCI}}$. These expressions are then substituted into the equation for the logarithontc differential of $\rho_{s}$, which in this case is,

$$
\frac{\delta \rho_{\mathrm{S}}}{\rho_{\mathrm{S}}}=\frac{\gamma_{\rho_{\mathrm{FCI}}} \delta \rho_{\mathrm{FCI}}}{\rho_{\mathrm{S}}^{\circ}}
$$

where $\rho_{s}$ in the denominator of the term on the right hand side has been approximated by $i$ ts ideal value $\rho_{\mathrm{s}}^{\circ}$, and

$$
\delta \rho_{\mathrm{FCI}}=t_{1 \mathrm{FCI}}+i t_{2 \mathrm{FCI}}
$$

When the resulting expression of equation (E) is separated into its real and imaginary parts, it yields the corrections to $\psi$ and $\Delta$ that must be made to compensate for the inperfections in the polarizer Faraday cell. The details of the matrix multiplication are glven next. The light beam leaving the polarizer is described by a Jones vector as,

$$
\mathrm{E}_{\mathrm{p}}=\left(1, \rho_{\mathrm{p}}\right)
$$


For the purpose of determining $\gamma_{\mathrm{FCI}}, \mathrm{P}_{\mathrm{P}}=0$, because in the linear anaiysis, component imperfections in the polarizer do not affect the analysis for the Faraday cell. On passing through the polarizer Faraday cel1, the Jones vector becomes

$$
\begin{aligned}
\underline{E}_{F C I} & =T_{F C I} I^{R\left(-P^{*}\right)} \underline{E}_{p} \\
& =\left(\cos P^{*}, \rho_{F C I} \sin P^{*}\right)
\end{aligned}
$$

where $\mathrm{P}^{*}=\mathrm{P}-\mathrm{FCI}$

After passing through the compensator,

$$
\begin{aligned}
\underline{E}_{c} & =T_{C} R\left(-C^{*}\right) \underline{E}_{F C I} \\
& =\left(F_{1}, F_{2}\right)
\end{aligned}
$$

where,

$$
\begin{aligned}
& F_{1}=\cos C^{*} \cos P^{*}-\rho_{F C I} \sin C^{*} \sin P^{*} \\
& F_{2}=\rho_{C}\left(\sin C^{*} \cos P^{*}+\rho_{F C I} \cos C^{*} \sin P^{*}\right)
\end{aligned}
$$

and $\mathrm{C}^{*}=\mathrm{FCI}-\mathrm{C}$. 
Upon reflection from the specimen, the light is 1inearly polarized so that $A=\pi$ and

$$
\rho_{\mathrm{s}}=-\tan \psi
$$

The Jones vector is given by

$$
\begin{aligned}
\underline{E}_{s} & =T_{s} R(-C) E_{c} \\
& =\left(E_{x, s}, E_{y, s}\right)
\end{aligned}
$$

where

$$
T_{S}=\left[\begin{array}{ll}
\rho_{S} & 0 \\
0 & 1
\end{array}\right],
$$

and

$$
\begin{aligned}
& E_{x, s}=\rho_{s}\left(F_{1} \cos C-F_{2} \sin C\right), \\
& E_{y, s}=\left(F_{1} \sin C+F_{2} \cos C\right) .
\end{aligned}
$$


For extinction for flux minimula), the value of $\psi$ is given by $A \pm 180^{\circ}$; substituting this into equation (12) gives

$$
\rho_{\mathrm{S}}=-\tan A \text {. }
$$

Combining this fact with the following defintion of $\rho_{s}$,

$$
\rho_{s}=\frac{E_{x, s}}{E_{y, s}} \text {, }
$$

where equations (14a) and (14b) have been substituted for $E_{x, s}$ and $E_{y, s}$ yields the following expression for $\rho_{\mathrm{s}}$ :

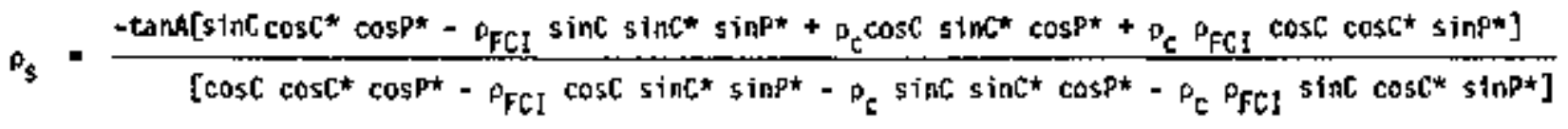

$$
\begin{aligned}
& \frac{-\tan A\left[\tan C-\rho_{\mathrm{FCI}} \tan C \tan C^{*} \tan P^{*}+\rho_{\mathrm{C}} \tan C^{*}+\rho_{\mathrm{C}} \rho_{\mathrm{FCI}} \tan \mathrm{P}^{*}\right]}{\left[1-\rho_{\mathrm{FCI}} \tan \mathrm{P}^{*} \tan C^{*}-\rho_{\mathrm{C}} \operatorname{tanC} \tan C^{*}-\rho_{\mathrm{C}} \rho_{\mathrm{FCI}} \operatorname{tanC} \tan \mathrm{P}^{*}\right]}
\end{aligned}
$$

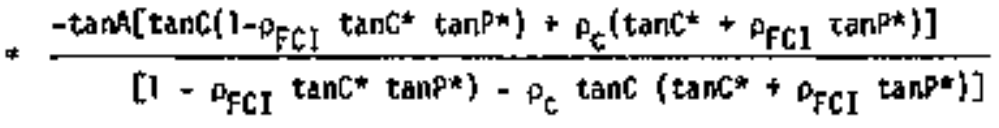

$$
\begin{aligned}
& =\frac{\tan A\left[\tan C+p_{C}\left(\tan C^{*}+p_{\mathrm{FCl}} \tan \mathrm{P}^{*}\right) /\left(1-p_{\mathrm{FCC}} \tan C^{*} \tan \mathrm{P}^{*}\right)\right]}{\left.p_{C}\right)} \\
& \rho_{G} \tan C\left(\tan C^{*}+\rho_{F C l} \tan p^{*}\right) /\left(1-\rho_{\mathrm{FCl}} \tan C^{*} \tan p^{*}\right)-1
\end{aligned}
$$


Assuming that the ideat relative transmittance for the Faraday cells is one, we can make the substitution $\rho_{\mathrm{FCI}}=1+8 \beta_{\mathrm{FCl}}$ in equation (16) to obtain,

$$
\rho_{S}^{*}=\frac{\tan A\left[\frac{\tan C+\rho_{C}\left(\tan C^{*}+\tan P^{*}+\delta \rho_{F C I} \tan P^{*}\right)}{1-\tan C^{*} \tan P^{*}+\delta \rho_{F C I} \tan C^{*} \tan P^{*}}\right]}{\rho_{C} \tan C \frac{\left(\tan C^{*}+\tan P^{*}+\delta \rho_{F C I} \tan P^{*}\right)}{\left(1-\tan C^{*} \tan P^{*}-\delta \rho_{F C I} \tan C^{*} \tan P^{*}\right)}-1}
$$

The terms,

$$
\begin{aligned}
& \frac{\rho_{C}\left(\tan C^{*}+\tan P^{*}\right)+\rho_{C} \delta \rho_{F C I} \tan P^{*}}{\left(1-\tan C^{*} \tan P^{*}\right)-\delta \rho_{F C I} \tan C^{*} \tan P^{*}} \text { in the muerator, and } \\
& \frac{\left(\tan C^{*}+\tan P^{*}\right)+\delta \rho_{F C I} \tan P^{*}}{\left(1-\tan C^{*} \tan P^{*}\right)-\delta \rho_{F C I} \tan C^{*} \tan P^{*}} \text { in the denominator }
\end{aligned}
$$

are both of the form $\left(x+\varepsilon_{1}\right) /\left(y+\varepsilon_{2}\right)$, which may be expanded as,

$$
\frac{\left(X+\varepsilon_{1}\right)}{\left(Y+E_{2}\right)}=\frac{X}{Y}+\frac{E_{1}}{Y}-\frac{\varepsilon_{2} X}{Y^{2}}
$$


This expansion is valtd for $\varepsilon_{2} \ll 1$, which is the case for sallall values of $\delta \rho_{\mathrm{FCI}}$.

The numerator term is expanded as follows:

$$
\begin{aligned}
\frac{\rho_{\mathrm{C}}\left(\tan \mathrm{C}^{*}+\tan \mathrm{P}^{*}\right)+\rho_{\mathrm{C}} \delta \rho_{\mathrm{FCI}} \tan \mathrm{P}^{*}}{\left(1-\tan \mathrm{C}^{*} \tan \mathrm{P}^{*}\right)-\delta \rho_{\mathrm{FCI}} \tan \mathrm{C}^{*} \tan \mathrm{P}^{*}} & =\frac{\rho_{\mathrm{C}}\left(\tan \mathrm{C}^{*}+\tan \mathrm{P}^{*}\right)}{\left(1-\tan \mathrm{C}^{*} \tan \mathrm{P}^{*}\right)}+\frac{\rho_{\mathrm{C}}{ }^{\delta} \rho_{\mathrm{FCI}} \tan \mathrm{P}^{\star}}{\left(1-\tan \mathrm{C}^{*} \tan \mathrm{P}^{*}\right.} \\
& +\frac{\rho_{\mathrm{C}}\left(\tan \mathrm{C}^{*}+\tan \mathrm{P}^{*}\right) \delta \rho_{\mathrm{FCI}} \operatorname{tanC^{*}} \tan \mathrm{P}^{*}}{\left(1-\tan \mathrm{C}^{*} \tan \mathrm{P}^{*}\right)^{2}}
\end{aligned}
$$

Using the trigonometric identfty $\tan (\alpha+\beta)=(\tan \alpha+\tan \beta) /(1-\tan \alpha \tan \beta)$, and combining the second and third terms, the expression becomes

$$
\begin{aligned}
& \frac{\rho_{\mathrm{C}}\left(\tan \mathrm{C}^{*} \tan \mathrm{P}^{*}\right)+\rho_{\mathrm{C}} \delta \rho_{\mathrm{FCI}} \tan \mathrm{P}^{*}}{\left(1-\tan \mathrm{C}^{*} \tan \mathrm{P}^{*}\right)-\delta_{\mathrm{FCI}} \tan \mathrm{C}^{*} \tan \mathrm{P}^{*}} \\
& \quad=\rho_{\mathrm{C}} \tan \left(\mathrm{C}^{*}+\mathrm{P}^{*}\right)+\frac{\rho_{\mathrm{C}} \delta \rho_{\mathrm{FCI}}\left[\tan \mathrm{P}^{*}+\tan \mathrm{C}^{*} \tan \mathrm{P}^{*} \tan \left(\mathrm{C}^{*}+\mathrm{P}^{*}\right)\right]}{\left(I-\tan \mathrm{C}^{*} \tan \mathrm{P}^{*}\right)}
\end{aligned}
$$


The expansion of the term in the denominator is:

$$
\begin{aligned}
& \frac{\left(\tan C^{*}+\tan P^{*}\right)+\delta \rho_{F C I} \tan P^{*}}{\left(1-\tan C^{*} \tan P^{*}\right)-\delta \rho_{F C I} \tan C^{*} \tan P^{*}}=\frac{\tan C^{*}+\tan P^{*}}{\left(1-\tan C^{*} \tan P^{*}\right)} \\
& +\frac{\delta \rho_{F C I} \tan P^{*}}{\left(1-\tan C^{*} \tan P^{*}\right)}+\frac{\left(\tan C^{*}-\tan P^{*}\right) \delta \rho_{F C I} \tan C^{*} \tan P^{*}}{\left(1-\tan C^{*} \tan P^{*}\right)^{2}} \\
& =\tan \left(C^{*}+P^{*}\right)+\frac{\delta \rho_{F C I}\left[\tan P^{*}+\tan C^{*} \tan P^{*} \tan \left(C^{*}+P^{*}\right)\right.}{\left(1-\tan C^{*} \tan P^{*}\right)}
\end{aligned}
$$

The result of putting the expansions of the numerator and denominator terns into equation (17) is another expression of the form of equation (18).

$$
\begin{aligned}
\frac{\rho_{S}}{\tan A} & =\frac{\left[\tan C+\rho_{C} \tan \left(C^{*}+P^{*}\right)\right]+\rho_{C} \rho_{F} \rho_{C I} \tan P^{*} \frac{\left[1+\tan C^{*} \tan \left(C^{*}+P^{*}\right)\right]}{\left(1-\tan C^{*} \tan P^{*}\right)}}{\left[\rho_{C} \tan C \tan \left(C^{*}+P^{*}\right)-1\right]+\rho_{C} \delta \rho_{F C I} \tan C \tan P^{*} \frac{\left[1+\tan C^{*} \tan \left(C^{*}+P^{*}\right)\right]}{\left(1-\tan C^{*} \tan P^{*}\right)}} \\
& =\frac{\tan C+\rho_{C} \tan \left(C^{*}+P^{*}\right)}{\rho_{C} \tan C \tan \left(C^{*}+P^{*}\right)-1}+\frac{\rho_{C} \delta \rho_{F C I} \tan P^{*}\left[1+\tan C^{*} \tan \left(C^{*}+P^{*}\right)\right]}{\left(1-\tan C^{*} \tan P^{*}\right)\left[\rho_{C} \tan C \tan \left(C^{*}+P^{*}\right)-1\right.} \\
& =\frac{\left[\tan C+\rho_{C} \tan \left(C^{*}+P^{*}\right)\right]\left[\rho_{C} \operatorname{sinCI} \tan C \tan P^{*}\left(1+\tan C^{*} \tan \left(C^{*}+P^{*}\right)\right)\right]}{\left(1-\tan C^{*} \tan P^{*}\right)\left[\rho_{C} \tan C \tan \left(C^{*}+P^{*}\right)-1\right]^{2}}
\end{aligned}
$$


Combining the second and third terms and replacing $\left(c^{\star}+p^{\star}\right)$ by $(\mathbf{P}-\mathrm{C})$ gives,

$$
\begin{aligned}
\frac{\rho_{s}}{\tan A} & =\frac{\tan C+\rho_{C} \tan (P-C)}{\rho_{C} \tan C \tan (\bar{P}-C)-1} \\
& +\frac{\rho_{C} \delta \rho_{F C I} \tan P^{*}\left[1+\tan C^{*} \tan (P-C)\right]\left[\rho_{C} \tan C \tan (P-C)-1-\tan C\left(\tan C+\rho_{C} \tan (P-C)\right)\right]}{\left(1-\tan C^{*} \tan P^{*}\right)\left[\rho_{C} \tan C \tan \left(C^{*}+P^{*}\right)-1\right]^{2}} \\
& =\frac{\tan C+\rho_{C} \tan (P-C)}{\rho_{C} \tan C \tan (P-C)-1}-\frac{\rho_{C} \delta \rho_{F C I} \tan P^{*} \sec C^{2} C\left[1+\tan C^{*} \tan (P-C)\right]}{\left(1-\tan C^{*} \tan P^{*}\right)\left[\rho_{C} \tan C \tan (P-C)-1\right]^{2}}
\end{aligned}
$$

Comparing the last expression to $\rho_{s}=\rho_{s}^{0}+\gamma_{F C I} \rho_{F C I}$ shows that

$$
\begin{aligned}
\rho_{s}^{0} & =\frac{\tan A\left[\tan C+\rho_{C} \tan (P-C)\right]}{\rho_{C} \tan C \tan (P-C)-1} \\
\gamma_{F C I} & =\frac{-\tan A \rho_{C} \tan ^{\star} \sec ^{2} C\left[1+\tan C^{\star} \tan (P-C)\right]}{\left(1-\tan C^{\star} \tan P^{\star}\right)\left[\rho_{C} \tan C \tan (P-C)-1\right]^{2}}
\end{aligned}
$$


The expression for $\gamma_{\mathrm{FCI}}$ can be simplifted as follows:

$$
\begin{aligned}
& Y_{F C I}=\frac{-\tan A p_{c} \sec ^{2} C\left[1+\tan C^{*} \tan (P-C)\right]}{\left(1 / \tan P^{*}-\tan C^{*}\right)\left[\rho_{C} \tan C \tan (P-C)-1\right]^{2}} \\
& =\frac{-\tan A \rho_{C} \sec ^{2} C\left[1+\sin C^{\star} \sin (P-C) / \cos C^{\star} \cos (P-C)\right]}{\left\{\cos P^{*} / \sin P^{\star}-\sin C^{\star} / \cos C^{*}\right)\left[\rho_{c} \tan C \tan (P-C)-1\right]^{2}} \\
& =\frac{-\tan A \rho_{C} \sec ^{2} C \sin P \star\left[\cos C^{\star} \cos (P-C)+\sin (P-C)\right]}{\cos (P-C)\left(\cos ^{* *} \cos C^{*}-\sin P^{*} \sin C^{\star}\right)\left[\rho_{C} \tan C \tan (P-C)-I\right]^{2}} \\
& =\frac{-\tan A \rho_{c} \sec ^{2} C \sin P^{*} \cos \left(C^{*}-(P-C)\right)}{\left.\cos (P-C) \cos \left(C^{*}+P^{*}\right)\left[\rho_{c} \tan C \tan (P-C)-\right]\right]^{2}} \\
& =\frac{-\tan A \rho_{c} \sec ^{2} C \sin \mathrm{P}^{*} \cos \mathrm{P}^{*}}{\cos (P-C)\left[\rho_{c} \tan C \tan (P-C)-1\right]^{2}} \\
& \frac{-\tan A \rho_{c} \sec ^{2} C \sec ^{2}(P-C) \sin 2 P *}{2\left[\rho_{c} \tan C \tan (P-C)-1\right]^{2}}
\end{aligned}
$$


The fractional error of $\rho$ due to birefringence in the Faraday cell core is

$$
\left(\frac{\partial \rho}{\rho}\right)_{F C I}=\left(\frac{Y_{F C I}}{\rho}\right)_{\delta \rho_{F C I}}
$$

where $\delta \rho_{\mathrm{FCI}}=\mathrm{t}_{1 \mathrm{FCI}}+\mathrm{it}_{2 \mathrm{FCI}}$. Ideally, the quarterwave plate affects only the phase shift measured by $\Delta$ and not the intensity of the beam and under this condition $\psi=45^{\circ}, \Delta=90^{\circ}$ and $\rho_{c}{ }^{\circ}--i$. When, in addition, $c=\pi / 4$, equation (22) gives,

$$
\begin{aligned}
\rho_{0}^{+} & =\frac{-\tan A[1-i \tan (P-\pi / 4)]}{[i \tan (P-\pi / 4)+1]} \\
& =\frac{\tan A(1+\tan P-i \tan P+i)}{(i \tan P-i+i+\tan P)} \\
& =\frac{-\tan A(\cos P+\sin P-i \sin P+i \cos P}{(i \sin P-i \cos P+\cos P+\sin P)} \\
& =-\tan A \frac{\left(e^{-i P}+i e^{-i P)}\right.}{\left(e^{i P}-i e^{i P}\right)} \\
& =-\tan A e^{-i 2 P\left(\frac{1+i}{i-i}\right)} \\
& =-i \tan A e^{-i 2 P}
\end{aligned}
$$


$\$$ \$milarly, for $c=-\pi / 4$, equation (22) reduces to

$$
\overline{\rho_{0}}=i \tan A e^{-i 2 P} .
$$

We can now use equations $(24),(25)$, and (26) to soive for $8 \psi_{\mathrm{FCI}}$ and $\delta \Delta_{\mathrm{FCI}}$. First, for $\mathrm{C}=\pi / 4$ and $\mathrm{o}_{\mathrm{c}}=-1$,

$$
\begin{aligned}
\gamma_{F C I} & =\frac{i \tan A \sec \left(P-\frac{\pi}{4}\right) \sin 2 P^{*}}{\left[i \tan \left(P-\frac{\pi}{4}\right)+1\right]^{2}} \\
& =\frac{i \tan A \sin 2 P^{*}}{\cos ^{2}\left(P-\frac{\pi}{4}\right)\left[\frac{i(\tan P-1)}{(1+\tan P)+1}\right]^{2}}
\end{aligned}
$$

$$
\begin{aligned}
& =\frac{i \tan A \sin 2 P^{\star}(1+\tan P)^{2}}{\left(\frac{1}{\sqrt{2}} \cos P+\frac{1}{\sqrt{2}} \sin P\right)^{2}[\tan P(i+1)+(-i+1)]^{2}} \\
& =\frac{i \tan A \sin 2 P^{*}\left[\frac{(\cos P+\sin P)}{\cos P}\right]^{2}}{\frac{1}{2}(\cos P+\sin P)^{2}\left[\frac{(1-i)(\cos P+i \sin P)}{\cos P}\right]^{2}} \\
& =\frac{2 i \tan A \sin 2 P^{*}}{(1-i)^{2} \mathrm{e}^{i 2 P}} \\
& =-\tan A \sin 2 P^{*} e^{-i 2 P}
\end{aligned}
$$$$
=-\tan A e^{-i 2 P}(\sin 2 \mathrm{P} \cos 2 \mathrm{FCI}-\cos 2 \mathrm{P} \sin 2 \mathrm{FCI})
$$ 
For $\rho=\rho_{0}^{+}$,

$$
\frac{\gamma_{F C I}}{\rho}=-i(\sin 2 P \cos 2 F C I-\cos 2 \mathrm{P} \sin 2 \mathrm{FCI})
$$

and for $C=-\pi / 4, \quad \rho=\rho_{0}^{-}$,

$$
\frac{\gamma_{F C I}}{\rho}=1(\sin 2 P \cos 2 \mathrm{FCI}-\cos 2 \mathrm{P} \sin 2 \mathrm{FCI})
$$

Equation (25) becomes

$$
\left(\frac{\partial \rho}{\rho}\right)_{F C I}=7 i(\sin 2 P \cos 2 F C I-\cos 2 P \sin 2 F C I)\left(t_{1 F C I}+i t_{2 F C I}\right)
$$

for $C= \pm \pi / 4$, and the corrections to $\Delta$ and $\psi$ are given by

$$
\delta \Delta=\operatorname{In}\left(\frac{\partial \rho}{\rho}\right)_{F G I}=F i(\sin 2 P \cos 2 F C I-\cos 2 P \sin 2 F C I) t_{1 F C I}
$$

and .

$$
\begin{aligned}
\delta \psi & =\frac{1}{2} \sin 2 \psi \operatorname{Re} \frac{\partial \rho}{\rho} \text { FCI } \\
& = \pm \frac{1}{2} \sin 2 A(\sin 2 P \cos 2 F C I-2 P \sin 2 F C I) t_{2 F C I}
\end{aligned}
$$

for those zones in which $\sin 2 \psi=\sin 2 A$. 
For those zones in which $\sin 2 \psi=-\sin 2 A$,

$$
\delta \psi=\mp \frac{1}{2} \sin 2 A(\sin 2 P \cos 2 F C I-\cos 2 P \sin 2 F C I) t_{2 F C I} .
$$

When the error terms have all been derived, they are added together to give the total correction to $\psi$ and to $A$. Care must be taken that the parameters appear with the correct signs; the signs depend on the setting of $C$ and the range of $A$ and the range of $P$. The result is that 32 equations are needed to characterize $\Delta$ and 32 more are needed to characterize $\psi$. Sixteen equations, one for each zone, are used when the nulling angles have been measured in standard azimuth angles, and the other sjxteen are used when the nuling angles have been measured in rotated azimuth angles. The equations for $\psi$ and $\Delta$ are written out in full in Tables Ila and IIb (Appendix A). Tables IIc, IId, IIIa, and II contain the signs of the parameters in the equations for $\psi$ and $\Delta$ for a.11 groups.

If the 1deal-value equations for $\Delta$ (Table I) are solved for $2 p$ and the resulting expression substituted for $2 p$ into the corrected equations for $A$, the final result is a set of equations for $p$. Replacing $2 a$ in the equations for $\psi$ with expressions in terms of the ideal value of $\psi$ yields a set of equations for a. If the same sort of substitution is made for $2 \mathrm{P}$ in the equations for $\Delta$ (for rotated azimuths), the resulting set of equations for $p$ are identical to those for $p$. The same 15 true of the equations for $A$; they are identical to those for a. The equations for $A$ and $P$ are used in linear combinations to solve for the parameters. The 
procedure witl be outlined in the next section.

Tables IVa and IVb show the complete equations for $A$ and $P$ for group B. The analysis also includes intensity effects in the analyzer Faraday cell. This involves use of the coupling constant $\gamma_{F C R}$, having the same form as $\gamma_{W R}$, derived in Ref. (1), and $\delta_{\rho_{F C R}}=t_{1 F C R}+i t_{2 F C R}$. $(\delta \Delta)_{\mathrm{FCR}}$ and $(\delta \psi)_{\mathrm{FCR}}$ are found as in equations (30) and (31). 


\section{EVALUATION OF THE PARAMETERS}

\section{A. Introduction}

Nineteen parameters have been used to characterize the coriponent imperfections, window birefringence, and azimuth angle errors. Eight of the parameters appear only in the equations for $\psi$ and are solved using the equations for $A_{2}, A_{2}, A_{3}$ and $A_{4}$. The other paraneters, with one exception, appear only in the equations for $\Delta$ and are evaluated using the $\mathrm{P}_{\uparrow}$ equations. The exception is $\delta \mathrm{C}$ which is in al1 of the equations.

The expressions contained in this section are those that were used to evaluate the parameters. Some alternate expressions have aiso been indicated if there is a chotce between deternining a parameter from measurements made on either a dielectric or a metal. In genera], the expressions presented are the simplest. A discrepancy of nearly half a degree In the value of $t_{1 F C R} \sin 2 F C R$ did not occur between dielectrtc and matal measurements; the value for the metal measurements was chosen.

The equations for $\Delta$ and $\psi$ in terms of the azimuth angles are different for each group of zones. As a result, the definition of a parameter depends on the group in which the measurenents occur. Once defined, however, the parameter does apply to other zones. The parameter definition does not depend on the use of standard or rotated azimuths for the measurement.

\section{B. Experimental Procedure}

Inspection of the complete equations for $\psi$ and $A$ in Table IVa and IVo show that the magnitude of the corrections depends upon $\phi$ and $\Delta$. By the appropriate choice of the specimen and the arrangement of the 
ellipsometer, this functional dependence on $\psi$ and $\Delta$ may be used to simplify the expressions. For reftection from a dielectric, $\Delta_{0}=0^{\circ}$ and $\Psi_{0}=45^{\circ}$.

Measurements were taken in each of the four zones for the group determined by the experimental value of $\Delta$. It will be shown that the appropriate averaging of the azimuths $A$ and $P$ for the zones isolates certain component parameters. Isolation of parameters is also achieved by making four-zone measurements with and without various components. It should be noted that when the Faraday cells are removed, manual ellipsometer measurements are necessary. These were performed by monitoring the output voltage from the photo-multiplier tube, and determining the mintmum intensity by averaging azimuths for $A$ and $P$ which give equal voltages on each side of the minitnum.

The ellipsometer was first placed in the straight-through position. With Faraday cells in place, the caltibration circles of $A$ and $P$ were adjusted to give minimuris for $A$ being perpendicular to $P$. The calibration circle for $C$ was adjusted to give the smaltest average deviation when set parallel to $A$ and $P$. The Faraday cells were removed, and a four-zone measurement was made.

The ellipsometer was then aligned to reflect at $75^{\circ}$ from a surface facing up. Aligniment was performed by auto-collimation from nirrors on a pristn accurate to 16 seconds of arc. Without the Faraday cells, multiple four-zone measurements were made from a clean, uncoated glass prisin. The specimen was reatigned for each four-zone measurement, to a) 30 we azimith angle $\delta 8$ to be averaged to zero in the analys is of the data. With the specimen fixed, the Faraday cells were inserted at a fixed orientation. One four-zone measurement was performed. The 
procedure for the dielectric was repeated for a metal surface. Finally, four zone measurements with and without the cell windows were conducted for reflection from the metal specimen.

\section{Expressions for the Paraneters}

The following subscripts have been used to identify the set of measurements used in the calculation of each parameter:

S - measurements made while the ellipsometer is in the straightthrough position,

D - measurements made using a dielectric as a specimen, FC, MFC - measurements made with and without the Faraday cells in place, respectively,

W, NW - measurements made with and without the windows in place, respectively,

The windows are always used in combination with the Faraday cells (though the Faraday cells are sometimes used atore), and in the context of thas paper, FC, NFC, and NW will all refer to measurements made on either a dielectric or metal specimen. In addition, the notation 〈> represents the average of multiple measurements of the quantity inside the brackets.

Whenever $A$ and $\psi$ appear in the expressions for the parameters, they refer to the four-zone average calculated from the set of measurements that is being used to evaluate the parameter. If the measurements are taken with the windows and/or Faraday cetlis in place, correction terms must be added to the four-zone average for $\Delta$. For measurements made with only the Faraday cells the correction term is $t_{2 F C R} \cos 2 F C R ;$ for measurements made with both the windows and Faraday cells in place, the correction term is the sum of $t_{2 F C R} \cos 2 F C R, t_{2 W I} \cos 2 W I$, and $t_{2 W R} \cos 2 W R$. 
The correction terms are the same for all groups. Table $V$ contains the formulas for the four-zone averages for $\Delta$ and $\psi$ for each group and the correction terms for the four-zone average of $\Delta$.

Because most of the parameters do not depend directly on other parameters, the order in which the parameters are calculated is not important except in a few instances. Some of the tems for the Faraday celts or windows involve a four-zone average of $\Delta$. Therefore they indirectly depend on $t_{2 W I} \cos 2 \mathrm{WI}, t_{2 W R} \cos 2 \mathrm{WR}$, and/or $t_{2 F C R} \cos 2 F C R$, terms which appear explicitly only in the equations for $A$. The expresstons for these parameters are given first.

From medsurements made on a dielectric:

$$
\begin{aligned}
t_{2 F C R} \cos 2 F C R= & \frac{1}{2}\left[\left(P_{1}-P_{2}+P_{3}-P_{4}\right)_{F C}-\left(P_{1}-P_{2}+P_{3}-P_{4}\right)_{N F C}\right] \\
& \text { for groups } A \text { and } C \\
= & \frac{1}{2}\left[\left(-P_{1}+P_{2}-P_{3}+P_{4}\right)_{F C}-\left(-P_{1}+P_{2}-P_{3}+P_{4}\right)_{N F C}\right. \\
& \text { for groups } B \text { and } D .
\end{aligned}
$$

The terms $t_{2 W I} \cos 2 W t$ and $t_{2 W R} \cos 2 W R$ always appear as a sum in the equations for $\Delta$ and $P_{j}$; therefore it is not necessary to solve for each parameter individually. From measurenents made on a metal:

$$
\begin{aligned}
t_{2 W I} \cos 2 W I+t_{2 W R} \cos 2 W R= & \frac{1}{2}\left[\left(P_{1}-P_{2}+P_{3}-P_{4}\right)_{W}-\left(P_{1}-P_{2}+P_{3}-P_{4}\right)_{N W}\right] \\
& \text { for groups } A \text { and } C, \\
= & \frac{1}{2}\left[\left(-P_{7}+P_{2}-P_{3}+P_{4}\right)_{W}-\left(-P_{1}+P_{2}-P_{3}+P_{4}\right)_{N W}\right] \\
& \text { for groups } B \text { and } D .
\end{aligned}
$$

The next ten expressions are for the parameters that appear in the equations for $\psi$, (from measurements made white the ellipsometer is in 
straight-through position):

$$
\begin{array}{ll}
\delta C_{c}+\delta A_{c}=90^{\circ}-J_{4}\left(A_{1}+A_{2}+A_{3}+A_{4}\right)_{s} & \text { for groups } A \text { and } D, \\
\delta C_{c}-\delta A_{C}=90^{\circ}-\frac{Z}{4}\left(A_{1}+A_{2}+A_{3}+A_{4}\right)_{5} & \text { for groups } B \text { and } C,
\end{array}
$$

From multiple measurements made on a dielectric with nefther the Faraday cells nor windows in place:

$$
\begin{aligned}
\sin 2 \psi_{D} \cos A_{D} \delta C_{c}+\delta A_{c}= & 90^{\circ}-\frac{1}{4}\left(A_{1}+A_{2}+A_{3}+A_{4}\right)_{D} \\
& \text { for groups } A \text { and } D, \\
\sin 2 \psi_{d} \cos \Delta_{D} \delta C_{C}-\delta A_{C}= & 90^{\circ}-\frac{1}{4}\left(A_{1}+A_{2}+A_{3}+A_{4}\right) D
\end{aligned}
$$

for groups $B$ and $C$.

Combining the approppiate form of equations (34) and (35) and solving for $\delta C_{c}$ gives

$$
\delta C_{c}=\frac{\left(A_{1}+A_{2}+A_{3}+A_{4}\right)_{s}-\left\langle A_{1}+A_{2}+A_{3}+A_{4}\right\rangle_{D}}{4\left(\cos A_{B} \sin 2 \psi_{D}-1\right)} \quad \text { for ałl groups. }
$$

The value of $\delta C_{c}$ may now be substituted into equation (34) to solve for $\delta A_{C}$.

$$
\begin{aligned}
& \delta A_{c}=90^{\circ}-\frac{1}{4}\left(A_{1}+A_{2}+A_{3}+A_{4}\right)_{s}-\delta C_{C} \quad \text { for groups } A \text { and } B, \\
& \delta A_{c}=-90^{\circ}+\frac{1}{4}\left(A_{1}+A_{2}+A_{3}+A_{4}\right)_{s}+\delta C_{c} \quad \text { for groups } B \text { and } C \text {. }
\end{aligned}
$$

From measurements made without Faraday cells on a dielectric: 


$$
\begin{aligned}
t_{2 P} & =\frac{\left(A_{1}-A_{2}-A_{3}+A_{4}\right)}{4 \sin 2 \psi} \quad \text { for groups } A \text { and } B, \\
& =\frac{\left(-A_{1}+A_{2}+A_{3}-A_{4}\right)}{4 \sin 2 \psi} \quad \text { for groups } C \text { and } 0 .
\end{aligned}
$$

From multiple measurements, without Faraday cells, on a metal:

$$
\begin{aligned}
& t_{1 C(1,3)}=\frac{\left\langle A_{1}+A_{3}\right\rangle-180^{\circ}-2\left(\sin 2 \psi \cos \Delta \delta C_{c}-\delta A_{C}\right\rangle}{\sin 2 \psi \sin \Delta} \\
& t_{1 C(2,4)}=\frac{-\left\langle A_{2}+A_{4}\right\rangle+180^{\circ}+2\left(\sin 2 \psi \cos \Delta \delta C_{c}-\delta A_{c}\right)}{\sin 2 \psi \sin \Delta}
\end{aligned}
$$

for groups $B$ and $C$. For groups $A$ and $D$,

$$
\begin{aligned}
& t_{1 C(1,3)}=\frac{-\left\langle A_{1}+A_{3}\right\rangle+180^{\circ}-2\left(\sin 2 \psi \cos \Delta \delta C_{C}+\delta A_{c}\right)}{\sin 2 \psi \sin \Delta} \\
& t_{1 C(2,4)}=\frac{\left(A_{2}+A_{4}\right\rangle-180^{\circ}+2\left(\sin 2 \psi \cos \Delta \delta C_{C}+\delta A_{C}\right\rangle}{\sin 2 \psi \sin \Delta}
\end{aligned}
$$

If the measure of the quarter waveplate in zones 1 and 3 is $q=45^{\circ}$ or $Q=135^{\circ}$, then $t_{1 C}^{+}=t_{1 C(1,3)}$ and $t_{1 C}^{-}=t_{1 C(2,4)}$. Otherwise, $t_{1 C}^{+}=t_{1 C(2,4)}$ and $t_{1 C}^{-}=t_{1 C(1,3)}$. 
From measurements made with the Faraday cells on a dielectric:

$$
\begin{aligned}
t_{2 F C I} \cos 2 F C I & =\frac{\left[\left(A_{1}+A_{2}+A_{3}+A_{4}\right)_{F C}-\left(A_{3}+A_{2}+A_{3}+A_{4}\right)_{N F C}\right]}{2 \sin 2 \psi \cos A} \quad \text { for groups } A \text { and } D \text {, } \\
& =\frac{-\left[\left(A_{1}+A_{2}+A_{3}+A_{4}\right)_{F C}-\left(A_{7}+A_{2}+A_{3}+A_{4}\right)_{F C I}\right]}{2 \sin 2 \psi \cos A} \quad \text { for groups } B \text { and } C .
\end{aligned}
$$

From measurements made using the faraday cells on a metal:

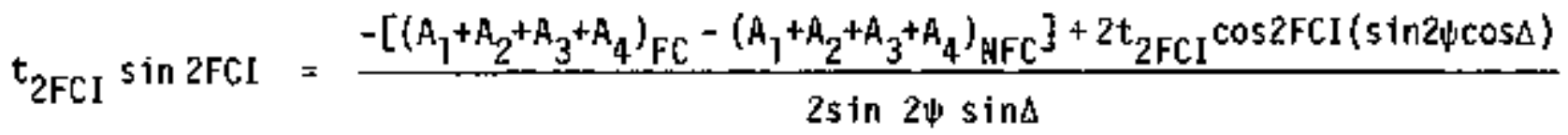

$$
\begin{aligned}
& \text { for group } A \text {, } \\
& \text { (4]a) } \\
& =\frac{-\left[\left(A_{1}+A_{2}+A_{3}+A_{4}\right)_{F C}-\left(A_{1}+A_{2}+A_{3}+A_{4}\right)_{A F C}\right]-2 t_{2 F C I} \cos 2 F C I(\sin 2 \psi \cos A)}{2 \sin 2 \psi \sin A} \\
& \text { for group B, (41b) } \\
& =\frac{\left[\left(A_{1}+A_{2}+A_{3}+A_{4}\right) F C-\left(A_{1}+A_{2}+A_{3}+A_{4}\right) A F C\right]-2 t_{2 F C I} \cos 2 F C I(\sin 2 \psi \cos A)}{2 \sin 2 \psi \sin \Delta} \\
& \text { for group } \mathrm{C} \text {, } \\
& \text { (4Ic) }
\end{aligned}
$$

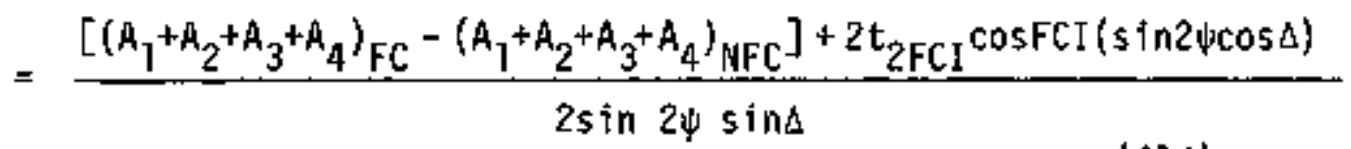

$$
\begin{aligned}
& \text { for group D. }
\end{aligned}
$$


From measurements made with the Faraday cells on either a dielectric or metal specimen:

$$
\mathrm{t}_{1 \mathrm{FCR}} \cos 2 \mathrm{FCR}=\frac{\left(\mathrm{A}_{1}-\mathrm{A}_{2}-\mathrm{A}_{3}+A_{4}\right)_{\mathrm{FC}}-\left(\mathrm{A}_{1}-\mathrm{A}_{2}-\mathrm{A}_{3}+A_{4}\right)_{\mathrm{HFC}}}{2 \sin 2 \psi}
$$

for groups $A$ and $B$,

$$
=\frac{\left(-A_{1}+A_{2}+A_{3}-A_{4}\right)_{F C}-\left(-A_{7}+A_{2}+A_{3}-A_{4}\right)_{M F C}}{2 \sin 2 \psi}
$$

for groups C and D,

and

$$
t_{\text {TFCR }} \sin 2 F C R=\frac{\left(A_{1}-A_{2}+A_{3}-A_{4}\right)_{F C}-\left(A_{1}-A_{2}+A_{3}-A_{4}\right)_{N F C}}{2 \cos 2 \psi}
$$

for groups $A$ and $C$,

$$
=\frac{\left(-A_{7}+A_{2}-A_{3}+A_{4}\right)_{F C}-\left(A_{1}+A_{2}-A_{3}+A_{4}\right)_{N F C}}{2 \cos 2 \psi}
$$

for groups $B$ and $D$.

Fram measurements made with both Faraday cel7s and windows in place on a metal:

$$
t_{2 W I} \sin 2 W I=\frac{-\left[\left(A_{7}+A_{2}+A_{3}+A_{4}\right)_{W}-\left(A_{1}+A_{2}+A_{3}+A_{4}\right)_{N W I}\right]}{2 \sin 2 \psi \sin A}
$$

for groups $A$ and $B$,

$$
=\frac{\left(A_{1}+A_{2}+A_{3}+A_{4}\right)_{H}-\left(A_{7}+A_{2}+A_{3}+A_{4}\right)_{N W}}{2 \sin 2 \psi \sin \Delta}
$$


The next six expressions are for the renaining paraneters that appear only in the equations for $\Delta$. Because the terms $t_{p}$ and ${ }^{S P}{ }_{C}$ always appear as a sum in the equations for $A$ and $P$, they are evaluated as a single term. From measurements made wthout the Faraday cells in place, on either a dielectric or metal spectmen:

$$
{ }^{t}{ }_{1 P}+\delta P_{C}=\delta C_{C}+90^{\circ}-\frac{3}{4}\left(P_{1}+P_{2}+P_{3}+P_{4}\right) \text { for all groups. }
$$

From measurements made without the Faraday cetls, on a meta1:

$$
\begin{aligned}
& t_{2 C(1,3)}=\frac{\left(-P_{1}+P_{3}\right)}{\sin A} \text { and } t_{2 C(2,4)}=\frac{\left(-P_{2}+P_{4}\right)}{\sin A} \\
& \text { for g }
\end{aligned}
$$

for groups $A$ and $C$,

for groups B and D.

From measurements made with the Faraday cells on a dielectric:

$$
\begin{aligned}
t_{2 F C R} \sin 2 F C R & =\frac{1}{2} \tan 2 \psi\left[\left(P_{1}-P_{2}-P_{3}+P_{4}\right)_{F C}-\left(P_{1}-P_{2}-P_{3}+P_{4}\right)_{N R C}\right] \\
& =\frac{1}{2} \tan 2 \psi\left[\left(-P_{1}+P_{2}+P_{3}-P_{4}\right)_{F C}-\left(-P_{1}+P_{2}+P_{3}-P_{4}\right)_{N F C}\right]
\end{aligned}
$$


Froril measurements made with the Faraday cells, on either a dielectric or metal specimen,

$$
\begin{aligned}
& t_{2 F C R} \sin 2 F C R=\frac{1}{2} \tan 2 \psi\left[\left(P_{1}-P_{2}-P_{3}+P_{4}\right)_{F C}-\left(P_{1}-P_{2}-P_{3}+P_{4}\right)_{N F C}\right. \\
& \text { for groups } A \text { and } B \text {, } \\
& =\frac{1}{2} \tan 2 \psi\left[\left(-P_{1}+P_{2}+P_{3}-P_{4}\right)_{F C}-\left(-P_{7}+P_{2}+P_{3}-P_{4}\right)_{N F C}\right. \\
& \text { for groups } C \text { and } D \text {. }
\end{aligned}
$$

From measurements made with the Faraday cells, on either dielectric or metal specimen:

$t_{1 F C I} \cos 2 F C I=\frac{\left(P_{1}+P_{2}-P_{3}-P_{4}\right)_{F C}-\left\langle P_{1}+P_{2}-P_{3}-P_{4}\right)_{F F C}}{2 \cos A}$ for all groups. (49)

From measurements made with the Faraday cells on a metal:

$$
\begin{aligned}
t_{\text {IFCI }} \sin 2 F C I & =\frac{\left.\left[P_{1}-P_{2}-P_{3}+P_{4}\right)_{F C}-\left(P_{1}-P_{2}-P_{3}+P_{4}\right)_{N F C}\right]+2 t_{2 F C R} \sin 2 F C R(\cot 2 \psi)}{2 \sin A} \\
\text { (50a) } & \text { for groups } A \text { and } B, \\
& =\frac{\left[\left(P_{1}-P_{2}-P_{3}+P_{4}\right)-\left(P_{1}-P_{2}-P_{3}+P_{4}\right)_{N F C}\right]-2 t_{2 F C R} \sin 2 F C R(\cot \psi)}{2 \sin \Delta}
\end{aligned}
$$




$$
t_{2 W R} \text { sin2WR }=\frac{3}{2}\left[\left(P_{1}-P_{2}-P_{3}+P_{4}\right)_{W}-\left(P_{1}-P_{2}-P_{3}+P_{4}\right)_{H W}\right]
$$

for groups $A$ and $B$,

$$
=\frac{1}{2}\left[\left(-P_{1}+P_{2}+P_{3}-P_{4}\right)_{W}-\left(-P_{1}+P_{2}+P_{3}-P_{4}\right)_{N H T}\right]
$$

for groups $\mathrm{C}$ and $\mathrm{D}$.

Now that all of the parameters have been defined, the specimen mispositioning error can be determined. For groups $A$ and 0 ,

$$
\delta \beta^{ \pm}=\frac{\frac{1}{2}\left(R^{ \pm}-\operatorname{Res} A^{ \pm}\right)-\sin 2 \psi \cos \Delta \delta C_{C}-\delta A C}{\cos 2 \phi+\sin 2 \psi \cos A}
$$

and for groups $B$ and $C$,

$$
\delta B^{ \pm}=\frac{\frac{1}{2}\left(R^{ \pm}-\operatorname{Res} A^{ \pm}\right)+\sin 2 \psi \cos \Delta \delta C C-\delta A_{c}}{\cos 2 \phi-\sin 2 \psi \cos \Delta} .
$$

The sign refers to the setting of the quarter wave plate. If $q=45^{\circ}$ or $Q=135^{\circ}$ for zones 1 and 3 , then $\operatorname{Res}^{+}=A_{1}+A_{3}$ and $\operatorname{Res} A^{-}=A_{2}+A_{4}$. otherwise, $\operatorname{Res} A^{+}=A_{2}+A_{4}$ and $\operatorname{Res} A^{-}=A_{1}+A_{3}$. Table $V I$ cantains the corresponding expressions for $R$ which are different for each group.

Ffnally, we have for the aztmuth angle errors,

$$
\begin{aligned}
& \delta C^{ \pm}=\delta C_{C}+\delta \beta^{ \pm} \\
& \delta P^{ \pm}=\delta P_{C}+\delta \beta^{ \pm} \\
& \delta A^{ \pm}=\delta A_{C}+(\cos 2 \phi) \delta \beta^{ \pm}
\end{aligned}
$$


where the errors $\delta A_{c}, \delta P_{c}$, and $\delta C_{c}$ in the calibration circle azimuths are given in equations (37), (45), and (36). Note that, for the purpose of calculation, the combinations $t_{1 \mathrm{p}}+\delta \mathrm{P}^{ \pm}-\delta c^{ \pm}$which appear in the equations for $\Delta$ and $P$ are equal to $t_{p P}+\delta P_{c}-\delta C_{c}$.

Table VII contains the numerical values of the parameters calculated for our experiments.

D. Index of Parameter Expressions

Parameters that appear in the equations for $\psi$ and $A$ :

$$
\begin{aligned}
& \delta A_{c} \ldots \ldots \text { equation (37) } \\
& \mathrm{\delta C}_{\mathrm{c}} \ldots \ldots \text { equation (36) } \\
& \delta \beta \ldots . . . . \text { equation (52) } \\
& \delta A \ldots . . . . \text { equation (55) } \\
& \text { sC ....... equation (53) } \\
& t_{1 C} \ldots \ldots \text { equation (39) } \\
& t_{2 p} \ldots \ldots \text { equation (38) } \\
& t_{2 \mathrm{FCI}} \cos 2 \mathrm{FCI} \ldots . \text { equation (40) } \\
& \mathrm{t}_{2 \mathrm{FCI}} \sin 2 \mathrm{FCI} \ldots . \text { equation (41) } \\
& t_{1 F C R} \cos 2 F C R \ldots \text { equation (42) } \\
& t_{1 F C R} \sin 2 F C R . . . \text { equation (43) } \\
& t_{2 W I} \sin 2 H I \ldots . . . \text { equation (44) }
\end{aligned}
$$

Parameters that appear in the equations for $\Delta$ and $P$ :

$$
\begin{aligned}
& { }_{\delta} C_{c} \ldots \ldots \text { equation (36) } \\
& \delta p_{c} \ldots \ldots \text { equation (45) } \\
& t_{1 P} \ldots . . . \text { equation (45) }
\end{aligned}
$$




$$
\begin{aligned}
& \delta_{\beta} \ldots \ldots \text { equation (52) } \\
& \text { sc ....... equation (53) } \\
& \delta P \ldots . . . \text { equation (54) } \\
& \mathrm{t}_{2 \mathrm{CC}} \ldots \ldots \text { equation (46) } \\
& t_{1 F C I} \cos 2 F C I \ldots \text { equation (49) } \\
& { }^{t}{ }_{1 F C I}{ }^{5 n 2 F C I} \cdot \text {. equation (50) } \\
& t_{2 F C R} \cos 2 F C R \text {. . equation (32) } \\
& t_{2 F C R} \sin 2 F C R \text {. . equation (48) } \\
& t_{2 W I} \cos 2 t R R \text { equation (33) } \\
& \mathrm{t}_{2 \mathrm{WR}} \cos 2 W R \ldots \text { equation (33) } \\
& \mathrm{t}_{2 W R^{5}}{ }^{\text {in2WR }} \ldots \text { equation (51) }
\end{aligned}
$$




\section{RESULTS AND DESCUSSION}

A. Parameter Values

The magnitudes of the twenty parameters (Table VII, Appendix A) indicate that the quarter wave piate has the largest imperfections. Intensity effects give a maximum error of 1.72 degrees $\left(t_{\eta_{c}}^{+}=-3.45^{\circ}\right)$ in the determination of the relative amplitude $\psi$, while shifts in the relative phase give a maximu error of 0.43 degrees in the determination of $\Delta\left(t_{2 c}^{+}=-0.43^{\circ}\right)$. Errors in the divided circle readings are next in importance, with $\delta \mathrm{A}_{\mathrm{C}}$ and $\delta \mathrm{C}_{\mathrm{c}}$ combining to give a maximum error of 1.1 degrees in $\psi$. The holders for the retarder and polarizing prisms would allow correction for these effects by the rotation of the components.

Both relative phase and relative attenuation effects are present in the Faraday cells. The largest parameters are for the analyzer Faraday cell ( $\mathrm{t}_{1 F C R} \sin 2 \mathrm{FCR}=0.242, \mathrm{t}_{2 \mathrm{FCR}} \cos 2 \mathrm{FCR}=-0.253$ ). The windows of the stagnant cell exhibit minor birefringence, with only $t_{2 W I} \sin 2 W I=$ -0.228 being significant. However, the windows of the ultra-high vaculam chämber have a much larger effect $\left(t_{2 W I} \cos 2 W I+t_{2 W R} \cos 2 W R=-1.54\right.$, $\left.t_{2 W I} \sin 2 W I=0.632\right)$.

B. The Varjation of Imperfection Effects with $\psi$ and $B$

The complete equations (Table I, Appendix A) show that the corrections for component imperfections have a trigonometric dependence on $\psi$ and $A$. This results from the use of the rotator matrix (p. 15) to orient the principal reference frame of each component. Figures 4 and 5 indicate this dependence. The computer program discussed in Appendix $C$ was used to correct experimental measurements on the anodic dissolution of zinc 


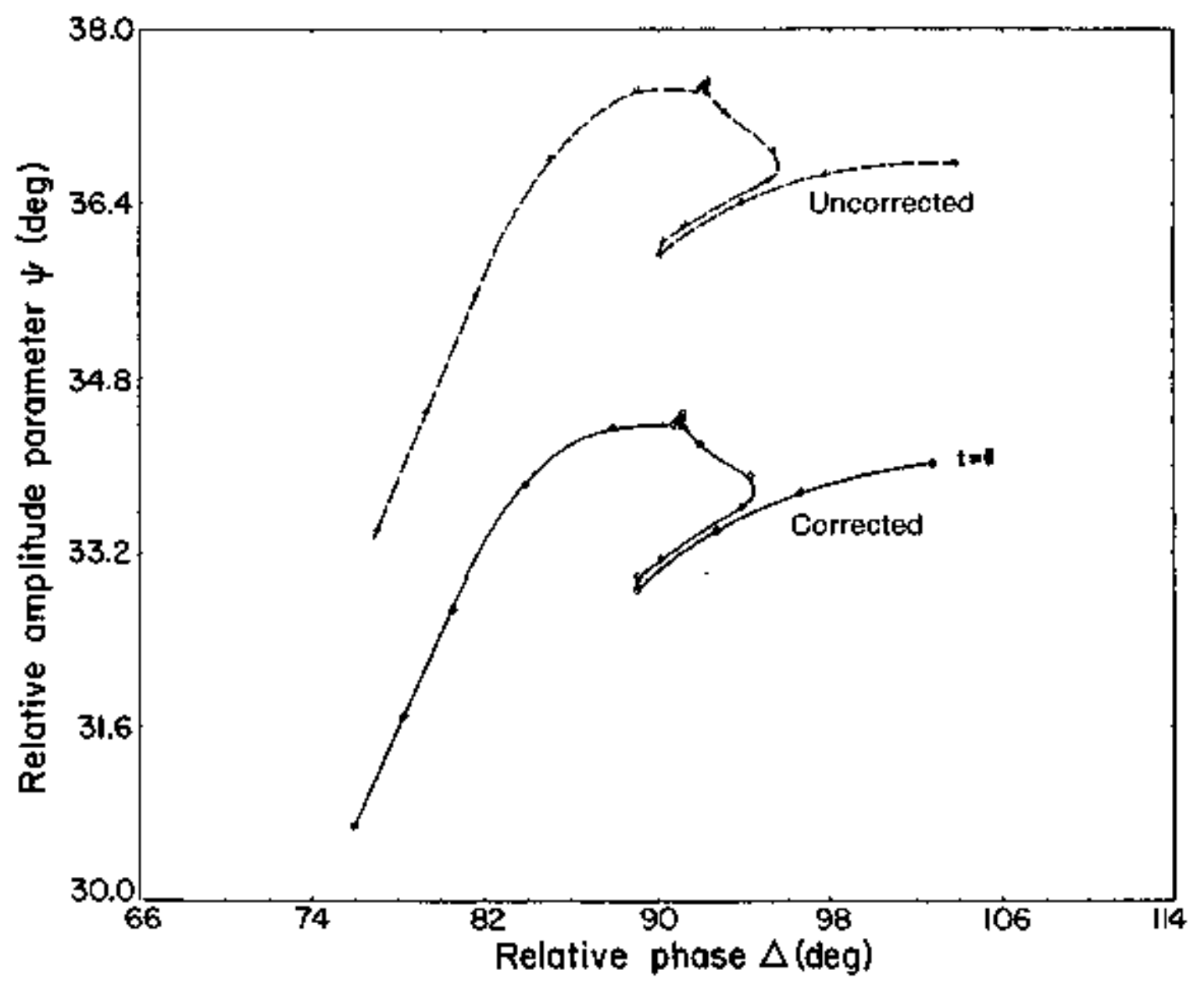

XES 7611-8910A

Fig. 4. Correction for ellipsometer imperfections $\mathrm{Zn}, 0.5 \mathrm{M} \mathrm{KOH,}-1.0 \mathrm{~V}$ vs. $\mathrm{Hg} / \mathrm{HgO}$. 


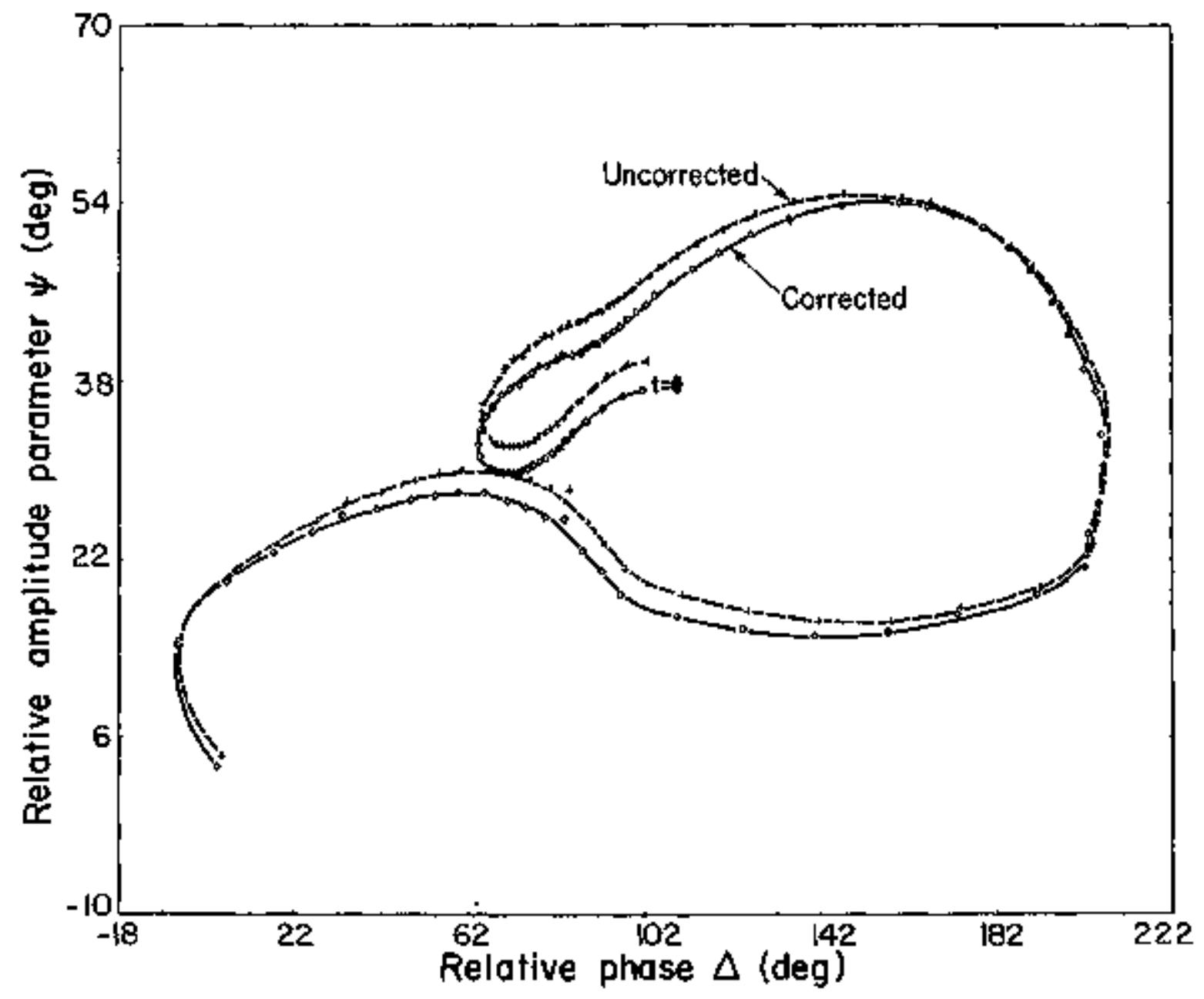

XBL $7611-9909 A$

Fig. 5. Correction for ellipsometer imperfections $\mathrm{Zn}, 0.5 \mathrm{M} \mathrm{KOH},-1.2 \mathrm{~V}$ vs. $\mathrm{Hg} / \mathrm{HgO}$. 
in alkaline solution. Ffgure 4 shows that over a small range of $\Delta$ and $\psi$, the corrections result in a parallel shift of the curve calculated by assuming ideal components. Figure 5 shows that over large ranges of $A$ and $\psi$, the magnitude of the corrections vary and may even change sign. An approximate correction procedure discussed in Appendix B shows explicitly the variation of the corrections for component imperfections with the orientation of the polarizer, analyzer, and quarter wave plate.

\section{c. Verification of the Theory}

Attempts were made to vertfy the theory used to derive the parametric equations by correcting 4-zone measurements on materials covering a range of $A$ and $\psi$ vatues. The measurements on $\mathrm{Cd}, \mathrm{Ag}, \mathrm{Cu}$, and $\mathrm{Zn}$ were randomly chosen from targe number of experiments conducted over a period of five months following the calibration of the ellipsometer. The measurements on $\mathrm{Ag}_{2} \mathrm{O}$ and $\mathrm{CdO}$ samples prepared from compressed powders were made fourteen months after the calibration. For comparison, $\Delta_{0}$ and $\psi_{0}$, calculated asstuming ideal components, and the range of the corrected $\Delta$ and $\psi$ values are also presented.

The corrected 4-zone measurements indtcate that the calibration procedure gives an excellent account of the effects of component imper+ fections in the determination of the relative amplitude parameter $\psi$. Over ranges of $\Delta$ vaiues of 0.34 to 101.82 , and $\psi$ values of 22.84 to 43.05 , the maximum spread in corrected $\psi$ values is \pm 0.06 degrees for the $\mathrm{Ag}_{2} \mathrm{O}$ sample. For the metal specimens, even better results were obtained, with the maximum spread being \pm 0.025 degrees. The corrections to the relative phase $\Delta$ at first appear less accurate, with the Iargest spread 
Corrected 4-zone measurements.

\begin{tabular}{|c|c|c|c|c|c|c|c|}
\hline Material & $p$ & $\mathrm{a}$ & $q$ & $\Delta_{0}$ & $\Delta$ & $\psi_{0}$ & $\psi$ \\
\hline $\mathrm{Cd} 0001$ & 86.20 & 40.72 & 45 & 97.60 & 96.48 & 40.72 & 38.13 \\
\hline \multirow[t]{4}{*}{ singte crystat } & 176.44 & 144.47 & 45 & 97.12 & 96.86 & 35.53 & 38.10 \\
\hline & 93.33 & 742.05 & 135 & 96.66 & 96.74 & 37.96 & 38.74 \\
\hline & 3.06 & 38.36 & 135 & 96.12 & 96.45 & 38.36 & 38.13 \\
\hline & \multicolumn{3}{|c|}{ Average: } & $\begin{array}{l}96.88 \\
\pm 0.74\end{array}$ & $\begin{array}{l}96.63 \\
\pm 0.20\end{array}$ & $\begin{array}{l}38.14 \\
\pm 2.60\end{array}$ & $\begin{array}{l}38.73 \\
\pm 0.02\end{array}$ \\
\hline Ag 100 & 93.22 & 45.75 & 45 & 83.56 & 82.45 & 45.75 & 43.05 \\
\hline \multirow[t]{4}{*}{ Single crystal } & 3.68 & 139.69 & 45 & 82.64 & 82.37 & 40.31 & 43.06 \\
\hline & 86.20 & 137.34 & 135 & 82.40 & 82.46 & 42.66 & 43.05 \\
\hline & 175.96 & 43.49 & 135 & $\underline{81.92}$ & 82.27 & 43.49 & $\underline{43.07}$ \\
\hline & \multicolumn{3}{|c|}{ Average: } & $\begin{array}{l}82.63 \\
\pm 0.82\end{array}$ & $\begin{array}{l}82.39 \\
\pm 0.10\end{array}$ & $\begin{array}{r}43.05 \\
+2.72\end{array}$ & $\begin{array}{l}43.06 \\
\pm 0.01\end{array}$ \\
\hline $\mathrm{Cu}$, off axis & 101.59 & 39.16 & 45 & 66.82 & 65.75 & 39.16 & 37.39 \\
\hline \multirow[t]{4}{*}{ Single crystal } & 11.71 & 144.37 & 45 & 66.58 & 66.26 & 35.63 & 37.39 \\
\hline & 78.05 & 142.27 & 135 & 66.7 & 66.22 & 37.73 & 37.40 \\
\hline & 167.65 & 37.11 & 135 & 65.3 & $\underline{65.58}$ & 37.11 & 37.40 \\
\hline & \multicolumn{3}{|c|}{ Average: } & $\begin{array}{l}56.20 \\
\pm 0.76\end{array}$ & $\begin{array}{l}65.95 \\
\pm 0.34\end{array}$ & $\begin{array}{l}37.40 \\
\pm 1.77\end{array}$ & $\begin{array}{l}37.395 \\
\pm 0.005\end{array}$ \\
\hline$Z n 1010$ & 83.64 & 39.52 & 45 & 102.72 & 101.61 & 39.52 & 36.82 \\
\hline \multirow[t]{4}{*}{ Single crystal } & 173.99 & 145.92 & 45 & 102.02 & 101.75 & 34.08 & 36.77 \\
\hline & 95.72 & 143.59 & 135 & 101.44 & 107.53 & 36.41 & 36.79 \\
\hline & 5.54 & 37.19 & 135 & 101.08 & $10 ? .40$ & 37.19 & 36.77 \\
\hline & \multicolumn{3}{|c|}{ Average: } & $\begin{array}{r}101.82 \\
\pm 0.82\end{array}$ & $\begin{array}{r}101.57 \\
\pm 0.38\end{array}$ & $\begin{array}{l}36.80 \\
\pm 2.27\end{array}$ & $\begin{array}{l}36.80 \\
\pm 0.025\end{array}$ \\
\hline \multirow[t]{5}{*}{ Ag polycrystal } & 93.52 & 44.46 & 45 & 82.96 & 81.85 & 44.46 & 41.75 \\
\hline & 3.24 & 141.05 & 45 & 83.52 & 83.25 & 38.95 & 41.69 \\
\hline & 86.49 & 138.72 & 135 & 82.98 & 83.05 & 41.28 & 41.73 \\
\hline & 175.72 & 42.20 & 135 & 81.44 & 81.78 & 42.20 & 41.75 \\
\hline & \multicolumn{3}{|c|}{ Average: } & $\begin{array}{l}82.73 \\
\pm 1,04\end{array}$ & $\begin{array}{l}82.48 \\
\pm 0.735\end{array}$ & $\begin{array}{l}41.72 \\
\pm 2.76\end{array}$ & $\begin{array}{l}41.72 \\
\pm 0.03\end{array}$ \\
\hline
\end{tabular}


Corrected 4-zone measurements (continued)

\begin{tabular}{|c|c|c|c|c|c|c|c|}
\hline Material & $p$ & A & $Q$ & $\Delta_{0}$ & $\Delta$ & $\psi_{0}$ & $\psi$ \\
\hline \multirow{5}{*}{$\mathrm{Ag}_{2} \mathrm{O}$ powder } & 140.65 & 67.80 & 135 & 11.30 & 11.95 & 22.20 & 22.87 \\
\hline & 50.69 & 113.45 & 135 & 71.38 & 12.13 & 23.45 & 22.83 \\
\hline & 40.18 & 113.65 & 45 & 9.64 & 9.59 & 23.65 & 22.94 \\
\hline & 129.91 & 67.95 & 45 & 10.78 & 9.83 & $\underline{22.05}$ & 22.94 \\
\hline & & & Average: & $\begin{array}{l}10.62 \\
\pm 0.98\end{array}$ & $\begin{array}{l}10.87 \\
\pm 1.26\end{array}$ & $\begin{array}{l}22.84 \\
\pm 0.79\end{array}$ & $\begin{array}{l}22.89 \\
\pm 0.06\end{array}$ \\
\hline \multirow[t]{5}{*}{ Cd0 powder } & 134.56 & 59.87 & 135 & 0.88 & 0.12 & 30.13 & 30.35 \\
\hline & 44.62 & 120.48 & 135 & 0.76 & 0.12 & 30.48 & 30.33 \\
\hline & 45.16 & 120.33 & 45 & 0.32 & 0.37 & 30.33 & 30.31 \\
\hline & 135.20 & 59.67 & 45 & $\underline{0.40}$ & 0.75 & 30.33 & 30.32 \\
\hline & & & Average: & $\begin{array}{r}0.59 \\
\pm 0.29\end{array}$ & $\begin{array}{r}0.34 \\
\pm 0.41\end{array}$ & $\begin{array}{l}30.32 \\
\pm 0.19\end{array}$ & $\begin{array}{l}30.33 \\
\pm 0.02\end{array}$ \\
\hline \multirow[t]{5}{*}{$\mathrm{PbO}_{2}$ powder } & 129.09 & 62.49 & 135 & 11.82 & 11.15 & 27.51 & 28.24 \\
\hline & 38.70 & 118.87 & 135 & 12.60 & 77.87 & 28.87 & 28.22 \\
\hline & 50.96 & 118.31 & 45 & 11.92 & 17.99 & 28.31 & 28.22 \\
\hline & 140.70 & 61.86 & 45 & 11.40 & 11.72 & 28.14 & 28.22 \\
\hline & & & Average: & $\begin{array}{l}11.94 \\
\pm 0.66\end{array}$ & $\begin{array}{l}11.70 \\
\pm 0.55\end{array}$ & $\begin{array}{l}28.21 \\
\pm 0.70\end{array}$ & $\begin{array}{l}28.22 \\
\pm 0.02\end{array}$ \\
\hline
\end{tabular}


for the metal samples bejng \pm 0.74 for the polycrystalline Ag surface, while the spread in corrected 4-zone measurements increases over the range of uncorrected values for the two compressed-powder oxide samples.

An explanation for the range of the corrected 4-zone values of $\Delta$ is anisotropy of the specimen surface. For the idealized planar, isotropic surface, $\Delta$ and $\psi$ would not depend upon the zone of measurement. However, structural Irregularities such as surface roughness, strain-induced birefringence, or crystaliographic orientation would lead to directionallydependent optical properties of the surface. Evidence supporting antsotropy is that the range of corrected values of $A$ is greatest among the single crystal specimens for the off-axis $\mathrm{Cu}$ surface. Also, it is certain that the oxide samples were strained by the elastic contraction of a protective brass ring following compression at 50,000 psia.

Another result which should be emphasized 15 that averaging of 4-zone measurements does not eliminate the effects of imperfections in the determination of the relative phase $A$ (Table $V$, Appendix $A$ ). The res1dual error $t_{2 F C R} \cos 2 F C R+t_{2 W I} \cos 2 W I+t_{2 W R} \cos 2 W R$ remains. This suggests that the glass rod with fewer imperfections is used for the analyzer Faraday cell. 
IV. CONCLUSIONS

The application of parametric equations to the calibration of our automatic ellipsometer indicates that the quarter wave plate contains the largest optical imperfections. The Faraday celis used for selfcompensation contain both dicroism and birefringence. The windows of the ultra-high vacum system exhibit significant birefringence.

The effectiveness of the calibration procedure rematns uncertain due to the possibility of surface anisotropies in the specimen being measured. The results of corrections to the determination of the relative amplitude parameter $\psi$ stuggest an exceptional accuracy of \pm 0.02 degrees. The consideration of surface anisotropies wilt be necessary to obtain a more definitive verification of the calibration procedure.

The caltbration was performed for the monochromatic Hg $5461 \AA$ line. It is expected that the 20 parameter values determined by the analysis will be functions of the wavelength of light.

This work was supported by the Division of Matertals Sciences, Office of Basic Energy Sciences, U. S. Department of Energy. 


\section{REFERENCES}

1. R.M.A.Azzam and N.M.Bashara, J. Opt. Soc. Am. 61, 600 (1971).

2. R.Muller, "Principles of Ellipsometry," in Advances in Electrochemistry and Electrochemical Engineering, Vol. 9 (John Witey Sons, Hew York, 1973\}, P.Delahay and C.W.Tobias, editors, pp.167-226.

3. R.Clark Jones, J. Opt. Soc. Alt. 31, 488 (1941); 31, 493 (1941); $\underline{31}, 500(1941) ; \quad \underline{32}, 486(1942) ; \quad 37,107(1947) ; \quad 37,110$ (1947); 38, $671(1948)$.

4. W.A.Shurcliff, Polarized Light (Harvard University Press, Cambridge Massachussetts, 1962). 


\section{APPENDIX A}

Table I Zone assignments and ideal values of $\psi$ and $A$.

Table IIa complete corrected equations for $\psi$ for Group B (standard azimuths).

Table IIb Complete corrected equations for $\Delta$ for Group B (standard azimuths).

Table IIc Signs of the parameters in the corrected equations for $\psi$ for all groups (standard aztinuths).

Table IId Signs of the parameters in the corrected equations for $\Delta$ for a11 groups (standard aziriuths).

Table IIIa Signs of the parameters in the corrected equations for $\downarrow$ for all groups (rotated gzimuths).

Table IIIb Signs of the parameters in the corrected equations for A for all groups (rotated azimuths).

Table IVa Complete corrected equations for the analyzer azimuth (standard aztmuths).

Table IVb Complete corrected equations for the polarizer azimuth (standard azimuths).

Table IVc Signs of the paraneters in the corrected equations for the anaiyzer azimuth for all groups.

Table IVd Signs of the paraneters in the corrected equations for the polarizer azimuth for a11 groups.

Table $V \quad$ Four-zone averages for $\psi$ and $A$.

Table VI Expressions for "R".

Table VII Values of the parameters.

Table VIII Complete equation for standard analyzer azimuth for Zone 81 . 
Zone Assiganents and IDEal Values of $\psi_{\text {AND }} \Delta$

\begin{tabular}{|c|c|c|c|c|c|c|c|c|c|c|c|c|c|c|c|c|c|c|c|}
\hline \multirow{2}{*}{ ZOME } & \multicolumn{8}{|c|}{ STANDARD AZITUTH ANGLES } & \multicolumn{11}{|c|}{ ROTRTED AZIMUTH ANGLES } \\
\hline & & $\mathrm{P}$ & & a & $\varepsilon$ & & $\iota^{\circ}$ & 40 & & $\mathbf{P}$ & & & A & & $\mathrm{c}$ & & $4^{\circ}$ & & 7 \\
\hline A1 & 0 & $-45^{\circ}$ & $90^{\circ}$ & $-180^{\circ}$ & $45^{\circ}$ & $90^{\circ}$ & - 2p & $190^{\circ}=\ldots$ & $\Leftrightarrow$ & - & $135^{\circ}$ & $a^{\circ}$ & - & $90^{4}$ & $135^{\circ}$ & $270^{\circ}$ & $-2 \mathrm{p}$ & $90^{\circ}$ & -2 \\
\hline 12 & $45^{\circ}$ & $-50^{\circ}$ & $90^{\circ}$ & $-180^{\circ}$ & $135^{\circ}$ & $2 \mathrm{~F}$ & $-90^{\circ}$ & $180^{\circ}=x$ & $135^{\circ}$ & & $180^{\circ}$ & $0^{\circ}$ & & $90^{\circ}$ & $45^{\circ}$ & $2 \mathrm{P}$ & $-270^{\circ}$ & $90^{\circ}$ & $-A$ \\
\hline$A 3$ & $90^{\circ}$ & $-135^{\circ}$ & $0^{\circ}$ & $=90^{\circ}$ & $45^{\circ}$ & $270^{\circ}$ & $-2 p$ & a & $0^{\circ}$ & & $45^{\circ}$ & $90^{\circ}$ & & $180^{\circ}$ & $135^{\circ}$ & $90^{\circ}$ & $-2 \bar{E}$ & & $-90^{\circ}$ \\
\hline A4 & $135^{\circ}$ & $-180^{\circ}$ & $0^{\circ}$ & $-90^{\circ}$ & $135^{\circ}$ & $2 p$ & $-270^{\circ}$ & $a$ & $45^{*}$ & & $90^{\circ}$ & 900 & & $180^{\circ}$ & $45^{\circ}$ & $2 P$ & $=90^{\circ}$ & & $-90^{\circ}$ \\
\hline Bl & $0^{\circ}$ & $-45^{\circ}$ & $0^{\circ}$ & $=90^{\circ}$ & $135^{\circ}$ & $90^{\circ}$ & $\div 2 p$ & $a$ & $90^{\circ}$ & & 2350 & $90^{\circ}$ & & $180^{\circ}$ & $45^{\circ}$ & $2 \mathrm{P}$ & $=90^{\circ}$ & & $-90^{\circ}$ \\
\hline $\mathrm{BZ}$ & $45^{\circ}$ & $-90^{\circ}$ & $0^{\circ}$ & $-90^{\circ}$ & $45^{\circ}$ & $270^{\circ}$ & $-2 p$ & a & $135^{\circ}$ & & $180^{\circ}$ & $90^{\circ}$ & & $280^{\circ}$ & $135^{\circ}$ & $450^{\circ}$ & $-2 P$ & & $-90^{\circ}$ \\
\hline B3 & $90^{\circ}$ & $-235^{\circ}$ & $90^{\circ}$ & $=I B D^{\circ}$ & $235^{\circ}$ & $2 p$ & $=90^{\circ}$ & $180^{\circ}-a$ & $0^{\circ}$ & & $45^{\circ}$ & $0^{\circ}$ & & $90^{\circ}$ & $45^{\circ}$ & $2 \mathrm{P}$ & $+90^{\circ}$ & $90^{\circ}$ & $-A$ \\
\hline BA & $135^{\circ}$ & $-180^{\circ}$ & $90^{\circ}$ & $-100^{4}$ & $45^{\circ}$ & $450^{\circ}$ & $-2 p$ & $190^{\circ}=$ & $45^{\circ}$ & & $90^{\circ}$ & $0^{\circ}$ & & $90^{\circ}$ & $135^{\circ}$ & $270^{\circ}$ & -28 & $90^{\circ}$ & $-x$ \\
\hline c1 & $0^{\circ}$ & $-45^{\circ}$ & $0^{\circ}$ & $=90^{\circ}$ & $45^{\circ}$ & $270^{\circ}$ & $-2 p$ & a & $90^{\circ}$ & & $135^{\circ}$ & $90^{\circ}$ & & $180^{\circ}$ & $135^{\circ}$ & $450^{\circ}$ & $-2 P$ & & $-90^{\circ}$ \\
\hline$c_{2}$ & $45^{4}$ & $-90^{\circ}$ & $0^{\circ}$ & $=90^{\circ}$ & $135^{\circ}$ & $2 p$ & $+90^{\circ}$ & a & $135^{\circ}$ & & $180^{\circ}$ & 900 & & $180^{\circ}$ & $45^{\circ}$ & $2 \mathrm{P}$ & $-90^{\circ}$ & A & $=90^{\circ}$ \\
\hline$c 3$ & $90^{\circ}$ & $-135^{\circ}$ & $90^{\circ}$ & $-180^{\circ}$ & $45^{\circ}$ & $450^{\circ}$ & $-2 p$ & $180^{\circ}-a$ & $0^{\circ}$ & & $45^{\circ}$ & $0^{\circ}$ & & $90^{\circ}$ & $135^{\circ}$ & $270^{\circ}$ & $-2 P$ & $90^{\circ}$ & $-A$ \\
\hline EA & $135^{\circ}$ & $-180^{\circ}$ & $90^{\circ}$ & $-180^{\circ}$ & $175^{\circ}$ & & $-90^{\circ}$ & $100^{\circ}-a$ & $45^{\circ}$ & & $90^{\circ}$ & $0^{\circ}$ & & $90^{\circ}$ & 150 & $2 \mathrm{P}$ & $+90^{\circ}$ & $90^{\circ}$ & $-\lambda$ \\
\hline $\mathrm{DL}$ & $\mathfrak{o}^{\circ}$ & $-45^{\circ}$ & $90^{\circ}$ & $-180^{\circ}$ & 1350 & $2 \mathrm{P}$ & $+270^{\circ}$ & $180^{\circ}-a$ & $90^{\circ}$ & & $135^{\circ}$ & $0^{\circ}$ & & $90^{\circ}$ & $45^{\circ}$ & $2 \mathrm{P}$ & $+90^{\circ}$ & $90^{\circ}$ & $-x$ \\
\hline $\mathrm{D} 2$ & $45^{\circ}$ & $-90^{\circ}$ & $90^{\circ}$ & $-100^{\circ}$ & $45^{\circ}$ & $450^{\circ}$ & - 2p & $190^{\circ}-\mathrm{a}$ & $135^{\circ}$ & & $180^{\circ}$ & $0^{\circ}$ & & $90^{\circ}$ & $135^{\circ}$ & $630^{\circ}$ & $-2 P$ & $90^{\circ}$ & $-A$ \\
\hline D3 & $90^{\circ}$ & $-135^{\circ}$ & $0^{\circ}$ & $=90^{\circ}$ & $135^{\circ}$ & $2 p$ & $-90^{\circ}$ & a & $0^{\circ}$ & & $45^{\circ}$ & $90^{\circ}$ & & $1 B b^{\circ}$ & $45^{\circ}$ & $2 \mathrm{P}$ & $+270^{\circ}$ & & $-90^{\circ}$ \\
\hline Q44 & $135^{\circ}$ & $-180^{\circ}$ & $0^{\circ}$ & $=9 \mathrm{~B}^{\circ}$ & $45^{\circ}$ & $630^{\circ}$ & $-2 \theta$ & $*$ & $45^{\circ}$ & - & $90^{\circ}$ & $90^{\circ}$ & - & $130^{\circ}$ & $135^{\circ}$ & $450^{\circ}$ & $=2 \mathrm{E}$ & A & $-90^{\circ}$ \\
\hline
\end{tabular}




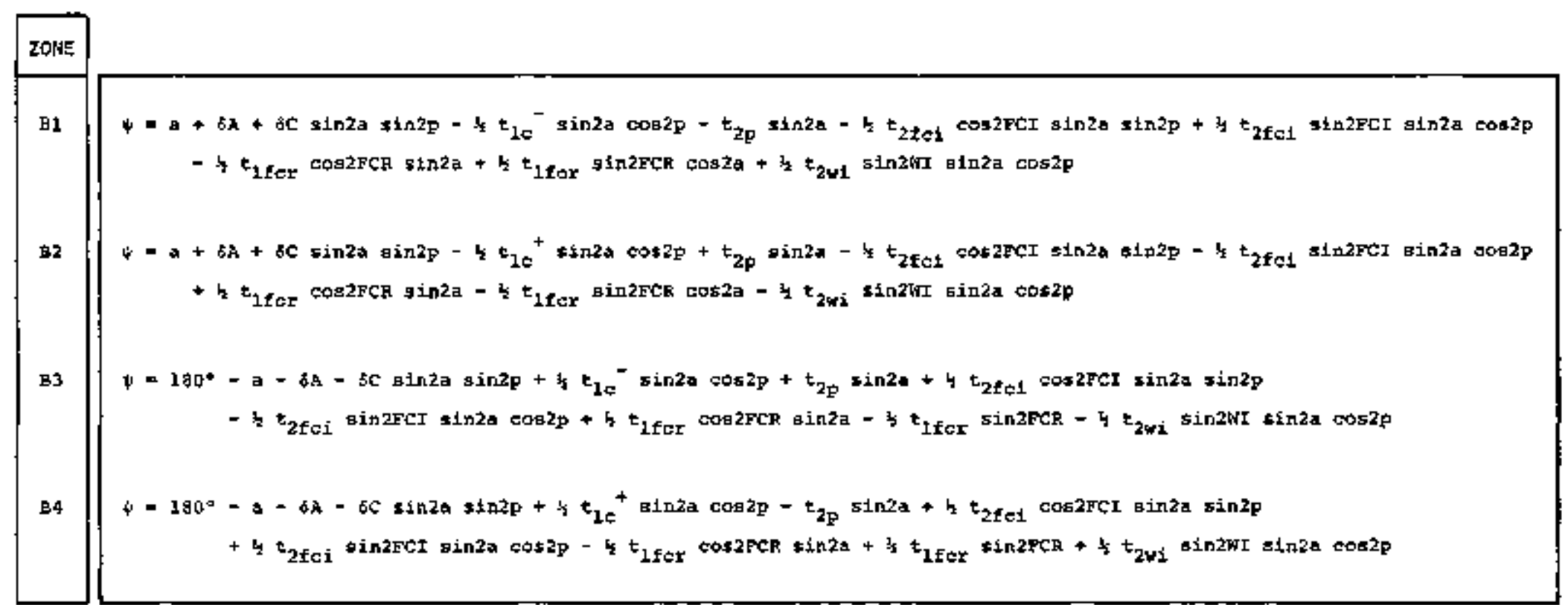




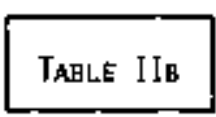

COMPLETE CORRECTEI EQUATIONS FOR $\triangle$ FOR GROUP B

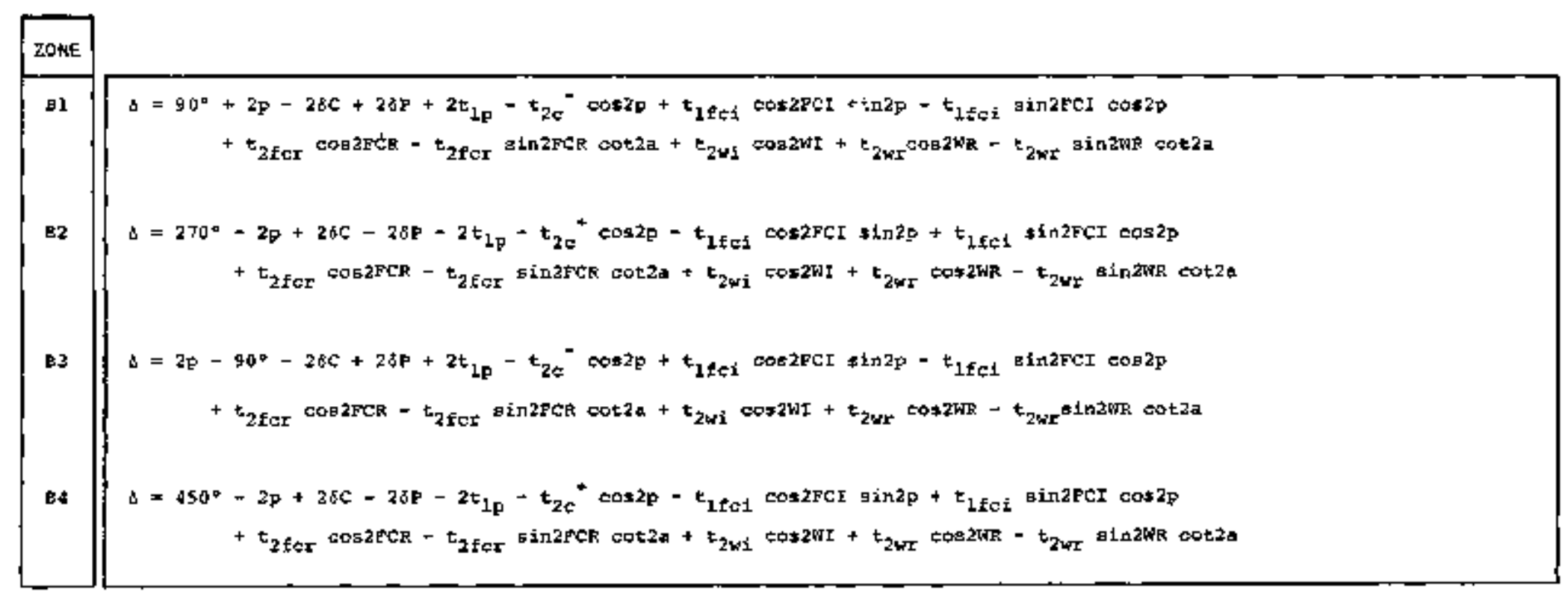

Note: $\left.\delta C-6 P=18 \varepsilon_{Q}+\delta B\right\}-\left(6 P_{Q}+E_{B B}\right.$

$=S C_{c}-\delta F_{F}$ 


\begin{tabular}{|c|c|c|c|c|c|c|c|c|c|}
\hline \multicolumn{3}{|c|}{ TABLE $1 \mathrm{I} C$} & \multicolumn{6}{|c|}{ 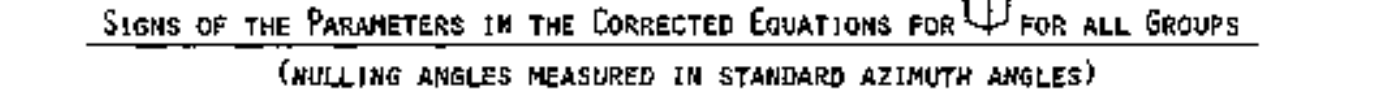 } & Table IIc \\
\hline 200 & $b^{\mathrm{s}}$ & 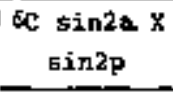 & $\begin{array}{c}1, t_{1 c} x \\
\operatorname{ain} 2 a \cos 2 p\end{array}$ & $\begin{array}{l}t_{2 p} x \\
\text { sinza }\end{array}$ & $\begin{array}{l}t_{2 f_{i j}} \cos 2 \mathrm{FCI} x \\
\text { gin2a } \sin 2 p\end{array}$ & $\begin{array}{c}\mathrm{t}_{2 \mathrm{f}_{\mathrm{G} 1}} \text { ain2FCI } \mathrm{K} \\
\text { Einza } \cos 2 \mathrm{~F}\end{array}$ & $\begin{array}{l}11 t_{1 \operatorname{for}} x \\
\cos 2 F C R \sin 2 *\end{array}$ & $\begin{array}{l}3_{f} t_{11 C x} x \\
\sin 2 p C A \cos 2 a\end{array}$ & 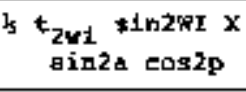 \\
\hline $\mathrm{A} 1$ & - & + & + & - & - & + & - & 4 & + \\
\hline$a^{A 2}$ & $=$ & + & + & + & - & - & + & - & $=$ \\
\hline $\begin{array}{l}\text { A.3 } \\
\text { A4 }\end{array}$ & + & - & - & \pm & + & + & - & $\begin{array}{l}- \\
+\end{array}$ & + \\
\hline B1 & + & + & - & - & - & + & - & + & + \\
\hline Bz & $1+$ & + & - & + & - & - & + & - & - \\
\hline $\begin{array}{l}B_{B 3} \\
B-1\end{array}$ & $1-$ & $\overline{-}$ & + & \pm & t+ & $\overline{+}$ & \pm & $\bar{t}$ & $i$ \\
\hline & 1 & & & & & & & & \\
\hline$c_{1}$ & + & + & + & + & $=$ & + & + & - & + \\
\hline c2 & + & + & + & - & - & - & - & + & - \\
\hline $\mid \begin{array}{l}\mathrm{C}^{3} \\
\mathrm{c4}\end{array}$ & 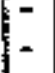 & - & $=$ & + & + & $\overline{+}$ & + & - & . \\
\hline D1 & $1-$ & $t$ & - & + & - & + & + & - & * \\
\hline 02 & $1-$ & 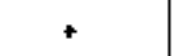 & - & 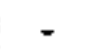 & 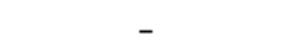 & - & - & + & _ \\
\hline p3 & \pm & - & + & $=$ & * & - & - & + & - \\
\hline D4 & \}$^{+}$ & - & + & + & 4 & + & • & - & $*$ \\
\hline
\end{tabular}




\begin{tabular}{|c|c|c|c|c|c|c|c|c|c|c|c|}
\hline \multicolumn{2}{|c|}{ TABLE 110} & & \multicolumn{8}{|c|}{$\frac{\text { SIGNS of THE PARAHETERS IN THE COARECTED EaUATIONS FOR } \triangle \text { FOR RLL GROUPS }}{\text { (NULLING AMGLES MEASURED IN STANDARD AZIMUTH ANGLES) }}$} & TABLE ItD \\
\hline sents & $26 c$ & $23 \mathrm{P}$ & $2 t_{1 p}$ & $\begin{array}{l}t_{2 c} x \\
\cos 2 p\end{array}$ & $\begin{array}{c}t_{1 f C 1} x \\
\cos 2 F C I \neq 1 n 2 P\end{array}$ & $\begin{array}{c}t_{1 t e 1} x \\
\Rightarrow 1 n 2 F C I \cos 2 p\end{array}$ & $\begin{array}{l}t_{2 f e r} x \\
\text { tos } 23 C R\end{array}$ & $\begin{array}{c}t_{2 x+x} x \\
\sin 2 P C R \cot 2 a\end{array}$ & $\begin{array}{l}t_{z W i} x \\
\cos 2 \mathrm{KI} I\end{array}$ & $\begin{array}{l}t_{2 W r} x \\
\cos 2 \mathrm{WR}\end{array}$ & $\begin{array}{c}t_{2 w r} x \\
\sin 2 \mathrm{WR} \cot 2 x\end{array}$ \\
\hline$A_{1}$ & + & - & - & - & + & + & + & $=$ & + & + & - \\
\hline $\mathrm{A} 2$ & - & 4 & + & - & - & - & + & - & + & + & - \\
\hline $\mathrm{A3}$ & + & - & - & - & + & + & + & - & + & + & - \\
\hline $\mathrm{A} 4$ & - & + & + & - & - & - & + & $=$ & + & + & - \\
\hline$B 1$ & - & + & + & - & + & $=$ & + & - & + & + & - \\
\hline $\mathrm{Bz}$ & + & - & - & - & - & + & + & - & + & + & $=$ \\
\hline B3 & $=$ & + & + & - & + & - & + & - & + & + & $=$ \\
\hline B4 & + & - & - & - & - & + & 4 & - & + & + & $=$ \\
\hline $\mathrm{Cl}$ & + & - & - & + & $=$ & - & 4 & - & + & + & - \\
\hline$c 2$ & - & $t$ & + & + & + & 4 & + & - & + & + & - \\
\hline C3 & + & - & - & + & $=$ & $=$ & + & - & + & + & - \\
\hline C4 & $=$ & + & + & + & + & + & + & - & + & + & - \\
\hline $\mathrm{DI}$ & - & + & + & + & - & + & + & - & + & + & - \\
\hline D2 & + & - & - & + & $\Rightarrow$ & 4 & + & - & + & 4 & - \\
\hline D3 & - & + & t & + & - & + & + & - & + & + & - \\
\hline $\mathrm{D} \&$ & + & - & - & + & + & - & + & - & + & + & - \\
\hline
\end{tabular}




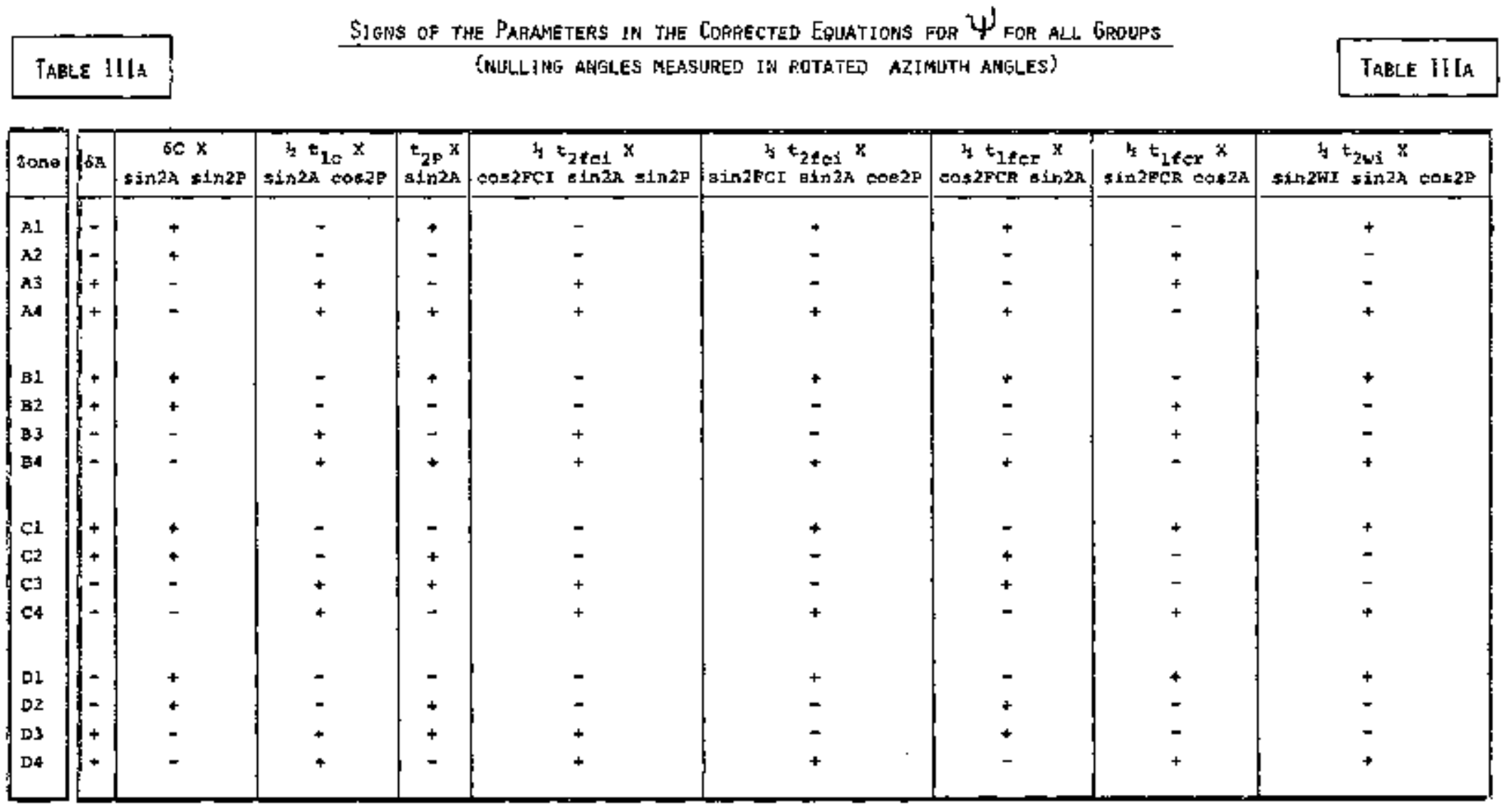




\begin{tabular}{|c|c|c|c|c|c|c|c|c|c|c|c|}
\hline \multicolumn{3}{|c|}{ Thale IIIB } & \multicolumn{8}{|c|}{$\frac{\text { SIGNS OF THE PARAMETERS IN THE CORRECTEO EQUATIDNS FOR } \triangle \text { FQR ALL GROUPS }}{\text { (NULLING ANGLES MEASURED IN ROTATED AZIMUTH ANGLES) }}$} & TABLE IIIs \\
\hline zone & $26 \mathrm{C}$ & $28 \mathrm{P}$ & ${ }^{2} t_{1 p}$ & $\begin{array}{l}t_{2 c} x \\
\cos 2 P\end{array}$ & 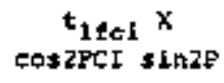 & $\begin{array}{c}t_{11<1} X \\
s=2 \text { PCI } \cos 2 \theta\end{array}$ & $\begin{array}{l}t_{2 f H_{1}} x \\
\cos 28 c k\end{array}$ & $\begin{array}{c}t_{2 f+\mathrm{t}} x \\
\text { sinzFCR } \cot 2 \mathrm{~A}\end{array}$ & $\begin{array}{l}t_{2 v i} x \\
\cos 2 W I\end{array}$ & $\begin{array}{l}t_{2 w r} x \\
\text { cos } 2 \omega_{R}\end{array}$ & $\begin{array}{c}t_{2 \text { Wre }} x \\
\sin 3 \text { wot } 2 A\end{array}$ \\
\hline Al & + & $=$ & $=$ & + & - & - & + & - & + & + & $=$ \\
\hline $\mathrm{A} 2$ & - & + & + & + & + & + & + & - & + & + & - \\
\hline A3 & + & - & - & + & - & - & + & - & + & + & - \\
\hline A4 & $=$ & $\downarrow$ & + & + & + & + & + & - & + & + & - \\
\hline$B 1$ & - & + & + & + & $=$ & + & + & - & + & + & - \\
\hline 32 & + & - & - & + & + & $=$ & + & $=$ & + & + & - \\
\hline 83 & - & + & + & + & - & + & + & - & + & $\bullet$ & - \\
\hline 自 4 & + & - & $=$ & + & + & - & + & - & + & + & - \\
\hline $\mathrm{Cl}$ & + & $=$ & - & - & + & + & + & - & + & + & - \\
\hline $\mathrm{C2}$ & - & + & + & - & - & - & + & - & + & + & - \\
\hline $\mathrm{C} 3$ & + & - & - & $=$ & $\dot{\boldsymbol{r}}$ & + & + & - & + & + & $=$ \\
\hline C4 & - & + & + & - & - & - & + & $=$ & + & $t$ & - \\
\hline$D t$ & - & + & + & $=$ & + & - & + & $=$ & + & + & - \\
\hline 02 & + & $=$ & - & - & - & + & + & $=$ & 4 & + & $=$ \\
\hline DJ & - & + & + & - & + & - & + & $=$ & + & + & - \\
\hline D4 & + & - & - & $=$ & - & + & + & $=$ & + & + & - \\
\hline
\end{tabular}




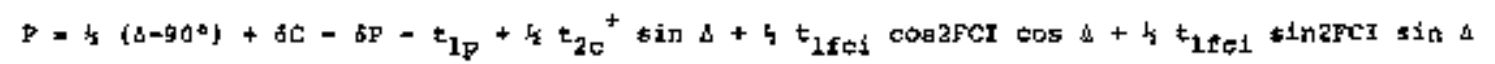

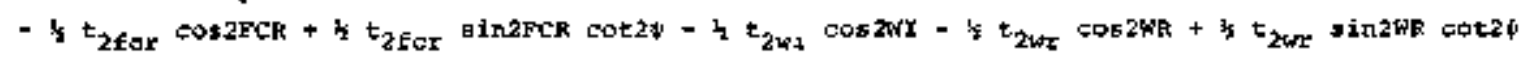

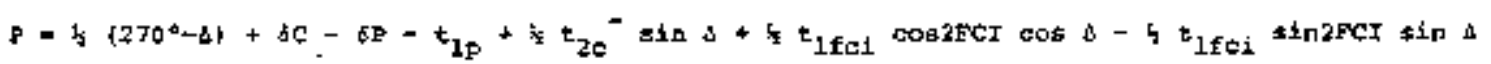

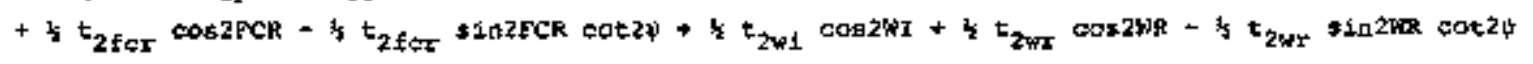

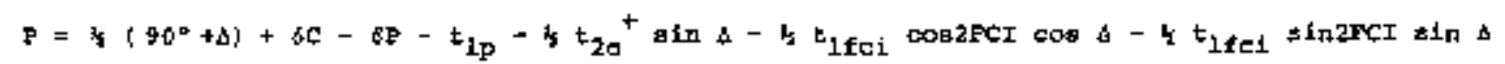

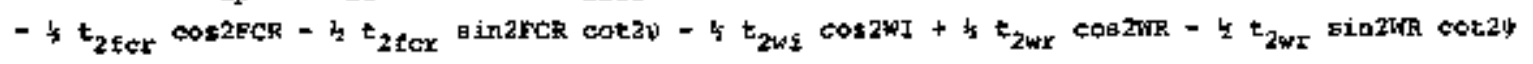

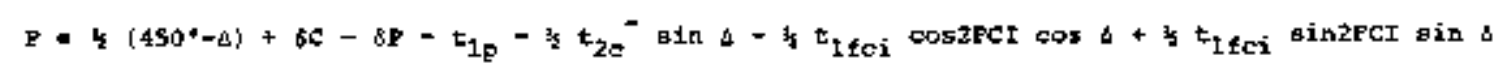

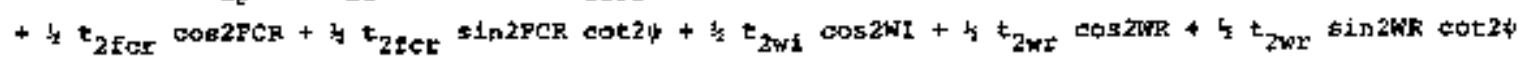

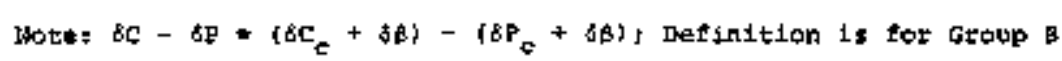

$=\delta \mathrm{c}_{c}-d \alpha$ 


\begin{tabular}{|c|c|c|c|c|c|c|c|c|c|}
\hline \multicolumn{3}{|c|}{$T_{A B L E} I V_{C}$} & \multirow{2}{*}{\multicolumn{6}{|c|}{ 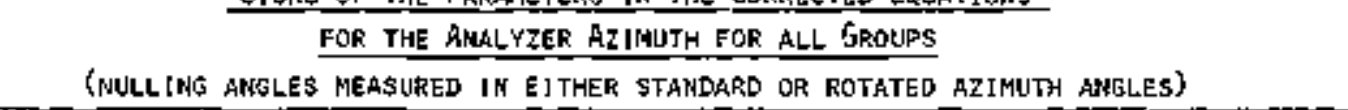 }} & \multirow{2}{*}{$T_{A B C E} W_{C}$} \\
\hline & & & & & & & & & \\
\hline zone & SA & $\begin{array}{c}60 x \\
\sin 20 \cos \theta\end{array}$ & $\mid \begin{array}{c}15 t_{1 e^{x}} x \\
\sin 2 \psi \sin 4\end{array}$ & $\begin{array}{l}t_{2 p} x \\
\operatorname{tin}_{2 n}\end{array}$ & $\begin{array}{c}4 t_{2 \operatorname{csi}} x \\
\cos 2 \cos \sin 20 \cos \theta\end{array}$ & 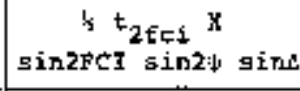 & $\begin{array}{c}t=t_{2 f<r} \times \\
\cos 2 \mathrm{FCR} \operatorname{ain} 2 y\end{array}$ & $\begin{array}{l}\Rightarrow t_{119 r} \times \\
\sin 2 \mathrm{PCR} \cos 26\end{array}$ & 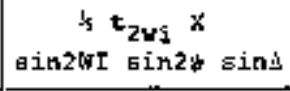 \\
\hline A1 & $1=$ & - & - & + & + & - & + & + & - \\
\hline$\$ 2$ & - & - & + & - & * & - & - & - & - \\
\hline A3 & 1- & - & - & - & + & - & - & 4 & - \\
\hline A4 & |- & - & + & + & + & - & + & - & - \\
\hline Bd & 1 & + & + & + & - & - & + & - & - \\
\hline \$2 & - & + & - & - & - & - & - & $*$ & - \\
\hline $\mid \begin{array}{l}53 \\
84\end{array}$ & - & * & + & - & - & - & - & 5 & - \\
\hline 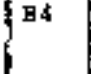 & 1- & $\bullet$ & ${ }^{-}$ & + & - & - & + & + & - \\
\hline$a_{1}$ & - & + & + & - & - & + & - & + & + \\
\hline c2 & - & + & - & 4 & - & + & + & - & + \\
\hline$c 3$ & - & + & + & + & - & + & + & + & • \\
\hline 61 & - & + & - & - & - & + & - & - & + \\
\hline $\mathrm{Dl}$ & 1- & - & - & - & $t$ & + & $=$ & - & 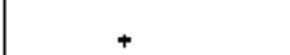 \\
\hline D2 & - & - & + & + & + & + & + & + & - \\
\hline 103 & - & - & - & + & + & + & + & - & t \\
\hline I & - & - & + & - & + & + & - & + & + \\
\hline
\end{tabular}




\begin{tabular}{|c|c|c|c|c|c|c|c|c|c|c|c|}
\hline \multicolumn{3}{|c|}{ TABLE IYD } & \multicolumn{8}{|c|}{$\begin{array}{c}\text { SIGNS OF THE PARANETERS 1H THE CORRECTED EQUATIONS } \\
\text { FOR THE POLARIZER AZIMUTH FOR, ALL GROPS }\end{array}$} & \multirow[t]{2}{*}{$T_{\text {ABLE }} \mid W_{D}$} \\
\hline & & & & & & & & & & & \\
\hline 20 one & $\mathbb{E C}$ & $\$ D$ & $t_{1 p}$ & $\begin{array}{c}\tan _{2 c} x \\
\operatorname{sins}\end{array}$ & $\begin{array}{l}h t_{1 \text { fer }} \bar{x} \\
\cos 2 \operatorname{ret} \cos 4\end{array}$ & $\begin{array}{l}=\bar{c}_{1 \text { fer }} x \\
\text { sinzfer airs }\end{array}$ & $\begin{array}{c}2 t_{2 \mathrm{far}} \mathrm{X} \\
\operatorname{cog} 2 \mathrm{PCR}\end{array}$ & $\begin{array}{c}3 t_{21 e r} x \\
\text { einzecR } \cos 24\end{array}$ & $\begin{array}{c}3 t_{2 w i x} x \\
\cos 2 H I\end{array}$ & 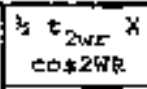 & 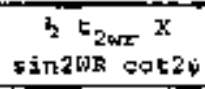 \\
\hline$x I$ & + & - & - & - & + & + & + & + & + & + & + \\
\hline $\mathrm{A} 2$ & + & - & - & - & $\bullet$ & - & - & - & - & - & $=$ \\
\hline 33 & + & - & - & * & - & - & + & - & + & + & $=$ \\
\hline $\mathbf{3 4}$ & + & - & - & + & - & $*$ & - & + & - & - & + \\
\hline B1 & + & - & - & + & + & + & - & + & - & - & + \\
\hline B2 & + & - & - & + & + & - & $\rightarrow$ & - & • & + & - \\
\hline 83 & + & - & - & - & - & - & - & - & - & - & - \\
\hline B4 & + & $=$ & - & - & - & + & + & + & + & + & + \\
\hline c1 & + & $=$ & - & - & + & + & + & - & + & + & - \\
\hline$c 2$ & + & - & - & - & + & - & - & + & $=$ & - & + \\
\hline $\mathrm{c}_{3}$ & + & - & - & 4 & - & - & + & 4 & • & + & + \\
\hline Cs & + & - & 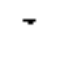 & + & - & + & $=$ & $=$ & - & - & $=$ \\
\hline D1 & + & - & $=$ & + & + & * & - & - & - & - & - \\
\hline $\mathrm{D} 2$ & + & $=$ & - & + & + & - & + & + & $\rightarrow$ & + & + \\
\hline$D_{3}$ & + & - & - & - & - & - & - & + & - & - & + \\
\hline$D 4$ & + & - & - & $=$ & - & * & • & - & $\rightarrow$ & + & - \\
\hline
\end{tabular}


FOUH-ZONE AVERAGES FOR $\Psi$ AND $\triangle$

\begin{tabular}{|c|c|c|}
\hline \multirow{2}{*}{ GRQUP } & \multicolumn{2}{|c|}{ STANDARD AZIMUTH ANGLES } \\
\hline & $\psi$ & II \\
\hline$\lambda$ & $-z_{2}\left(a_{1}+a_{2}-a_{3}-a_{4}\right)+90^{\circ}$ & $\left.-x_{1}+P_{1}-P_{2}+P_{3}-P_{4}\right)+\Delta c$ \\
\hline 9 & $+a_{2}\left(a_{2}+a_{2}-a_{3}-a_{4}\right)+90^{0}$ & $+h_{1}\left(\mathrm{P}_{1}-\mathrm{P}_{2}+\mathrm{P}_{3}-\mathrm{P}_{4}\right\}+180^{\circ}+8 \mathrm{~s}$ \\
\hline c & $\left.+4 i a_{1}+a_{2}-a_{3}-a_{4}\right)+90^{\circ}$ & $-u+P_{1}-B_{2}+e_{3}-P_{4} j+180^{\circ}+\Delta c$ \\
\hline $\mathrm{D}$ & $-z_{4}\left(\Delta_{1}+s_{2}-*_{3}-*_{4}\right)+90^{\circ}$ & $+1,1 p_{1}-p_{2}+P_{3}{ }^{4} P_{1} \mid+360^{\circ}+\Delta 0$ \\
\hline
\end{tabular}

\begin{tabular}{|c|c|}
\hline \multicolumn{2}{|c|}{ ROTATED AZIMUTH ANGLES } \\
\hline$\underline{\psi}$ & 5 \\
\hline$-A_{1}\left(A_{1}+A_{2}-A_{3}-A_{4}\right)$ & $=L_{2}\left(P_{1}-P_{2}+P_{3}-P_{4}\right)+\Delta C$ \\
\hline$+\therefore\left(A_{1}+A_{2}-\lambda_{3}-\lambda_{4}\right)$ & $+B_{7}\left(P_{1}-P_{2}+P_{3}-P_{4}\right\rangle+I B 0^{\circ}+A C$ \\
\hline$+h\left(A_{1}+\right.$ & $-2\left(P_{2}-P_{2}+P_{3}-P_{4}\right)+180^{+}+\Delta \sigma$ \\
\hline$-s_{1}\left(\lambda_{1}+\lambda_{2}-\lambda_{3}-\lambda_{4}\right)$ & $+z_{3}\left(P_{1}-P_{2}+P_{3}-P_{4}\right)+360^{\circ}+\Delta C$ \\
\hline
\end{tabular}

Por pressursmente made without Poradxy gells and windors, de = 0

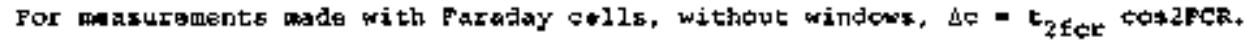

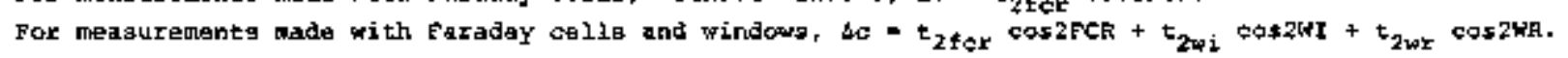




\section{EXPRESSIONS FOR "R}

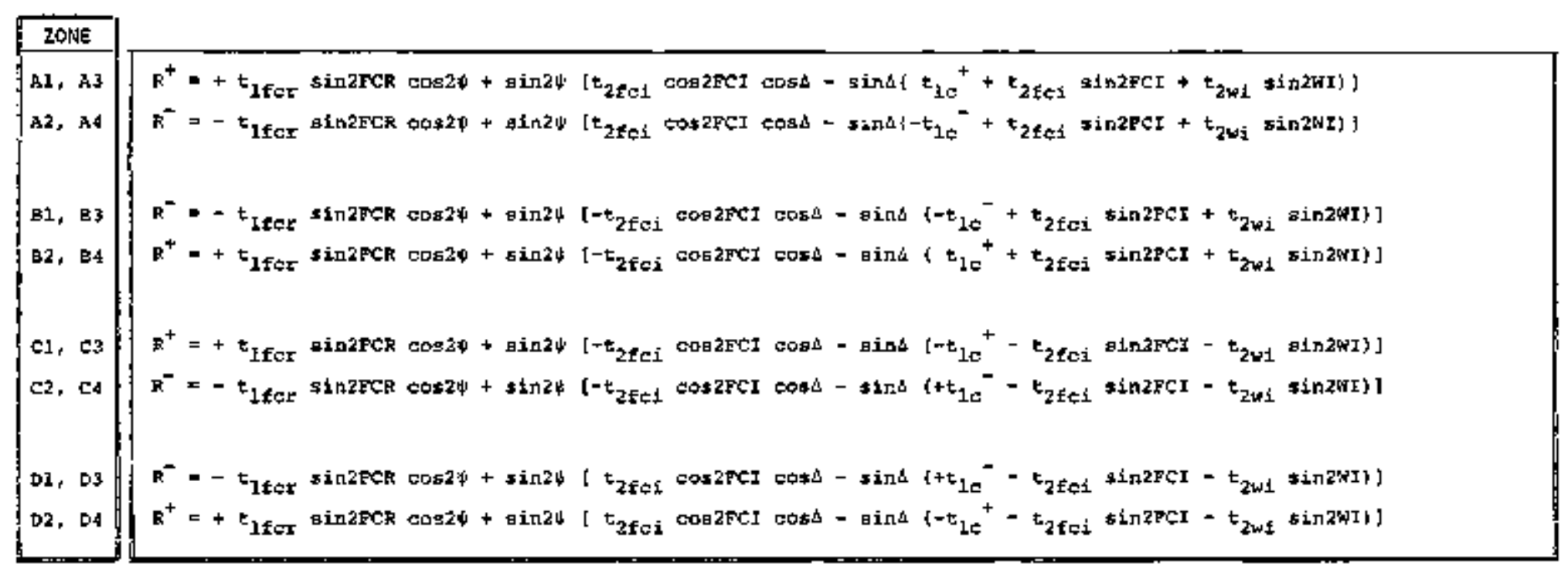


TABLE VII

TABLE VII

\section{Values of the Parameters}

(IN DEGREES)

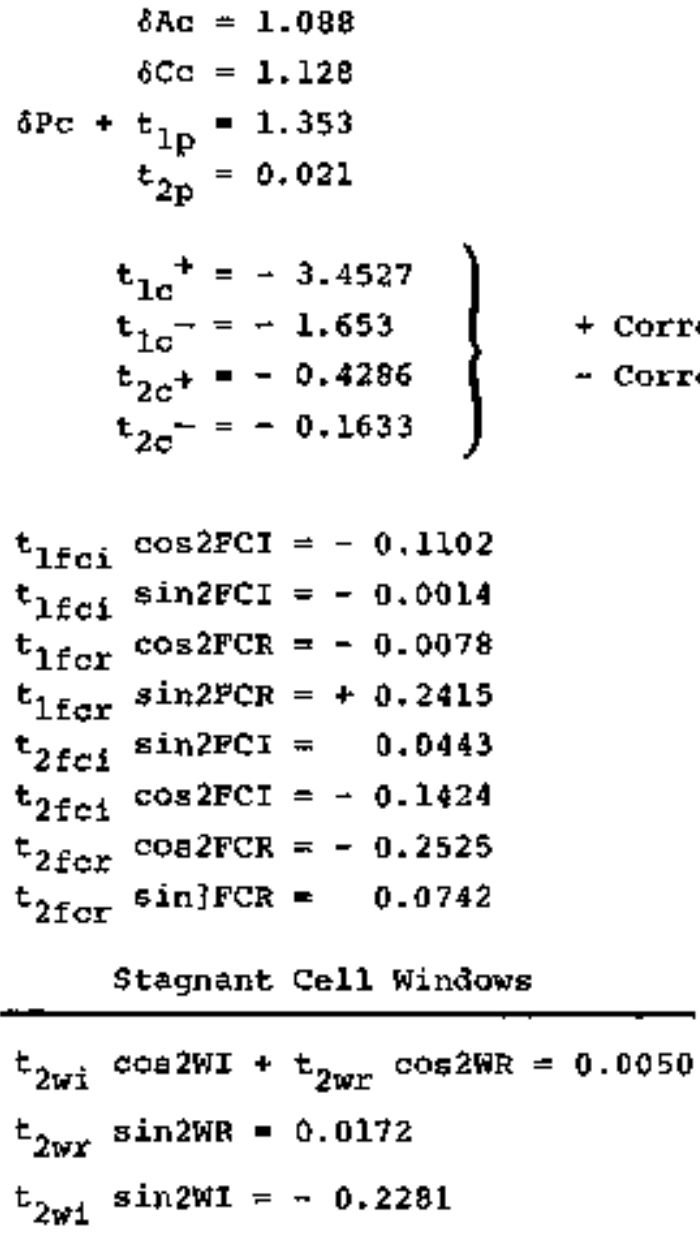




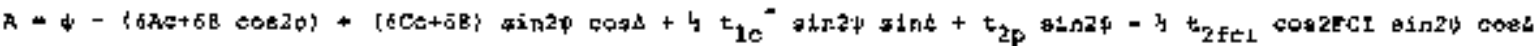

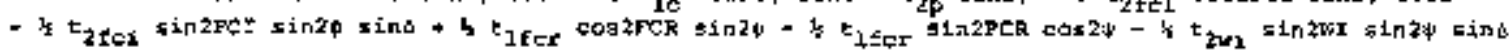

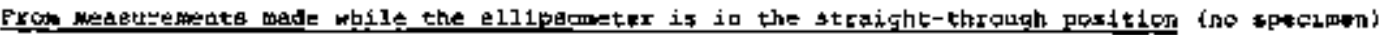

- without the Faraday solls or the cell windowe.

gippiltications

1. Wo terng for the Eartactay ceils or ckll vithows.

2. $\$ \mathrm{~B}=0$

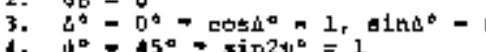

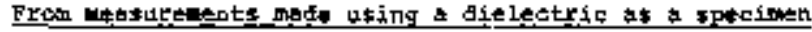

A. Wh thout the Faraday callo or call w1 ndows.

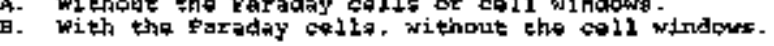

A. Simplificxtions

1. Wo torns for tho Faradiny eolla or eoll windown,

R. Reduced Equation

$A=\psi-z h+\Delta C \sin 2 \psi+t_{2 p} \sin 2 \phi$

B. 5 implifications

1. No ternt for the coli windows,

Reducad Equation

$B=D-6 \mathrm{Ac}+8 \mathrm{CG}+t_{2 p}$

B. Reducad Equatican

$x=\psi-s s+\delta c \operatorname{con} 2 v+t_{2 p}$ aid $z y$

- $\leqslant t_{2 f c i}$ eoserci einzt

- ts tiras $\cos 2 \mathrm{FCR} \operatorname{tin} 2 \psi$

- it tifer BLezFCR $\cos 2 \psi$

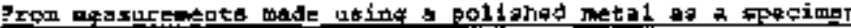

A. W1 thoue the Faraday galls or toll winsowis.

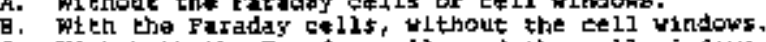

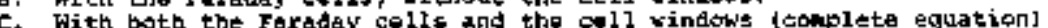

A. Simpilficationg

- No terms for the Faraday celle or coll windores.

B. Gitmpletioatione

- Wo terms for the tall sibdows
A. Eaduced Equation

$A=\psi=U A+6 C \ln 2 \psi \cos \$ \Delta+t_{2 E} \sin 2 \psi$

$+\frac{1}{5}=10 \sin 20$ alns

B. Rodpcad Equation

$h=v-6 \hat{A}+5 \tau \sin 2 \varphi \cos t+t_{2 \beta} \sin 2 \dot{v}$ $+4 \tau_{1 \varepsilon} e^{-} \operatorname{tin} 2 \psi \sin b$

- L t2res cosfret sinzv cod

- L $t_{2501} \pm$ in2por $\sin 2 \psi$ eini

- 4 tJfer cosifek sinzo

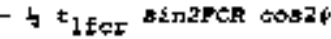


APPENDIX B. AN APPROXIMATE DETERMIRATION OF $\psi$ AND $A$

Once the parameter values describing component imperfections have been detemined, experinental azimuths may be transformed to the relative phase $\Delta$ and relative intensity parameter $\psi$. The specimen mispositioning error $\delta \beta$ (equation $52, \mathrm{p} .45$ ) is the only correction term which varies between experiments. This term affects only $\psi$, and has the magnitude

$$
|\delta \beta|=|\delta \beta[\cos 2 \phi+\sin 2 a \sin 2 p]|
$$

where $\phi$ is the angle of incidence. For the corrected 4-zone measurements on $\mathrm{Cd}(p .52),|\delta \psi|=0.213,0.236,0.108$, and 0.109 degrees.

A graphical correction procedure may be used if reduced computation time justifies the uncertainty in $\psi$ introduced by neglecting $\delta B$. Computergenerated plots are constructed for each set of the 20 paraneter values, with $\delta \beta=0$. The corrections to $\Delta$ and $\psi$ due to component imperfections $\delta \Delta$ and $\delta 4$ are presented as functions of the poiarizer and analyzer azimuths $P$ and $a$. Fígures $B 1$ and $B 3$ show the corrections for $q=45^{\circ}$; Figures $B 2$ and $B 4$ show the corrections for $q=135^{\circ}$. The parameter values in Table VII (Appendix A, p. 7l) with the stagnant cell windows have been used. The correction terms $\delta \Delta$ and $\delta \psi$ are added to the values of $\Delta$ and $\psi$ calculated by assuming ideal components.

It should be noted that graphical procedures 1ntroduce human error in the reading of the plots. For data acquisition systens with computational capabilities, a fors of the computer program in Appendix $\mathrm{C}$ should be used. 


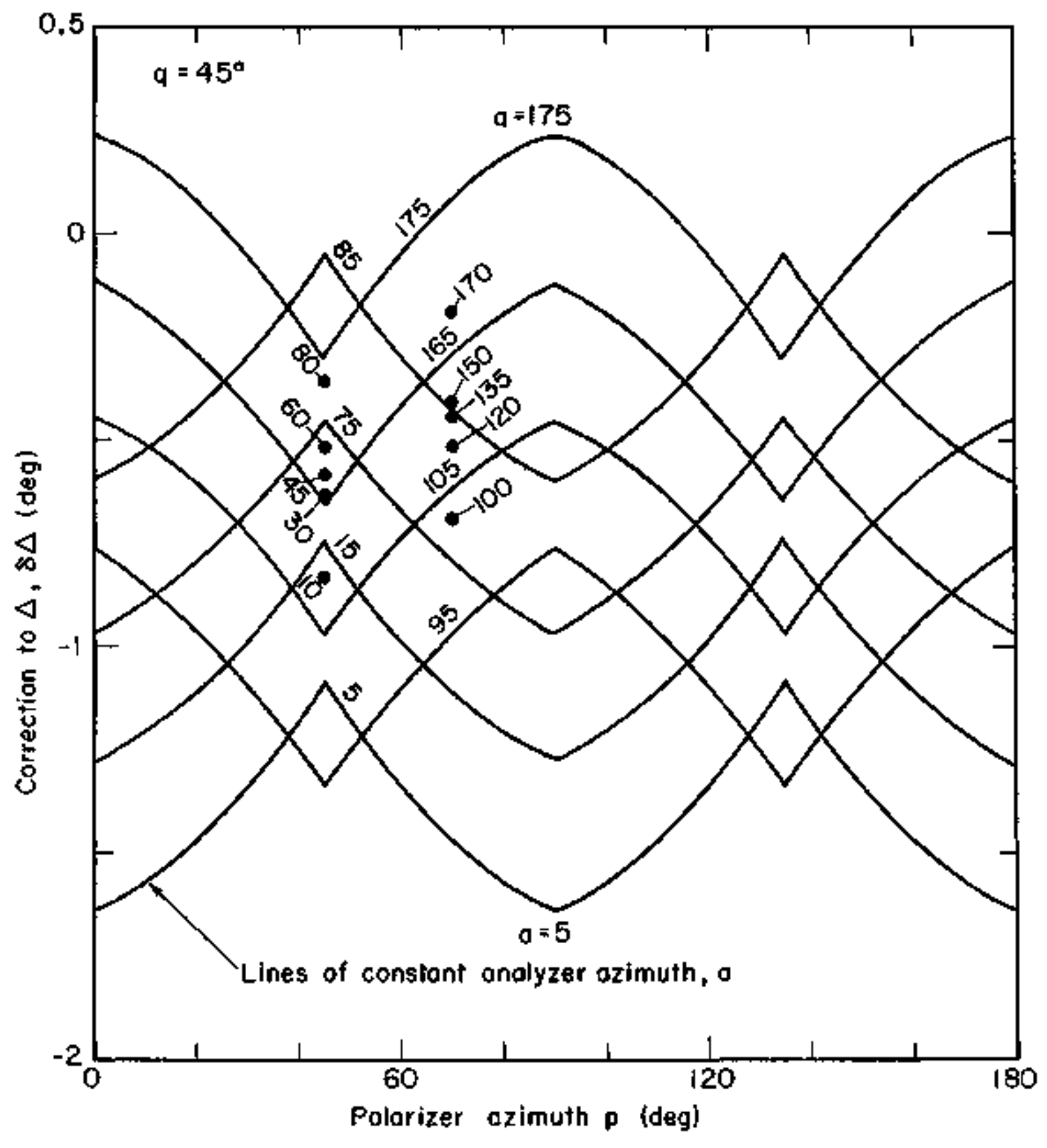

Y्र:LITik-3298

Fig. B1. Correction to $\Delta$ due to component imperfections. Quarter wave compensator at $45^{\circ}$, specimen mispositioning error $\delta \beta=0$. 


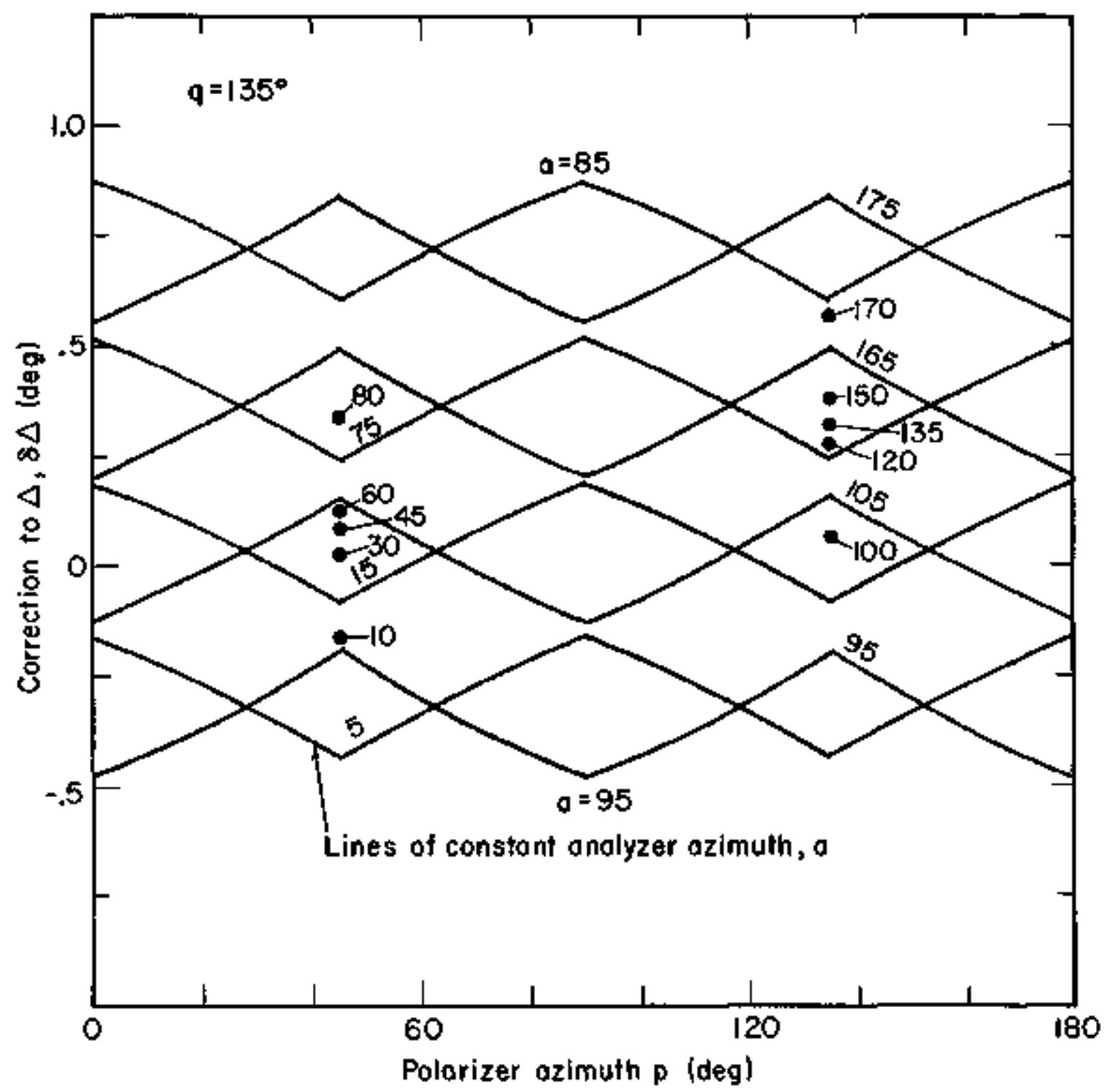

KBLT7F-9297

Fig. B2. Correction to $\Delta$ due to companent imperfections. Quarter wave compensator at $135^{\circ}$, specimen mispositioning error $\delta \beta=0$. 


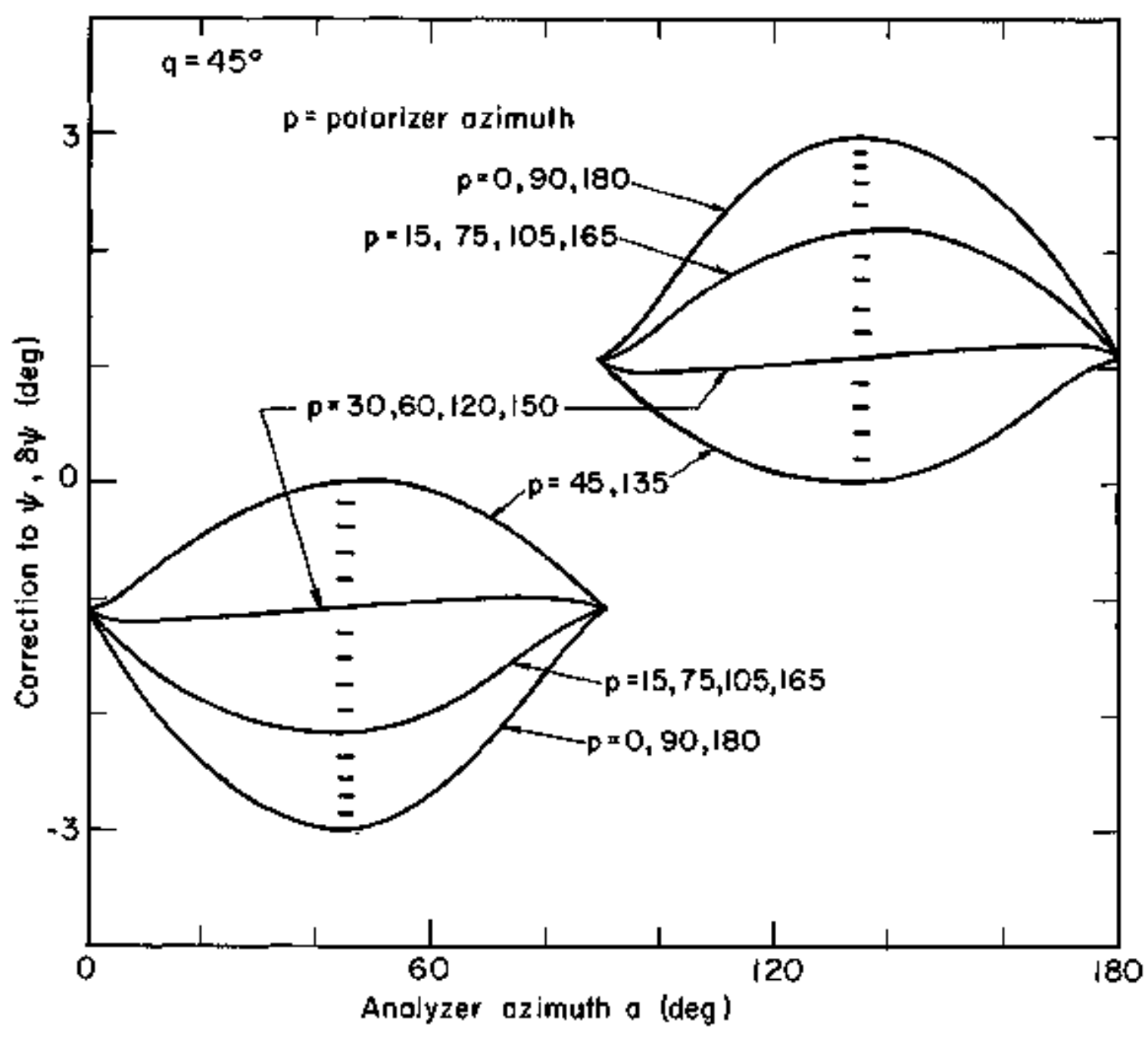

XBL $374-7296$

Fig. B3. Correction to $\psi$ due to component imperfections. Quarter wave compensator at $45^{\circ}$, specimen mispositioning error $\delta \beta=0$. 


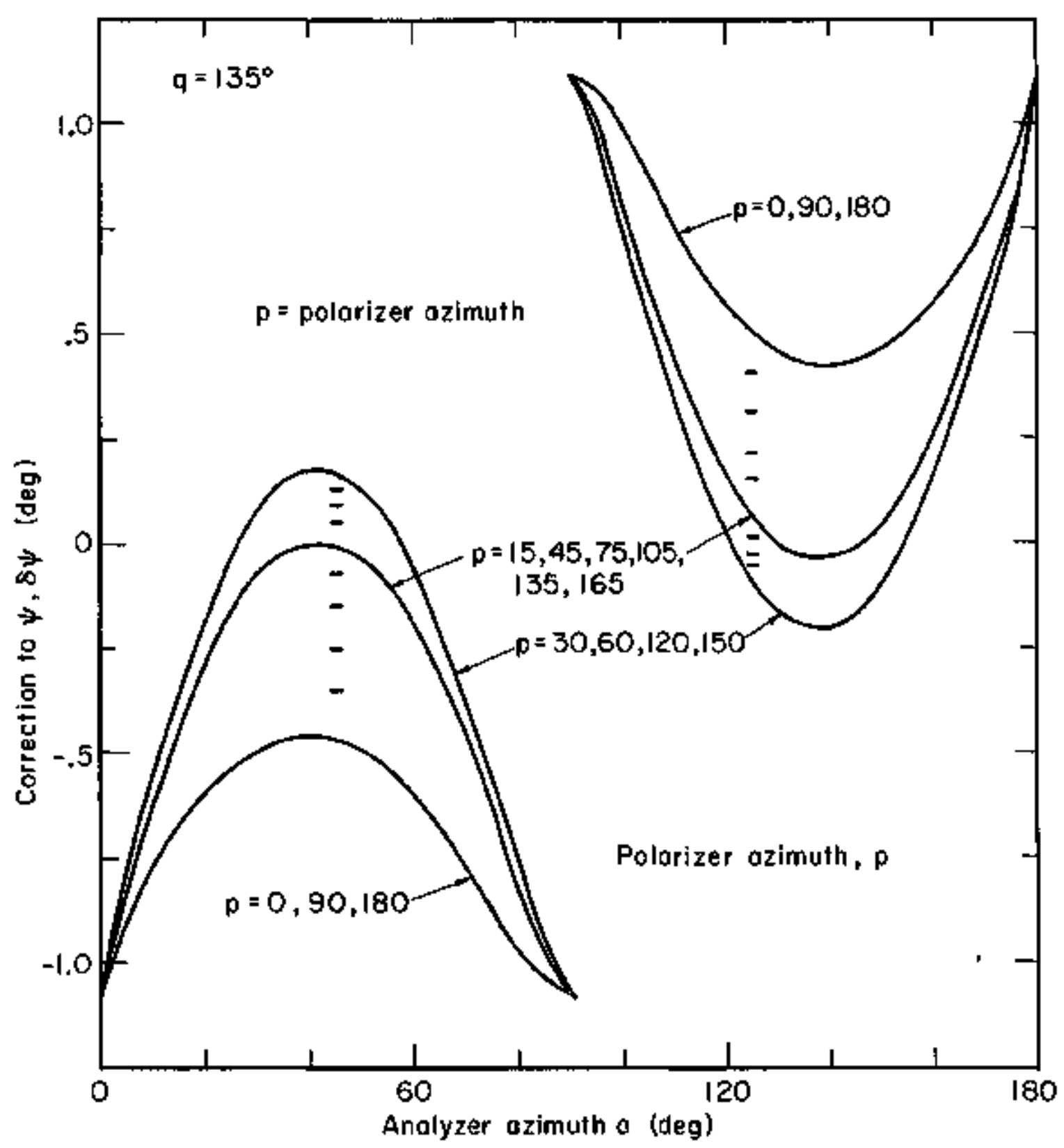

XGLT7A-3295

Fig. B4. Correction to $\psi$ due to component inperfections. Quarter wave compensator at $135^{\circ}$, specimen mispositioning error $\delta \beta=0$. 


\section{APPENDIX C. PROGRAM COMPER}

The computer program COMPER calculates values of the relative phase $\Delta$ and the refative amplitude parameter $\psi$ using the error analysis outlined in this report. In addition, the corrected values of $\Delta$ and $\psi$ may be displayed graphícally by the CALCOMP plotter.

The program is structured to interpret sets of one-zone measurements from experiments on changing surfaces. Before initiating the surface changes, a 4-zone measurement should be taken on a reference state of the surface, to allow calculation of the specimen mispositioning error $\delta \beta$ (equation 52 p. 45 ). From this 4-zone measurement, the Res A (p. 45) and the 4-zone averages of $A$ and $\psi$ (Table $V$, Appendix $A$ ) anust be calculated and entered as input data to the program.

\section{Input Variables}

INUABBER is the number of data sets in the input file.

WPLOT controls plotting on the CALCOMP plot. If WPLOT $=1$, a graphical display of $\psi$ vs. $\Delta$ is given. If WPLOT $=0$., plotting statements are ignored.

TITLE,RANGE are 80 character alphanumeric labels for the output.

INOCAT indicates the specimen orientation. For INDCAT $=1$, the specimen is vertical and the measured azimuths are in rotated form. For INDCAT $=0$, the specimen is horizontal and the measured azimuths are in standard form.

No is the number of data points in the set.

$c$ is the quarter-wave piate setting (et ther $45^{\circ}$ or $135^{\circ}$ ). 
DELTAV is the 4-zone average of $\Delta$.

PSIAV is the 4-zone average of $\psi$.

RESA $\quad=A_{2}+A_{4}$ for $q=45^{\circ}$ or $Q=135^{\circ}$;

$=A_{1}+A_{3}$ for $q=135^{\circ}$ or $Q=45^{\circ}$.

PHI

is the angle of incidence (degree).

$\mathrm{A}\{\mathrm{I}\}, \mathrm{P}(\mathrm{I}) \quad$ are the analyzer and polarizer azimuths for data point I (degree).

A Sample Data Set

Coluan: $\begin{array}{llllllll}0-9 & 10-19 & 20-29 & 30-39 & 40-49 & 50-59 & 60-69 & 70-79\end{array}$ INUMBER WPLOT

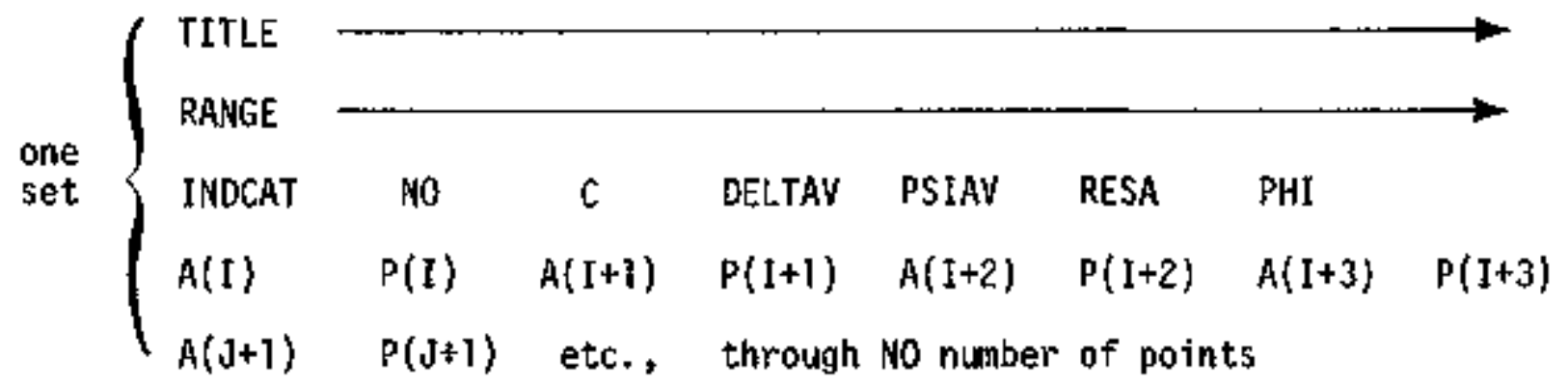

Note: Fixed-point variables (first letter is I-N) must be right-justified in its column.

The computer program with sample output follows. 


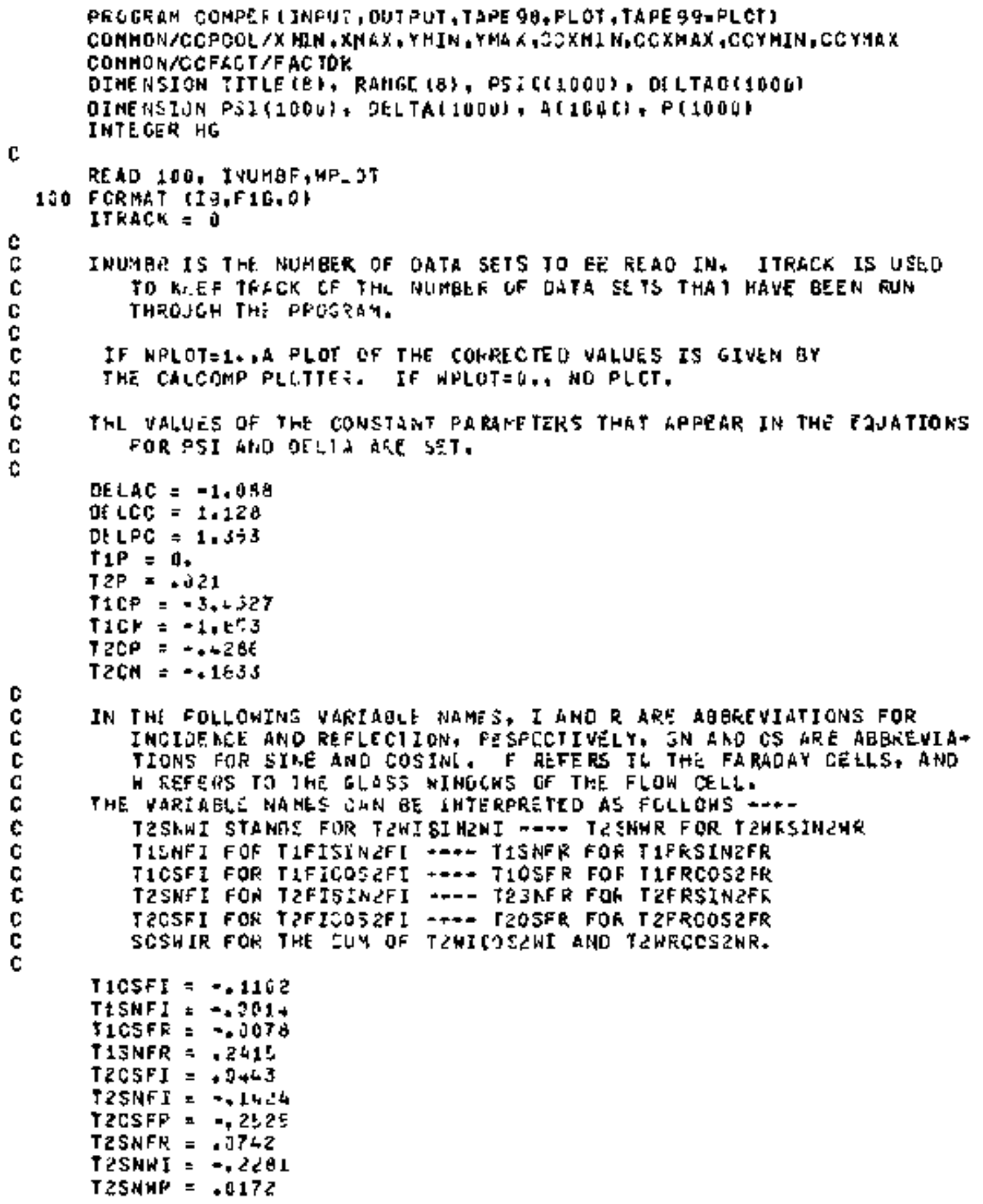




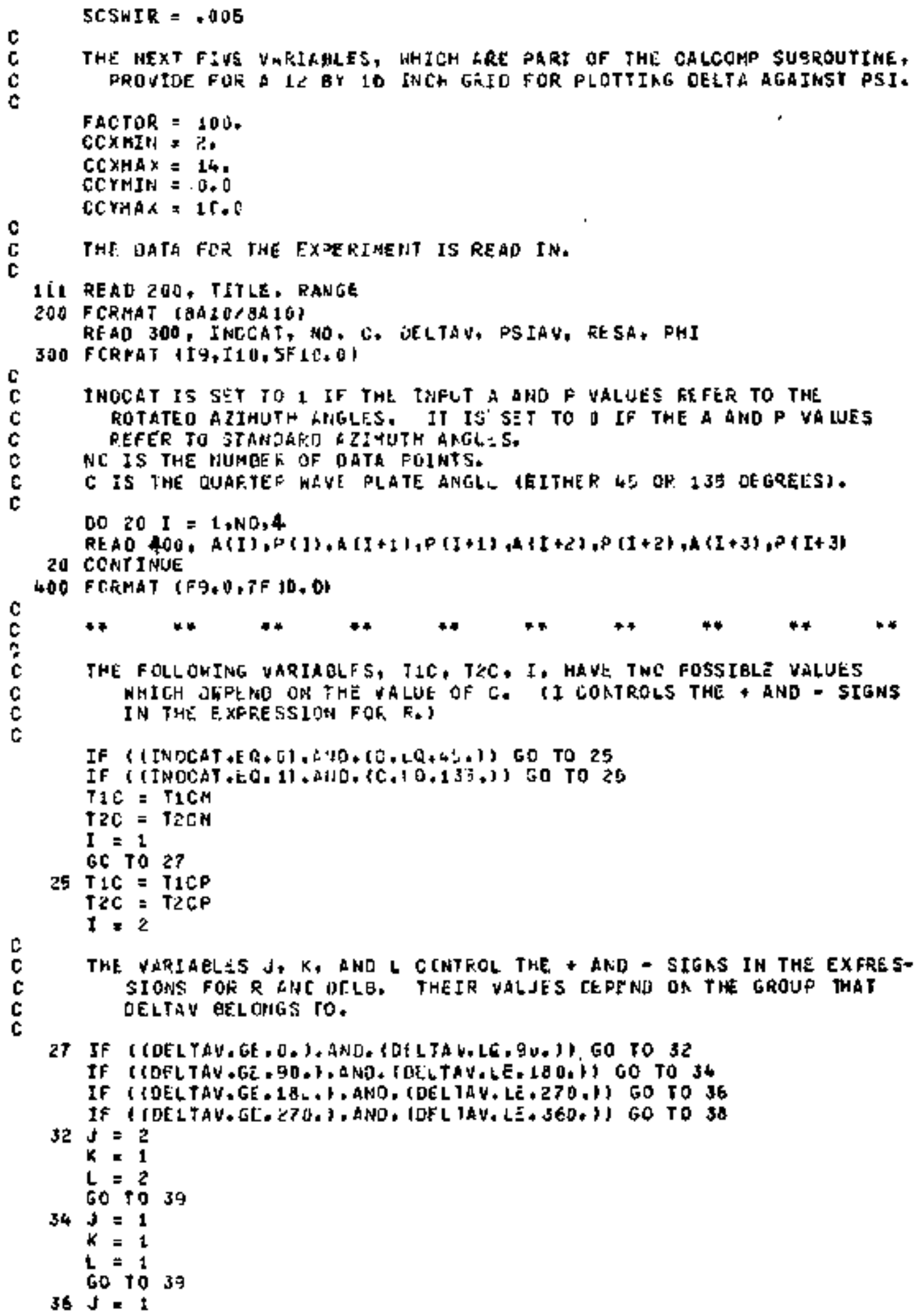


$K=2$
$k=2$

GO TO 39

$30 \mathrm{~J}=\mathrm{s}$

$K=2$

C
C
C

C
C
C
C

$\mathbf{L}=\mathbf{1}$

THE SUBROUTING LIR GRAO GHANGLS OE GRFE ME ASUKËHËNTS TO RAOIANS.

39 CALL OU TRADIFHII

CALL DF.GRADIPSI $E$ YH

CALL IEERAO(OLLTAV)

SINE AND COSIHE FUMCTIONS WHICH AFPEAF hCKE THAN ONCE IN THE EXPRE SSIONS FUK R TKO DELE ATPE CALCULATEO.

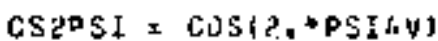

SNEPSI = SIN(7,*FSIAV)

COSDEL = COSLOL LTHI

SINOEL = SINIOELTAW

c

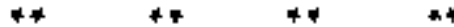

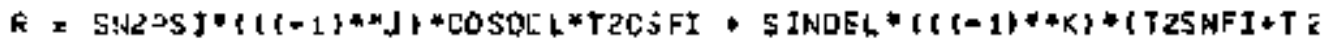

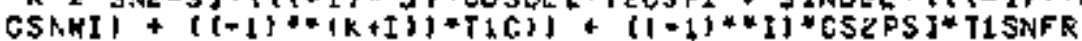

OELE IS THE AZI TUTH CORKF CI IUN GISEL:

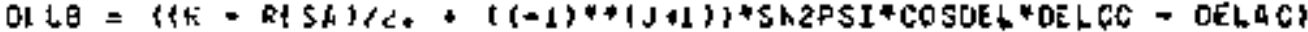

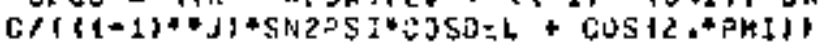

OFLC $=\mathrm{LIELCC}+6 ! \mathrm{LL}$

DL LP = DELPC + OE L H

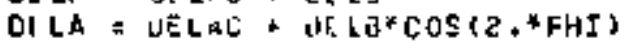

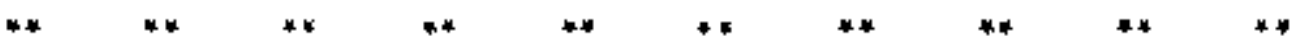

THE FULLOWING LOOP COLCULATS OLL TAO, PSIG, OELTA, ANO PSI.

$00 \$ 0 I=1,1+0$

THE FOUATIONS FOCF DELYA, FSI, OELTAU, ANO PSIO ARE WRITTSN IN TERMS DF YHE STANOAET AZIMLTH RNELAS. IF THE INPLT A ANDP VALLES AR. ROTHTED ALI!WTH ANGLES \#- IF INDCAT I 1 - THEY HUST BE EXPRESSE IN AN EQUIVALENT STANDAPD MZIMUTH ANGL FOKM. TME ŞHQHOUTINI CONVRT HAKES THE FRANSFORMATION FROM RUTATE ANGLES TO ETLMSAKO AKCLES.

IF IIHOSAT.ZU,LI CLLL COHUKTIA,F,JI

THF FULLOWIYG IF STATEMEHTS OE TELHLVE THE ZONE ANC GROUP OF THE INPUT SET OF $A$ ANG P ANGLES. N ANO N ARE ASSIGREO CEKTAIN

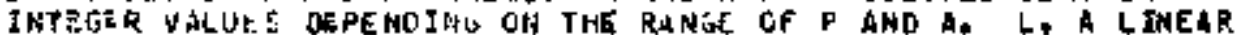
COHAIHATION OF H AYO N GI WS THE LINE NUMAER OF THE GORRECT SET OF EQUATIOHS FOF VILTAO AAO PSIC. THE FITST EIGHF SETS OF EQUATIOISS ART FCF. $C=48$, INDLAT $=0$ OR $C=13 E$, INDCAT $=1$.

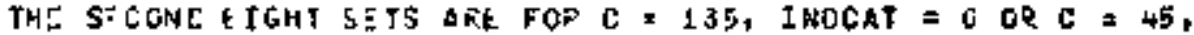
I AOCAT $x 1$.

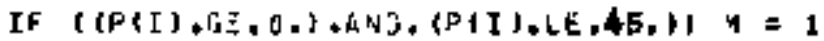

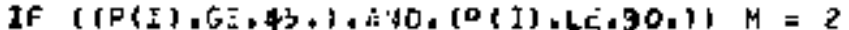

IF ( $P$ (t) 


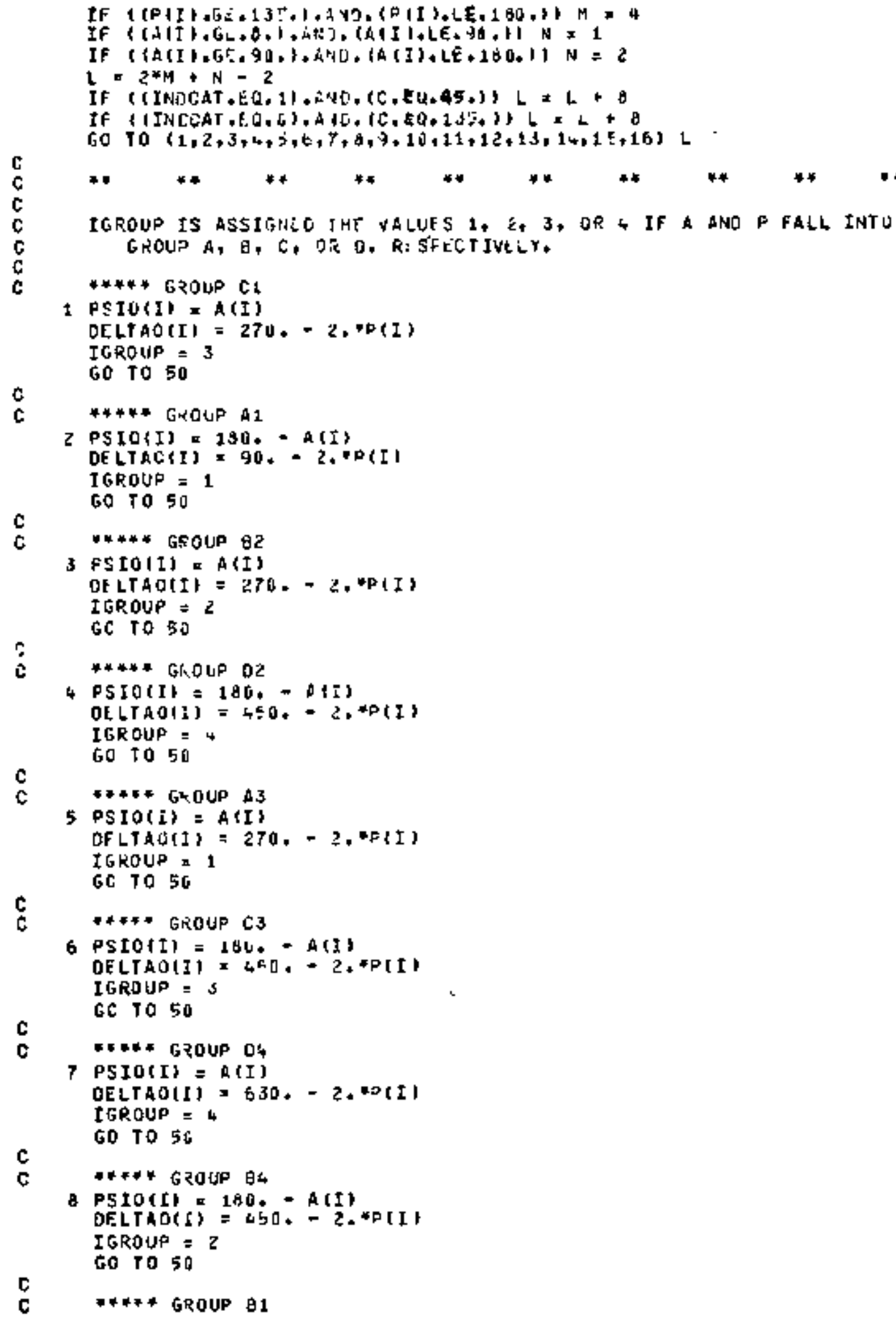




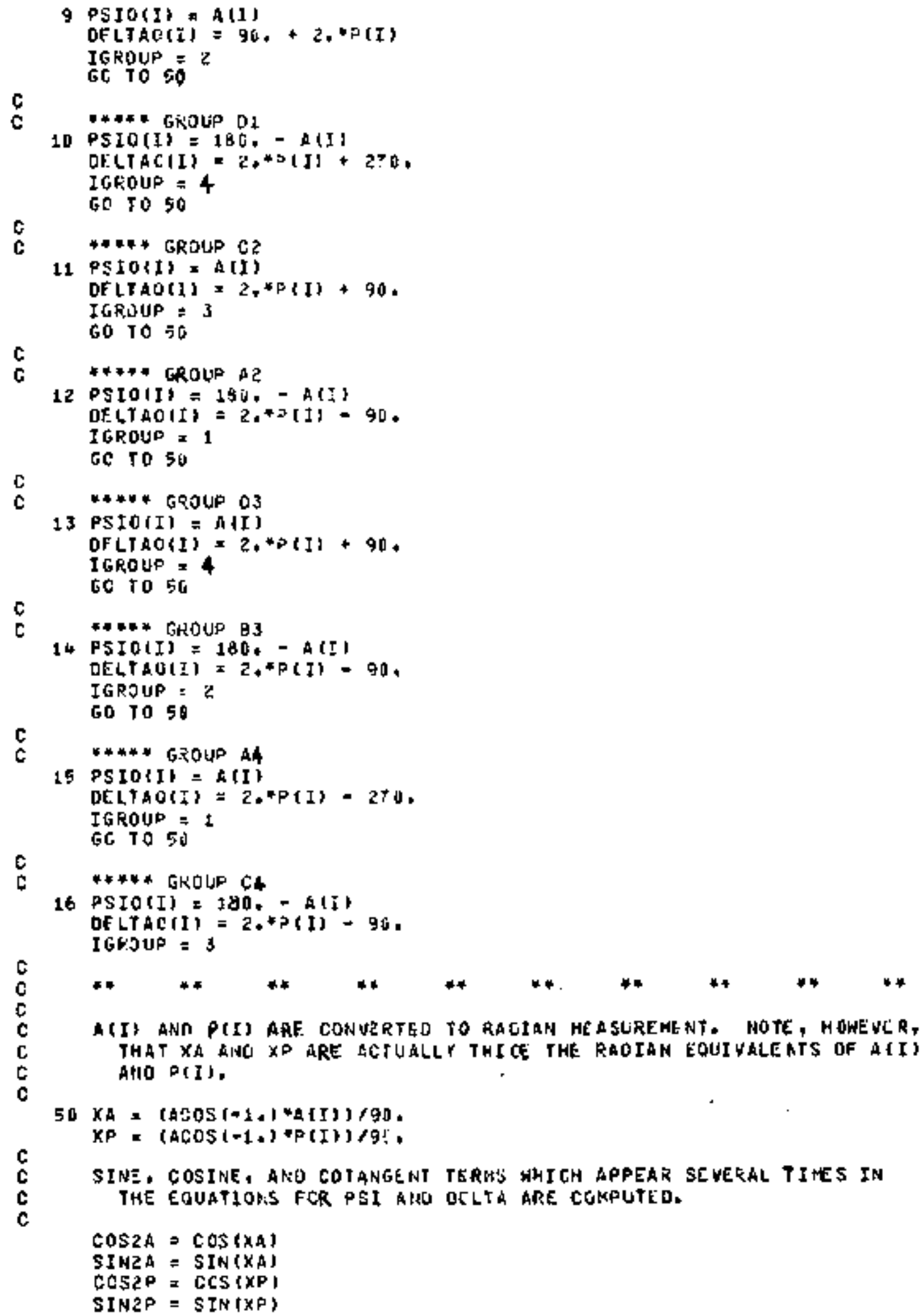


$\cot Z A=\cos (x) / \operatorname{SIn}(x)$

DELTA(IJ ÁNO PSI(1) ARE THE COHKECTED (FOR EOMPONEMT IMPE RFECTIOHS) WALUtS OF DELJAOLIV ATQ FSIOIII.

THE VAREABLES J $I$, KZ, JG, KG, LG, HG, HG, AHD K CCATKOL THE + AND

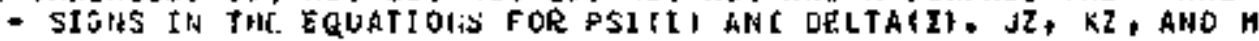
DLPẼND ONEY ON THE 2ONE, NG DEPENOS CALY ON THE GROLP, AND THE OTHES VARIAELL S SEPEMO ON JGTH THE GFOUP AND THE ZONE.

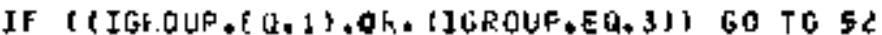

$I G=c$

$K G=1$

G0 $10 \quad 54$

$52 \quad \begin{aligned} I G & =1 \\ K G & =2\end{aligned}$

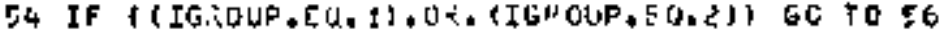

$4 G=2$

$\mathbf{L G}=1$

$N E=2$

L'E TC TO

LG $=2$

FiG $=1$

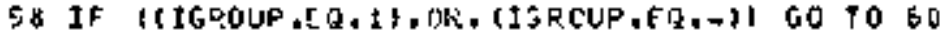

$H G=1$

$M G=2$

G0 $10 \leqslant 1$

$50 \quad H G=2$

$M E=1$

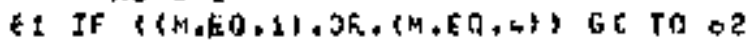

$\sqrt{Z}=2$

$J G=J G+1$

60 TO 64

E $\mathrm{J} 2=1$

E4 IF $(\{1, E A, 1), Q R,(M, E Q, Z)\} G O$ TO EO

$K Z=2$

$M G=M G+1$

$K G \times X G+1$

GO TO

$66 \quad K Z=1$

68 If (M.EN.1).UR, \{M.EQ.3\}) GC TO 74

$H G=N G * 1$

$I G=I G+1$

$L G=L G+1$

C

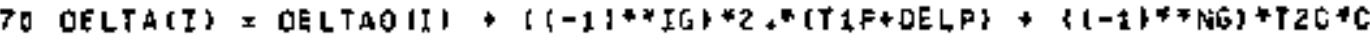

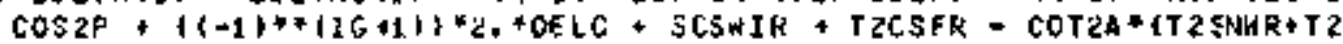

$\mathrm{c}$

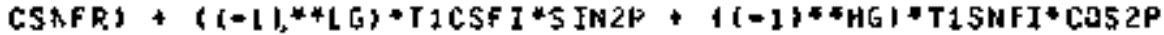

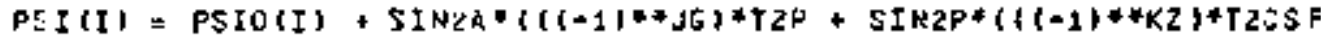

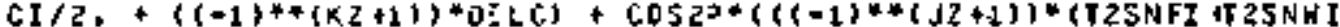

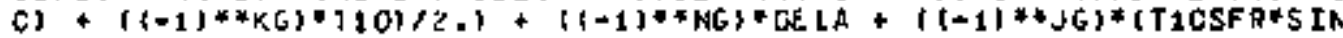

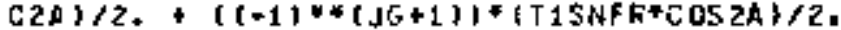

30 CONT I NU::

ITRACK I ITRACK + 1

c

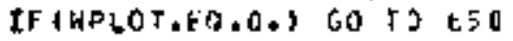




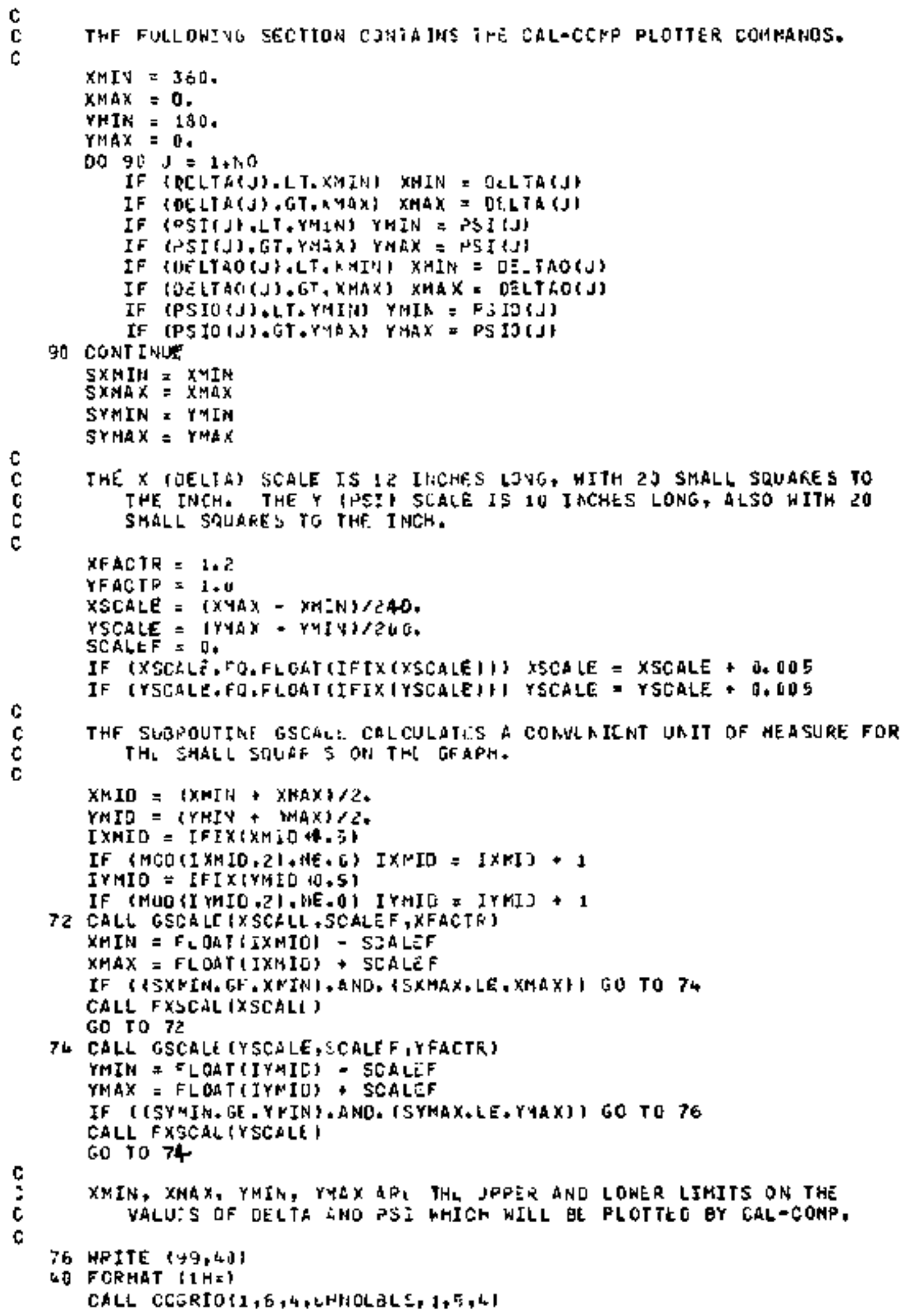


CALL FIXLBL $\{0,5,2,-1,-1\}$

CALL CCLTRT $6.63,-0,5,0,2,5 H D E L T A I$

CALL CCLTF(1, 12+5. $1+0,2,3 H P S I$,

CALL CCLTFT 2, 25,0,5,0,1,49HTHI IOCQL WALUtS OF DELTA AND PSI ARE $R$ CEPRE.S'NTEE)

CELL CCLTFI2, 25, $1, \angle 5,0,1,47 \mathrm{~h}$ GY A OLUS, THE CORRECTE V VALUES BY A C OIAMONO.)

CALL LCLTRT $2,2 \overline{3}, 9,75,0,2$, II RE, $B 0$ )

CALL CCLTF!2.25,9.5, 1 ,2,FANGE,BU!

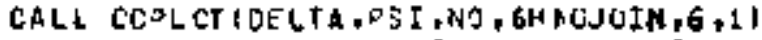

CALL CCOLCTIDFLTAC,DSIO,NO,GHNOJUIN, $\angle 3,11$

CALL CCLTGLCCXNAX,0, $0+1, \pm H$,

CALL CGIIE XT

c
c
c

6

550 CONT INUL

PRIHT 1:1, TITLE, \&ANG

101 FCRHAT $(* 1$ *, BA1Q 1 BA1U) PRINT 2D1*C

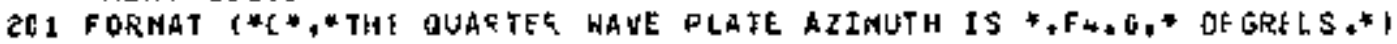
PFI $=(P H)^{*} 1 B 0,1 / A C O S I-1,1$ FEINT 3 3 , PHI

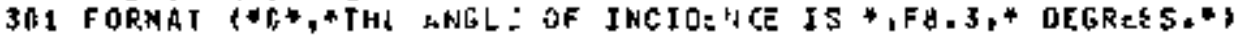
PRINT 4 U1, DELB

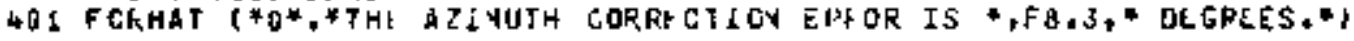
IF (INDSAT, EQ.J) Fr:SNT $\approx 01$ IF (INOCAT,EO.1) PRINT $\div$ OS

$5 O 1$ FERMAT ${ }^{*} 0^{*}, * A$ ANO $P$ ZFFER TO TH. STANGARD HZIHUTH AMGLES GF THE AR CALYZER HNC POLATZZ Y RESFLCTJUILY*)

503 FCKMAT \{ * ${ }^{*}+A$ ANO F FFFER TO TH: FOTATET AZIMUTH ANELES OF IHE AMA CLYZER AND POLAKIZZ, R. RE.SP.,CTIVLLY.*I

PRINT 6 3, ITO

601 FCRMAT 1*0*,*NUMEL" OF DATA PCINTS **+14I PRINT 701

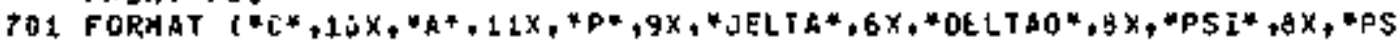
ctcel

$c$
$c$
$c$

IF INUCAT = 1, A AHO P AKE COR WERTEE BACK TO ROTATED AZIMUTH ANGL: 5 .

$00 B 0 \quad I=1, N O$

IF IINOCAT+EOTI CRLL CONWR IM,F, II

PRINT \$OL+ AIIL, PIIS, OELTA(I), CELTAUCIH+ PSICII, FSIOLIS

8. CONTINUE.

OO 1 FCRHAT (" $\left.\left.0^{*}, 6 X, 54 F B, 3,4 X\right), F 8,3\right)$

If (ITRACK. NF . I บUHAR) GO TO 111

IF ( NPLOT\&ËQ1,) CALL GCEZL

STOP

EhD

SUBROUTINE GSCALL1SCALII, SCALEF,FACTRI

IF (SCALE J+GE + 0,9$)$;O TO 05

IF (SCALEI, LT, 0, O G) SCALF I 5CAL:I*1DO.

If I ISCALEI.GE.0.131, ANG, (SCALEI,LT,0.9)' SCALL II SCALEI*20. ISCAL $\vec{t}=$ IFIX 1SCA LF' + 1

IF (SCALE, ,Q,FLOAT IIFIX(SGALE) II ISZALE = IFIX(SCALE)

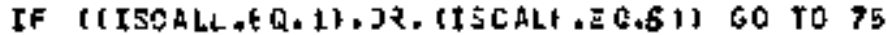

IF (nOO \{ISCALE +2).N. D) ISCALC $x$ ISIALL + 1

IF IISCALL+EQ,6) ISNALE a 6

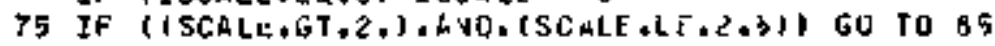


IF (SCALE].LT*0.09) SGALLF F (FLCAT(ISCALEW*FACTF

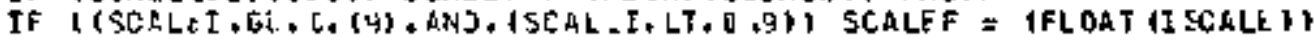
C*10, $F$ FAC T

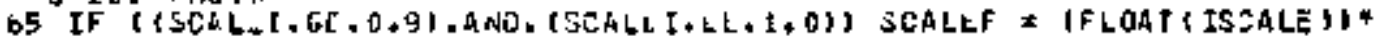
C1C \&.+FATTR

IF (SCALCI.GT,1,0) SCALEF $=1 \pm 0 . * F A C T F$

to $10 \mathrm{~g}^{\mathrm{t}}$

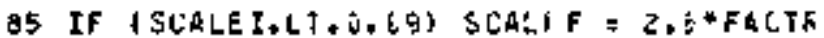

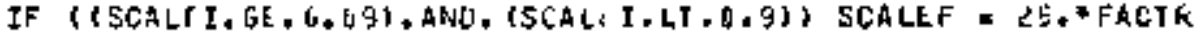

95 Rt TURN

ENO

SUEROUTINE CONVATIA,P,IN,

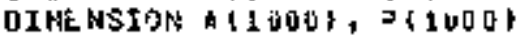

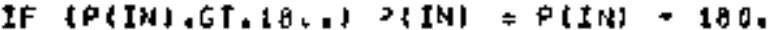

IF TAGNB, GE,90, ), „NO. IN(IN), Li, 18J, H) GU TO 24

$A(I N)=A(I)+94$.

GO TO 25

$24 A[I N]=A\{I N\}+94$.

26 IF $(\{P(I N), G E .90 .1 ., 40.1 P(j Y) .15 .190, J) 60$ TO 28

$P(I N)=P\{I N \mid+94$.

GC TO $\angle C$

$28 P\{I N)=P(I M)-90$.

22 RETURN

EMD

SLBROUTIN1- GRRBD(X)

$x=1 A C . J S[-1,1+x, 117 i$.

RL TURN

END

SUBROUTINE FYGCLL SSCLLLII

IF ISCALEJ.LT, 0.1I SCALEI = SCALLI + . DI

IF $(S C A L E I, E T, 0,1) \leqslant C A L I I=5 C A L-I+0, I$

RF TURN

EMO

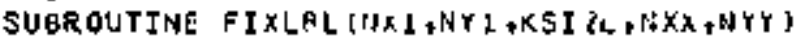

COMMON/CCPOOL IXMIH, XUAX, YMIN, YMA X, ECXMI R, LCXMAX, CCYMIN, CCYMAX

COHMON/CCFACT IFAC JGH

NXPINXX B HYPINYY

FXPGMIN INXP,7) \& WYSEMIN (LYP,7) \& FACT=KSIZE/FACTOF

$X F$ CTR $=\mathbf{2}+0$ DFCTR=1, D

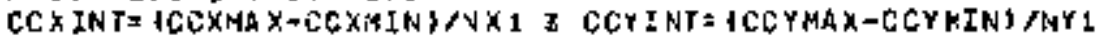

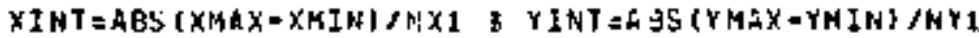

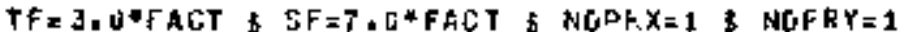

X-AXIS NOFNALIZBTIJN.......

$\checkmark K V=A M A X I$ (AES $\{X+I H I+A B S\{X M A X)\}+1,0 E-10$ B $X M=10,0=M X P$

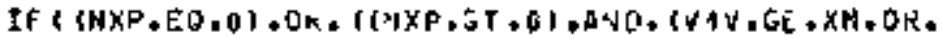

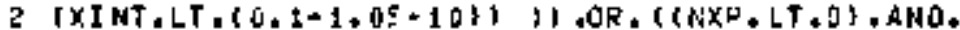

3 IXINT+LT, (XH-1, Q\&-1OH IIGO TO $\rightarrow E$

IF (NXP. LT ,OINOPQ X = HI)

$N \times P=R$ : 50 TO 5 :

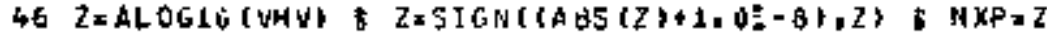

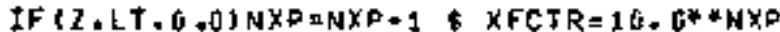

c

$Y$ YXIS HOFIAALIZATIOH.........

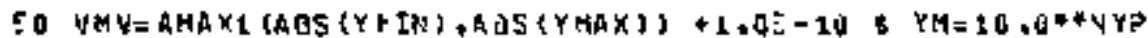

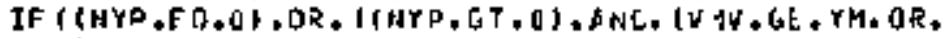

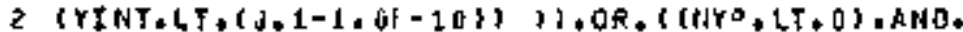

3 (YINT,LT, (YM-1, OL -10$)$ ) ) 60 IC $\$ 3$

IF $\{N Y P+L T+C H H C P P Y=+N Y P$ I HYP $=: \$$ GO TO 60

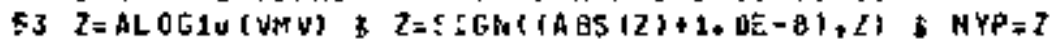




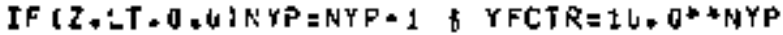

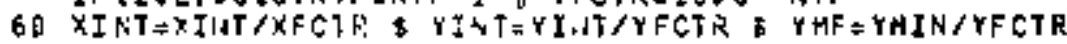

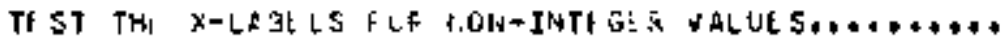

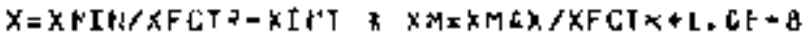

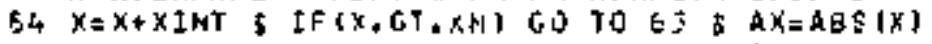

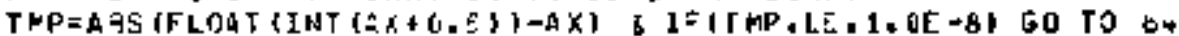
GQ TO OS

F. NTPRX $P=0$

TE ST THZ Y-LABłLS

66 YNXYMAXPYFCTK+1+0I-1 Y YXYNIN/YFQTR-YINT

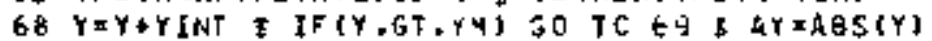

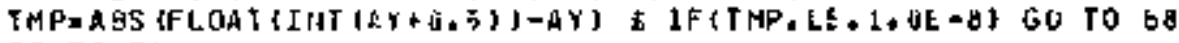
GC TO $7 \mathrm{U}$

69 NOPKYJO

c

LAEEL THE. $X$ AXIS+ $\ldots \ldots \ldots \ldots$

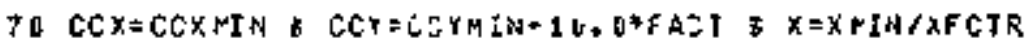

$7 y$ IF $X$, LT, XMI 60 TO 9

COLL FIXXICNTEYP,NC,NPINDPRX,XI

$N M O=M O Q 1 N C+2)$

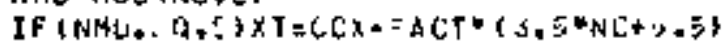

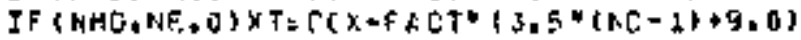

CALL CCLTECXT,CCY, I, XSIZE, NTEMP, NPI

CCX $=C D X+C D X I N T$ F $X=X+x I N T$ \& 60 id $T^{\prime}$

$c$

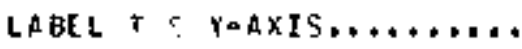

$90 \operatorname{CE} Y=\operatorname{CCYMIN-TF}$

$Y=r H F$

95 IF (Y, GT, YM) F, TURL,

CALL FIXXIS1JTEMO, NE, NP, NDPRY, Y

JFIY, LQ. YMF, C.CY $\mathbf{X} C \mathrm{C} Y+T F$

$C C X=C C X M I R=\$ F * N$,

CALL CCLTKICLX, CCY, U, XSIZT, AFE MP, NPI

IF I $Y$, I $Q, Y H F) C C Y=C C Y-I F$

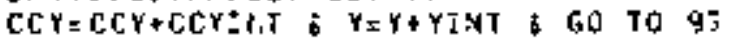

ENT

SUBROLTINE FIXXX(1, T NP, YC, NP, HOF $X, X X)$

TIME HSION NART (1)

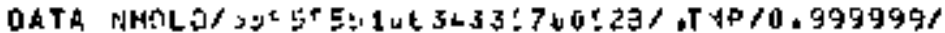

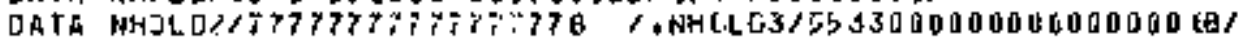

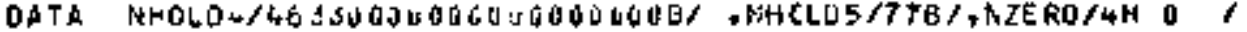

$X=X X$ I $A X=A B S(X)$ \& $I F(A X+L T, 1, I=7$ \& 30 TO 79 \& $N O P l=1$

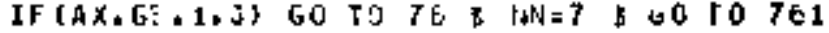

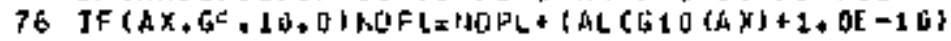

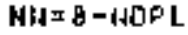

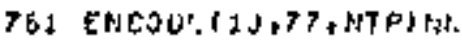

77 FCRRATIIC)

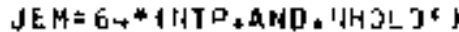

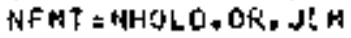

ERCOOZ $110, N F M T, N F[M \geqslant \mid X$

IF $\{$ KX,G, TMP.OR, $X+\angle 2,0,0) G 0$ TO Tे

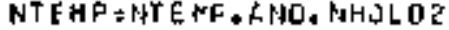

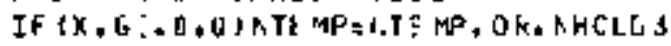

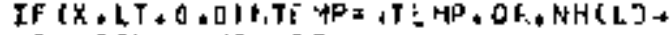

7 G NC $=N O P L$ \& $N O=H O P L+1$

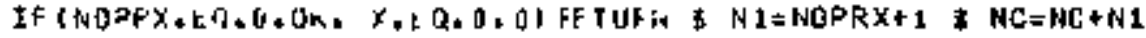


$-90-$

$N P=N P+M 1$

REF TURP.

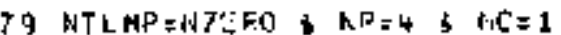
IFF TURN

ENO 
ZN IN 0,54 KOF

CONSTANT POTENTIAL E $=-1 . Z$ VOLTS VS HG/HGO

THE dUARTEF WRUE PLATF AJIMUTH IS 45. DEgREES.

THF ANCLE OF INCIOENCE IS 75.000 DE CRESS.

THE AZTMUTH COFRECTION TRPOR IS -.0 0 OEGREES,

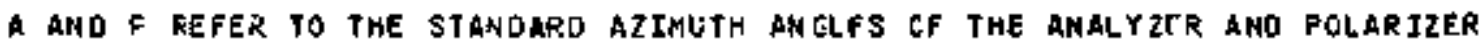
NUMEER DF DATA POINTS -- 10

\begin{tabular}{|c|c|c|c|c|c|}
\hline$A$ & $p$ & DE TTA & OEL TAO & PSI & PSIO \\
\hline 39.980 & 83.630 & $101, E 34$ & $162+740$ & 37.311 & 39.980 \\
\hline 39.630 & 85.830 & 97.218 & 98.340 & 36.057 & 39.630 \\
\hline 38.560 & $\$ 8.150$ & 92,603 & 93,740 & 35.716 & 38.500 \\
\hline 37.410 & 99.935 & 88.991 & $90+140$ & 34.490 & 37.410 \\
\hline 36.330 & 91,450 & 85.953 & $87+100$ & 33.527 & 36.390 \\
\hline 35.500 & $92.37 \mathrm{C}$ & 94.115 & 85.260 & 32.874 & 35.690 \\
\hline 34.900 & 93.0 .90 & 62.676 & 83.820 & 32,137 & 34.900 \\
\hline 34.360 & $93.93 \mathrm{c}$ & $81+059$ & 62.200 & 31.641 & $\$ 4.360$ \\
\hline 35.920 & 94,690 & 79.482 & 80.520 & 31.243 & 33.920 \\
\hline 33.550 & 55.296 & 70.304 & 79,440 & 30.887 & 33,530 \\
\hline
\end{tabular}


APPEMDIX D. THE GROUP DEPENDENCE OF THE SIGNS

OF THE PARAMETER VALUES.

The parametric equations describing component imperfections were derived for Group B (Tables IIa and IIb, Appendix A). Many of the terms in the equations are multiplied by trigonometric functions of the polarizer and analyzer azimuths. Allowance for the sign changes of sin2p and $\cos 2 \mathrm{P}$ (vectors $\mathrm{b}$ and $\mathrm{a}$ in Figure Di) must be made in applying the derivation to Groups $A, C$, and $D$.

The signs of the parameters for all groups (Tables IIC and IId, Appendix A) were obtained by using Group B as a standard. As ar example (Figure 01), the temis multiplied by strip change sign in zones 61 and D4 from the equation describing 82 . Similarly, the terms multiplied by $\cos 2 P$ for zones $A 1$ and $A 3$ have signs opposite those in the expression for B2. The same allowance was made in obtaining expressions for calculating $\Delta$ and $\psi$ from rotated polarizer and analyzer azimuths (vertical specimen). 

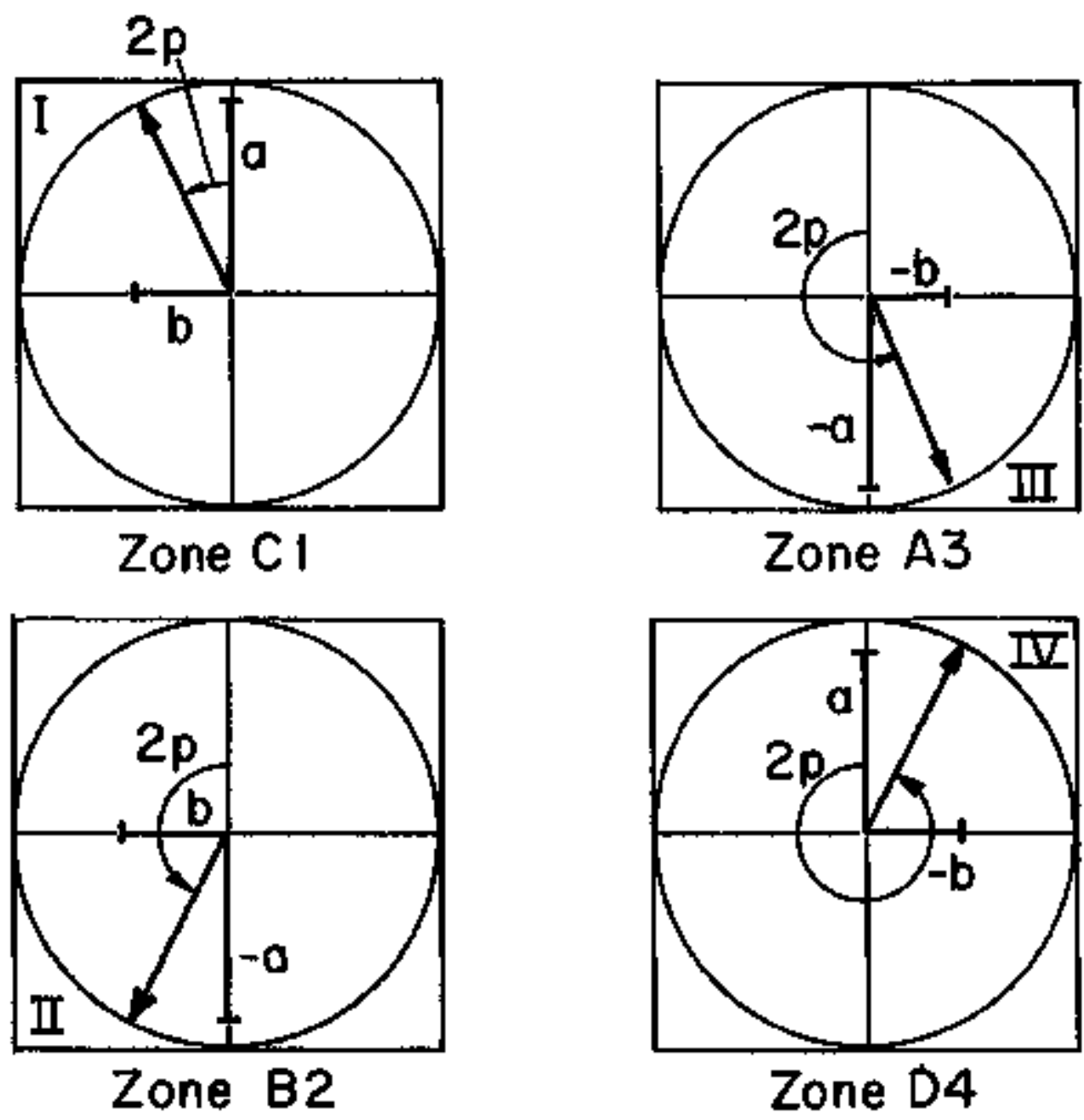

XBL774-3292

Fig. D1. Group dependence of the signs of the parameter values. Vector components $a$ and $b$ represent sin2P and $\cos 2 \mathrm{P}$. 
APPENDIX E. MEASUREMENTS USSED TO

DETEPIME PARAMETER VALUES.

For the following experimental measurements, the notation NW and NFC refers to the absence of windows and Faraday cells. Five sets of 4-zone medsurements, with re-alignment of the specimen between each set, were made on the dielectric and metal surfaces to allow averaging out the specimen mispositioning error $\delta \beta$. The horizontal surfaces faced up and the angle of incidence was $75^{\circ}$.

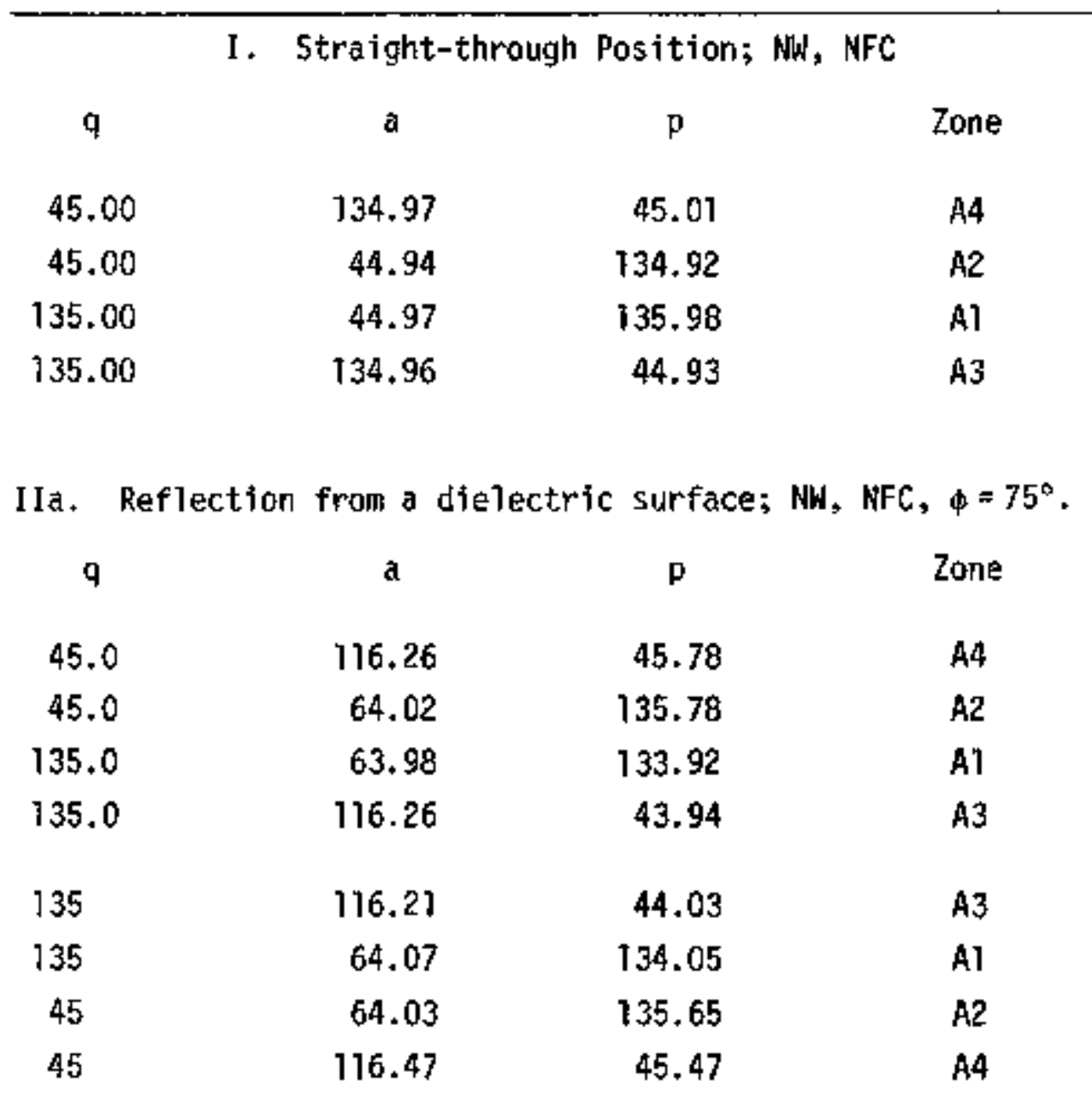


IIà. (continued)

$\mathbf{q}$

45

45

135

135

135

135

45

45

45

45

135

135 a

116.21

63.94

64.09

116.37

116.42

64.12

64.08

116.40

116.40

64.03

64.12

116.42 p

45.76

135.79

134.06

43.99

43.96

133.98

135.97

46.02

45.85

136.00

$\uparrow 33.85$

44.00
Zone

A4

A2

A1

A3

A3

A1

A2

A4

A4

A2

A1

A3

IIb. Reflection from a dielectric surface; $N$ W, $\phi=75^{\circ}$.

$q$

135

135

45

45 a

116.60

64.35

64.26

116.58 $p$

44.13

133.98

135.99

45.84
Zone

A3

A1

A2

A4

IIIa. Reflection frofin a metal surface; NW, NFC, $=75^{\circ}$.

$q$

135

135

45

45 a

62.70

122.53

120.28

60.46 p

86.84

176.46

92.93

3.52
Zone

B4

B2

B1

B3 
IIIa. (cantinued)

\begin{tabular}{rrrr}
$\mathrm{q}$ & \multicolumn{1}{c}{$\mathrm{a}$} & \multicolumn{1}{c}{$\mathrm{p}$} & Zone \\
45 & 60.53 & 3.57 & $\mathrm{~B} 3$ \\
45 & 120.15 & 93.26 & $\mathrm{~B} 1$ \\
135 & 122.29 & 176.85 & $\mathrm{~B} 2$ \\
135 & 62.67 & 86.38 & $\mathrm{~B} 4$ \\
135 & & & \\
135 & 62.56 & 86.77 & $\mathrm{~B} 4$ \\
45 & 122.40 & 176.73 & $\mathrm{~B} 2$ \\
45 & 120.27 & 93.00 & $\mathrm{~B} 1$ \\
& 60.43 & 3.29 & $\mathrm{~B} 3$ \\
135 & 62.56 & 86.98 & $\mathrm{~B} 4$ \\
135 & 122.44 & 176.67 & $\mathrm{~B} 2$ \\
45 & 120.31 & 93.21 & $\mathrm{~B} 1$ \\
45 & 60.38 & 2.83 & $\mathrm{~B} 3$ \\
& & & $\mathrm{~B}$ \\
45 & 60.20 & 92.25 & $\mathrm{~B} 3$ \\
45 & 120.50 & 177.24 & $\mathrm{~B} 2$ \\
135 & 122.64 & 86.92 & \\
135 & 62.46 & &
\end{tabular}

IIIb. Reflection from a metal surface; NW, $\phi=75^{\circ}$

$q$

335

135

45

45 a

62.36
122.47
120.34
60.14

p 87.45 177.29 92.10

2. $3 B$

Zone

B4

B2

B1

B3

IIIc. Reflection from a metal surface; $\phi=75^{\circ}$

$\begin{array}{rrrr}135 & 62.11 & 87.75 & \text { B4 } \\ 135 & 122.06 & 177.85 & \text { B2 } \\ 45 & 119.94 & 91.47 & \text { B1 } \\ 45 & 59.92 & 2.06 & \text { B3 }\end{array}$


This report was done with support from the Department of Energy. Any conclusions or opinions expressed in this report represent solely those of the author(s) and not necessarily those of The Regents of the University of California, the Lawrence Berkeley Laboratory or the Department of Energy. 